\title{
Steady state thermal stress analyses of two-dimensional and three-dimensional solid oxide fuel cells
}

\author{
Srividya Valluru \\ West Virginia University
}

Follow this and additional works at: https://researchrepository.wvu.edu/etd

\section{Recommended Citation}

Valluru, Srividya, "Steady state thermal stress analyses of two-dimensional and three-dimensional solid oxide fuel cells" (2005). Graduate Theses, Dissertations, and Problem Reports. 1583.

https://researchrepository.wvu.edu/etd/1583

This Thesis is protected by copyright and/or related rights. It has been brought to you by the The Research Repository @ WVU with permission from the rights-holder(s). You are free to use this Thesis in any way that is permitted by the copyright and related rights legislation that applies to your use. For other uses you must obtain permission from the rights-holder(s) directly, unless additional rights are indicated by a Creative Commons license in the record and/ or on the work itself. This Thesis has been accepted for inclusion in WVU Graduate Theses, Dissertations, and Problem Reports collection by an authorized administrator of The Research Repository @ WVU. For more information, please contact researchrepository@mail.wvu.edu. 


\title{
Steady State Thermal Stress Analyses Of Two-Dimensional And Three-Dimensional Solid Oxide Fuel Cells
}

\author{
Srividya Valluru \\ Thesis submitted to the \\ College of Engineering and Mineral Resources \\ at \\ West Virginia University \\ In partial fulfillment of the requirement for the degree of \\ Master of Science \\ in \\ Mechanical Engineering \\ Bruce Kang, Ph.D., Chair \\ Ismail B. Celik, Ph.D. \\ Liu Xingbo, Ph.D. \\ Travis R. Shultz \\ Mechanical and Aerospace Engineering Department \\ Morgantown, West Virginia \\ 2005
}

Keywords: Solid Oxide Fuel Cells, Stress Analysis, ANSYSTM. 


\title{
ABSTRACT \\ Steady State Thermal Stress Analyses Of Two-Dimensional And Three-Dimensional Solid Oxide Fuel Cells
}

\author{
Srividya Valluru
}

Fuel cells are electrochemical devices which convert fuels directly into electrical energy without combustion. The Solid Oxide Fuel Cell (SOFC) is the most promising energy saving technology to generate electric power. The present work characterizes the thermal stresses arising during the operation of planar solid oxide fuel cells which is a critical factor in the development of an efficient fuel cell. The thermal stresses are calculated from the temperature fields using ANSYS ${ }^{\mathrm{TM}}$. A sequentially coupled thermal stress analysis approach is implemented for the two-dimensional five stack fuel cell model and a structural analysis for the three-dimensional single stack fuel cell. The stresses due to the difference in the thermal expansion coefficients of the components of the fuel cell, geometry of the model and temperature gradients is presented in the results. 


\section{ACKLOWLEDGEMENTS}

Firstly, I would like to thank my advisor, Dr. Bruce Kang for providing me the opportunity to work under his guidance. This thesis would not have been possible without his encouragement, constant support and invaluable suggestions. I would like to thank Dr. Ismail B. Celik, Dr. Liu Xingbo and Mr. Travis R. Shultz for serving as my committee members.

I would like to thank Mr. Pakalapati Suryanarayana and Mr. Andrew Burt for their timely guidance in SOFCs. I am thankful to all my friends who directly and indirectly helped me in the successful completion of the work assigned to me.

I would like to thank my parents for their support and encouragement, for always pushing me after my goals. Finally, I would like to thank the Almighty for showing me the right path in my life. 


\section{TABLE OF CONTENTS}

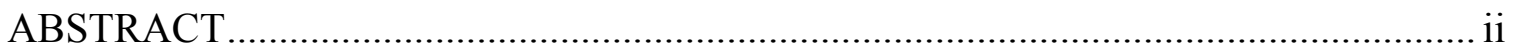

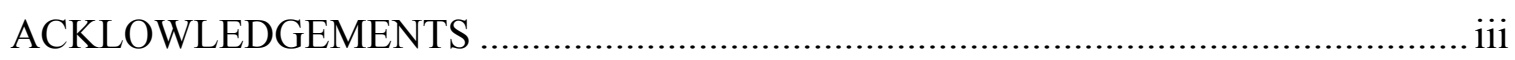

TABLE OF CONTENTS ................................................................................. iv

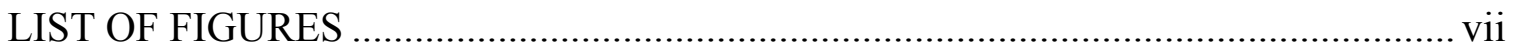

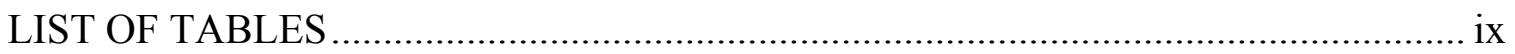

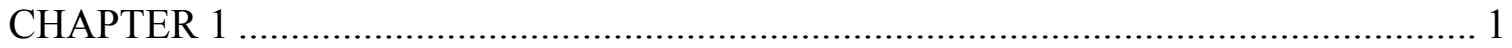

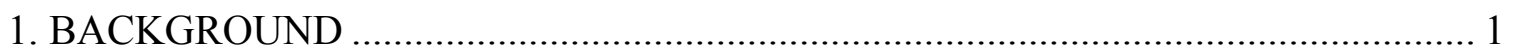

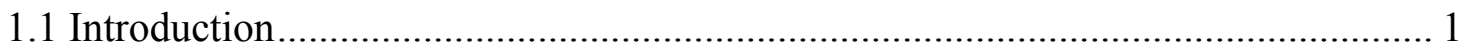

1.2 Principle of Operation of a Fuel Cell ................................................................. 1

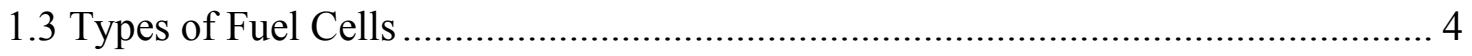

1.3.1 High Temperature Fuel Cells .................................................................... 4

1.3.1.1 Solid Oxide Fuel Cells ....................................................................... 5

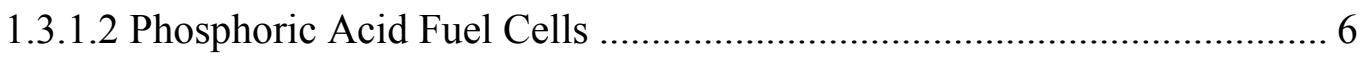

1.3.1.3 Molten Carbonate Fuel Cell ............................................................... 6

1.3.2 Low Temperature Fuel Cells ..................................................................... 7

1.3.2.1 Alkaline Fuel Cells ............................................................................ 8

1.3.2.2 Proton Exchange Member (PEM) or Solid Polymer Fuel Cells (SPFCs). 9

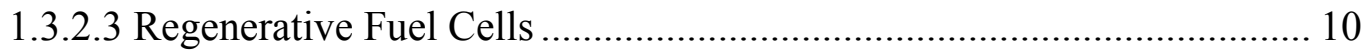

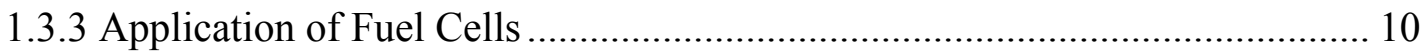

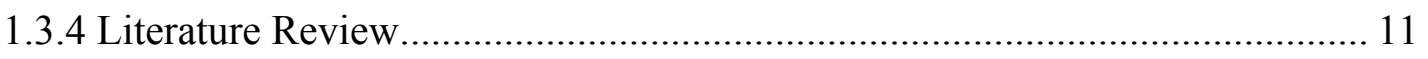

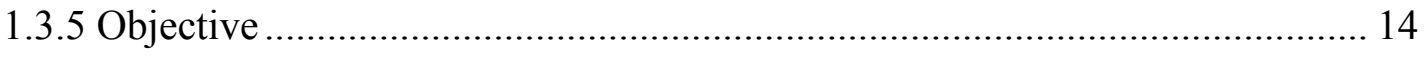

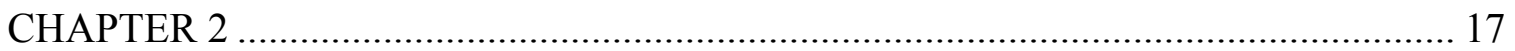

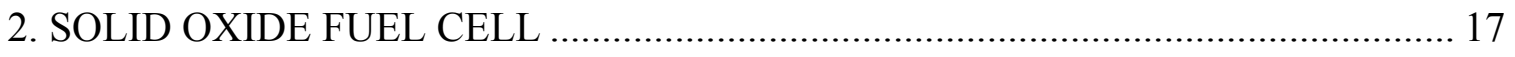

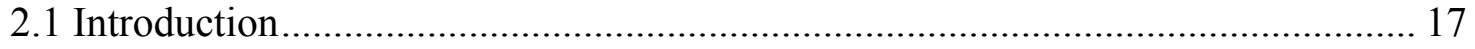

2.2 Current Solid Oxide Fuel Cell Technology …................................................... 17

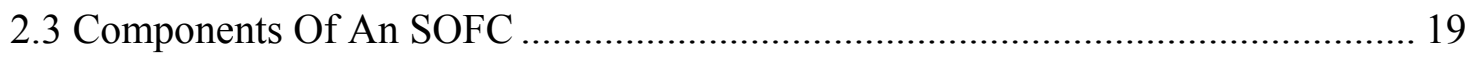

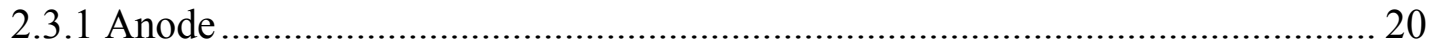

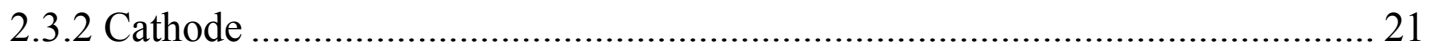




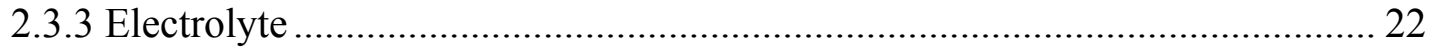

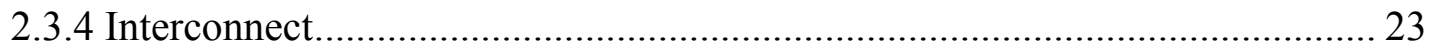

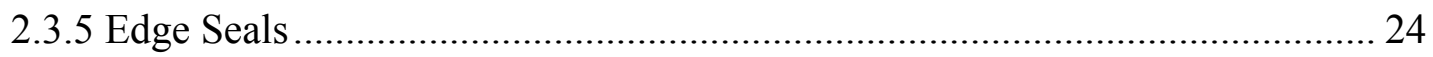

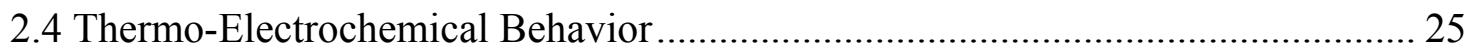

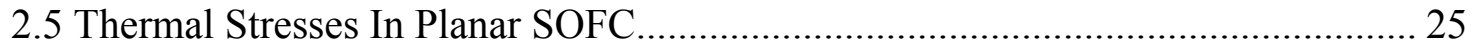

2.5.1 Stresses During Fabrication of Planar SOFC.............................................. 26

2.5.2 Stresses During Operation of Planar SOFC .................................................. 26

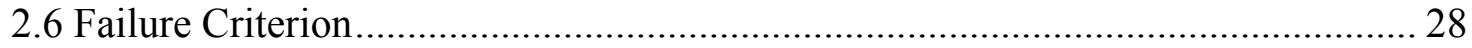

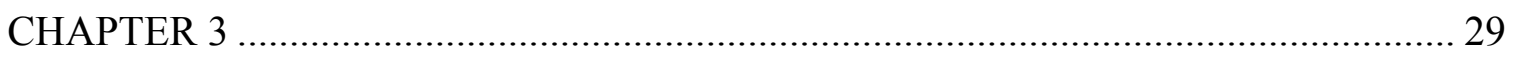

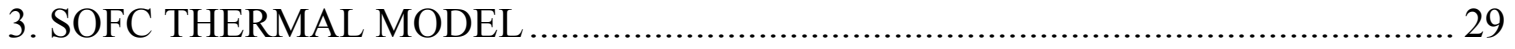

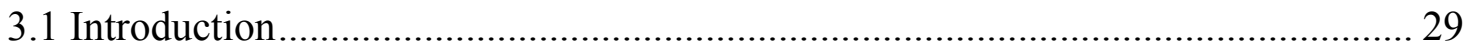

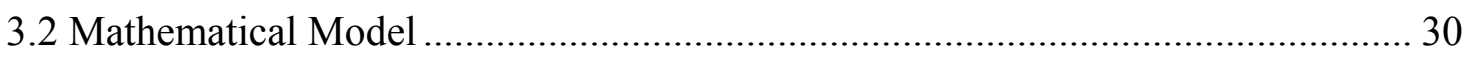

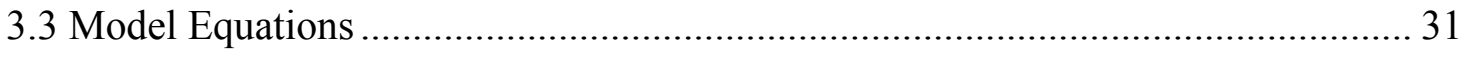

3.3.1 Electric Potential Field.............................................................................. 31

3.3.1.1 Sources in Electric Potential Field ......................................................... 31

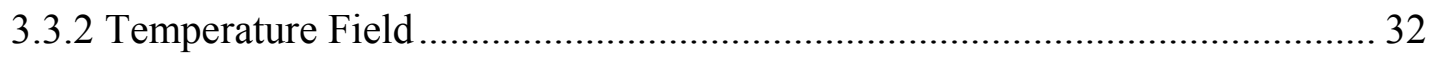

3.3.2.1 Sources in Temperature Field ............................................................. 33

3.3.3 Specie Transport Equation ....................................................................... 33

3.3.3.1 Sources For The Specie ...................................................................... 33

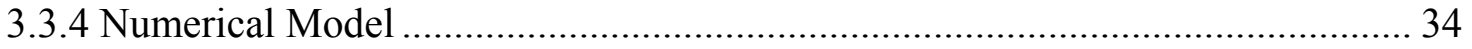

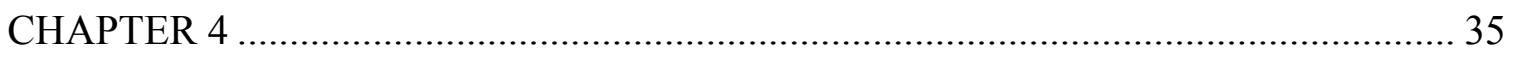

4. TWO-DIMENSIONAL THERMAL STRESS ANALYSIS DURING ……................ 35

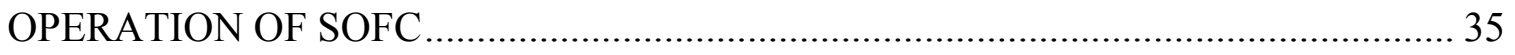

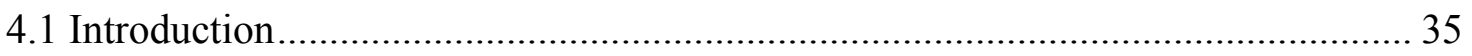

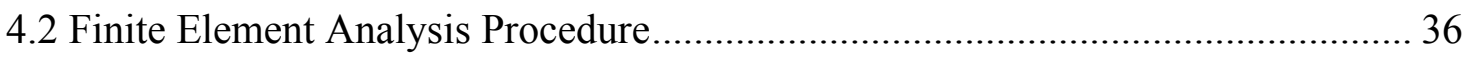

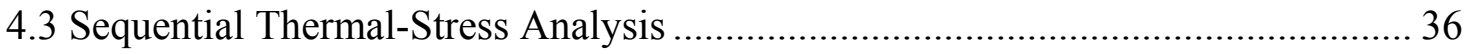

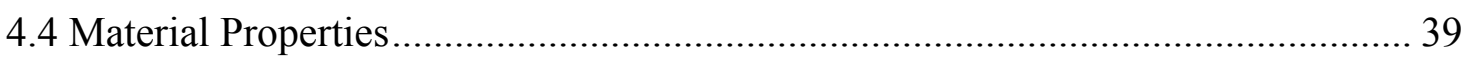

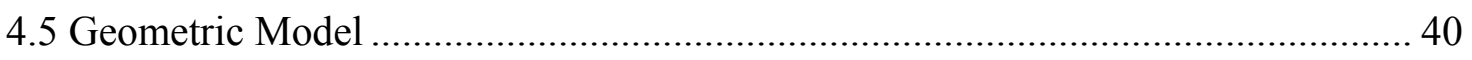

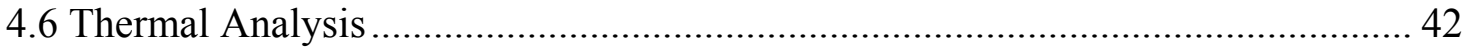

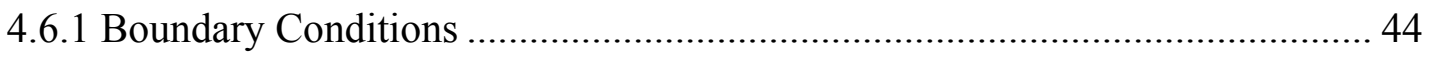




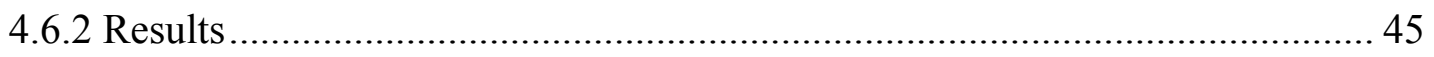

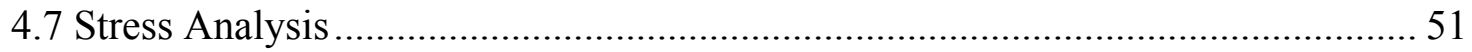

4.8 Boundary Conditions for the First Model......................................................... 52

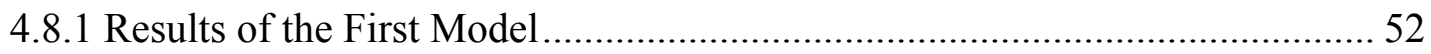

4.9 Boundary Conditions for the Second Model ........................................................ 65

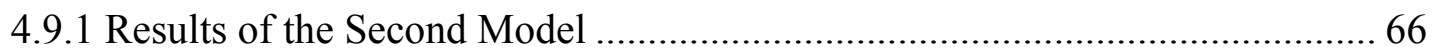

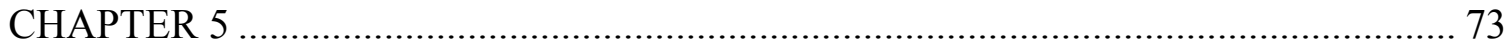

5. THREE-DIMENSIONAL THERMAL STRESS ANALYSIS DURING OPERATION

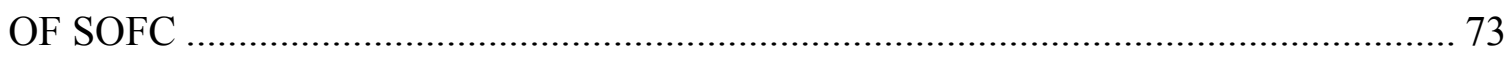

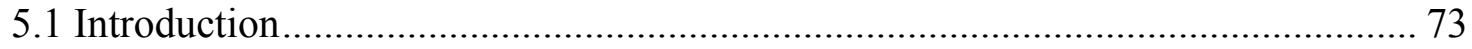

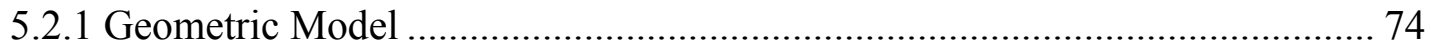

5.2.2 Meshing Of The Three-Dimensional Model................................................ 75

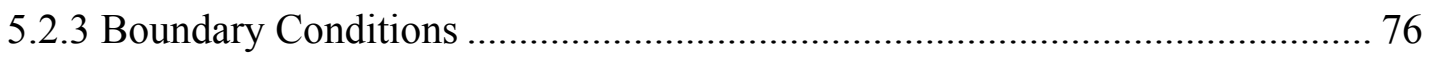

5.3 Boundary Constraints on the First Model.............................................................. 77

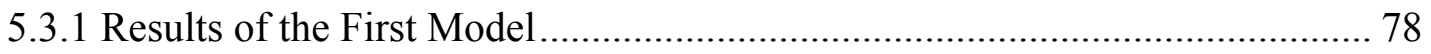

5.4 Boundary Constraints on the Second Model ……….......................................... 80

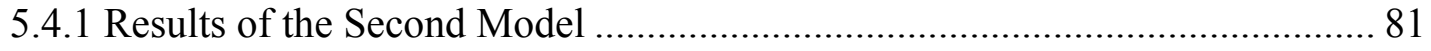

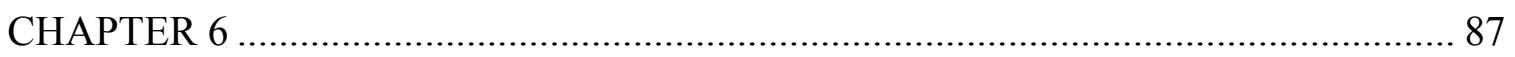

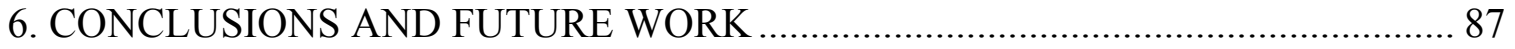

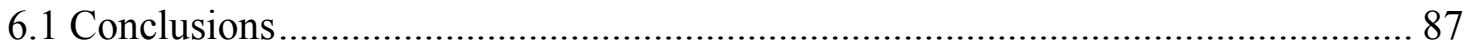

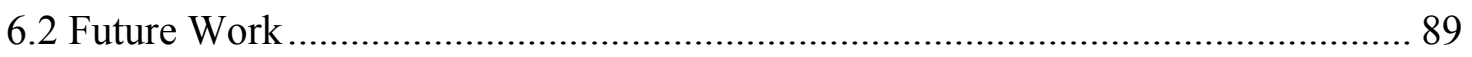

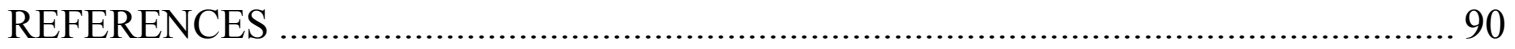

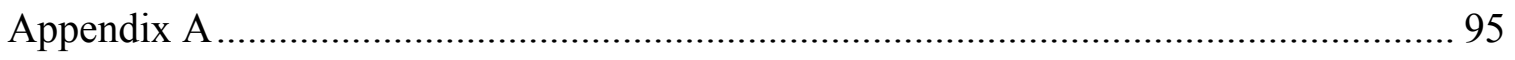

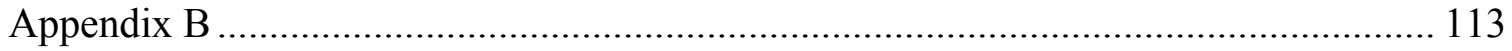

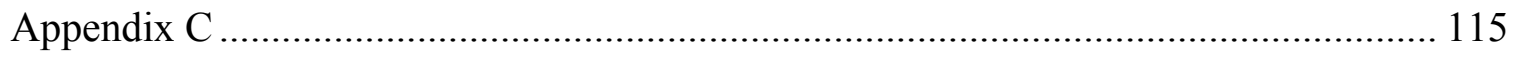




\section{LIST OF FIGURES}

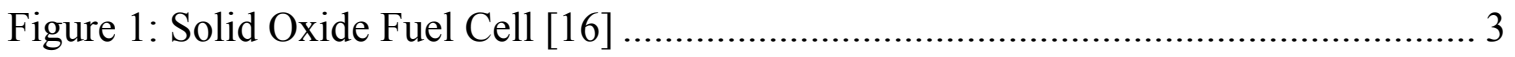

Figure 2: Various Solid Oxide Fuel Cell Designs [2] ............................................... 19

Figure 3: Data Flow for a Sequential Coupled-Field Analysis [18] .............................. 37

Figure 4: Two-dimensional view of the six parts of five stack SOFC ........................... 41

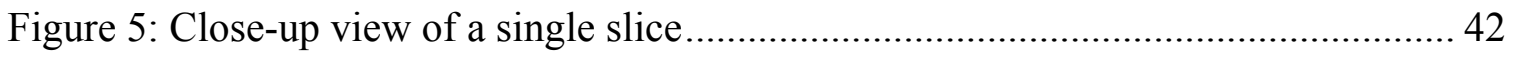

Figure 6: Five stack two-dimensional meshed models ................................................. 43

Figure 7: Close-up view of the mesh in cathode and electrolyte of the model................ 44

Figure 8: First slice (temperature profile at the inlet) .......................................... 45

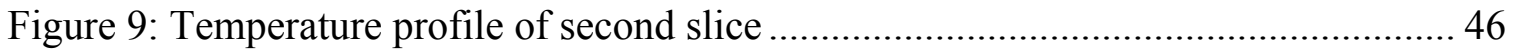

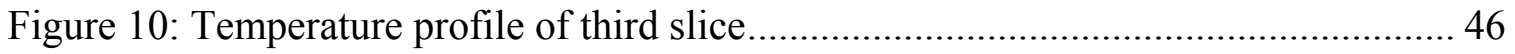

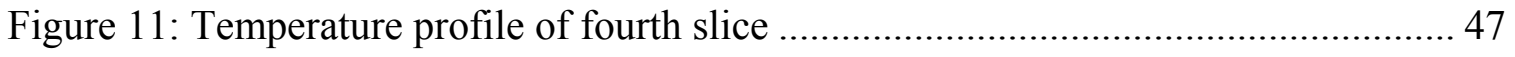

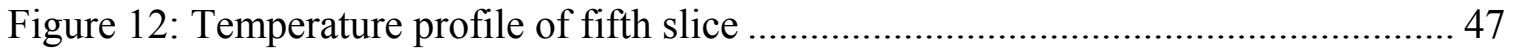

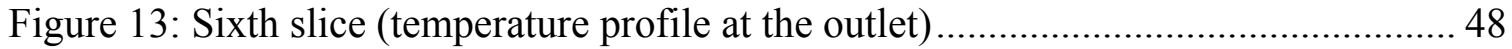

Figure 14: Close-up view of the temperature profile in the top half of first slice ........... 49

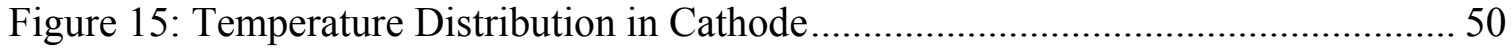

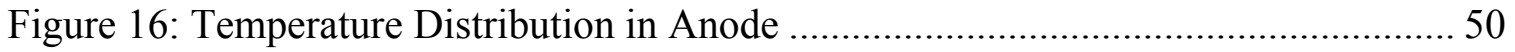

Figure 17: Temperature Distribution in Electrolyte................................................. 51

Figure 18: First slice (von Mises stresses near the inlet of gases of $1^{\text {st }}$ model) ................ 53

Figure 19: von Mises stresses in the second slice $\left(1^{\text {st }}\right.$ model $)$..................................... 54

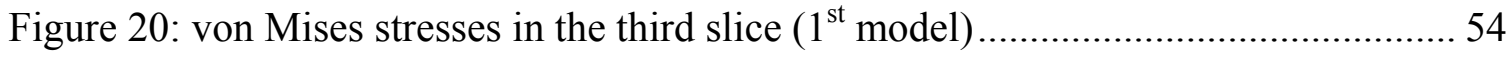

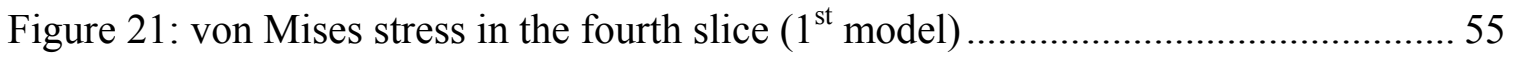

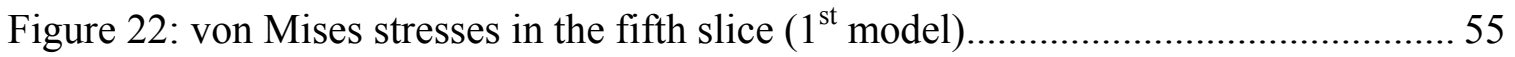

Figure 23: Sixth slice (Von Mises stresses near the outlet of gases of $1^{\text {st }}$ model)........... 56

Figure 24: von Mises stress near the inlet of gases (left) and near the outlet of gases

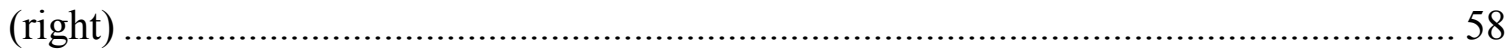

Figure 25: von Mises stress in the top part of the fuel cell ........................................ 59

Figure 26: Stresses near the inlet of gases of the fuel cell $\left(1^{\text {st }}\right.$ model $)$........................... 60

Figure 27: Stresses near the outlet of gases of the fuel cell $\left(1^{\text {st }}\right.$ model $) \ldots \ldots \ldots \ldots \ldots \ldots \ldots \ldots \ldots . . . . . . . . . . . . .61$ 
Figure 28: Maximum principle stress of $\mathrm{LaCrO} 3$ interconnect near the inlet of gases $\left(1^{\text {st }}\right.$ model) 62

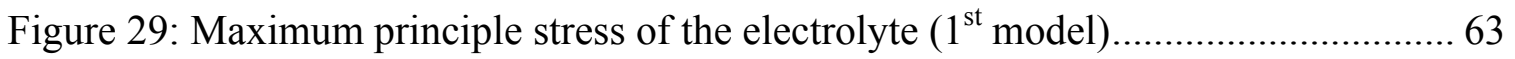

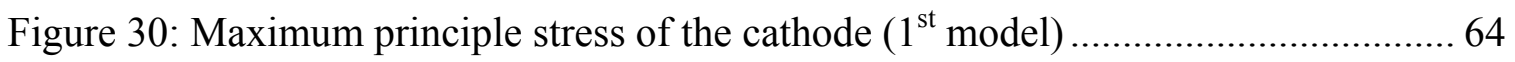

Figure 31: Maximum principle stress of the anode $\left(1^{\text {st }}\right.$ model $)$......................................... 64

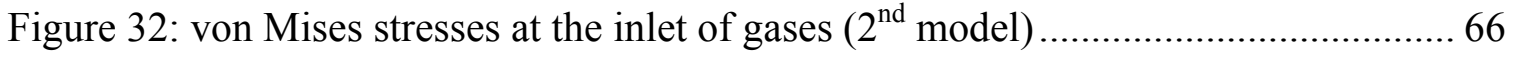

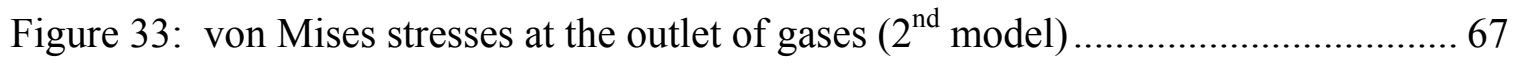

Figure 34: Maximum Principle Stress at the inlet of gases $\left(2^{\text {nd }}\right.$ model $)$........................... 68

Figure 35: Maximum principle stresses at the outlet of gases $\left(2^{\text {nd }}\right.$ model $) \ldots \ldots \ldots \ldots \ldots \ldots . . . . . . . .68$

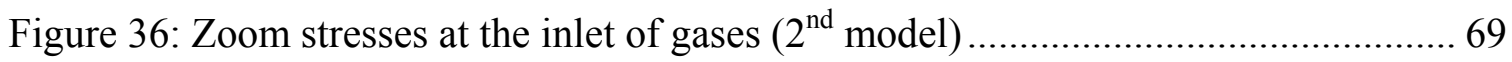

Figure 37: Zoom stresses at the outlet of gases $\left(2^{\text {nd }}\right.$ model $)$........................................... 70

Figure 38: Maximum principle stresses at the inlet of gases (left) and outlet of gases

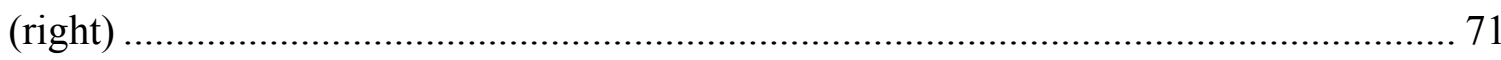

Figure 39: Maximum principle stresses found in the fuel cell (2nd model) .................... 72

Figure 40: Three-dimensional view of a single stack cross-flow SOFC .......................... 74

Figure 41: Three-dimensional meshed model............................................................ 76

Figure 42: Boundary constraints on the three-dimensional SOFC $\left(1^{\text {st }}\right.$ model $) \ldots \ldots \ldots \ldots \ldots . . . . . .78$

Figure 43: Maximum principle stress in the three-dimensional SOFC $\left(1^{\text {st }}\right.$ model $)$.......... 79

Figure 44: Boundary constraints on the three-dimensional SOFC $\left(2^{\text {nd }}\right.$ model $) \ldots \ldots \ldots \ldots \ldots . . . . .81$

Figure 45: Maximum principle stress in the three-dimensional SOFC $\left(2^{\text {nd }}\right.$ model $) \ldots \ldots . . .82$

Figure 46: Comparison of the principle stresses with the model by Jason LeMaster, 2004

Figure 47: Maximum principle stress in the Anode of the three-dimensional SOFC ...... 84 Figure 48: Maximum principle stress in the Electrolyte of the three-dimensional SOFC 84 Figure 49: Maximum principle stress in the Cathode of the three-dimensional SOFC .... 85 Figure 50: Maximum principle stress in the Interconnect of the three-dimensional SOFC 


\section{LIST OF TABLES}

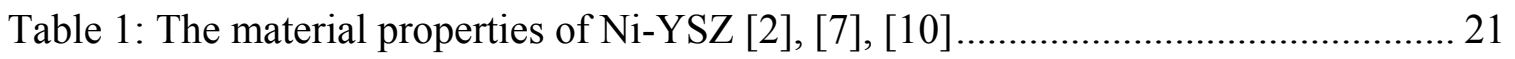

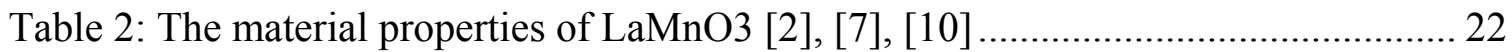

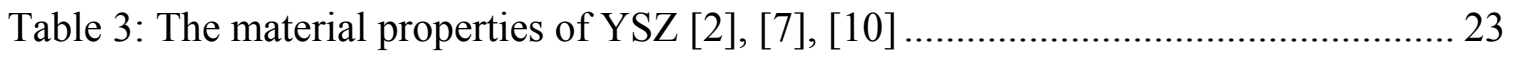

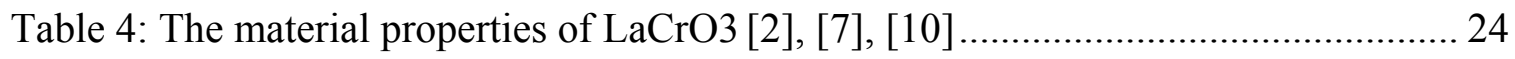

Table 5: Properties of the components used in the analysis [2], [7], [10] ...................... 40

Table 6: Maximum principle stresses found in the PEN and interconnect ( $1^{\text {st }}$ model) .... 65

Table 7: Maximum principle stresses found in the fuel cell (2nd model) ....................... 72

Table 8: Maximum stresses found in the three-dimensional model $\left(1^{\text {st }}\right.$ model $) \ldots \ldots \ldots \ldots . . . . .80$

Table 9: Maximum stresses found in the three-dimensional model ( $2^{\text {nd }}$ model) $\ldots \ldots \ldots \ldots . . . . .82$ 


\section{CHAPTER 1}

\section{BACKGROUND}

\subsection{Introduction}

Fuel cells are potentially useful energy conversion systems due to high power generation and heat recovery efficiency with low pollution rate. A fuel cell produces electricity directly from a gaseous fuel by electrochemical thermal reaction of the fuel with an oxidant. Solid oxide fuel cells (SOFCs) are the promising candidates for energy conversion systems because of their higher energy conversion efficiency than those of conventional heat energy systems and other types of fuel cells. Moreover, solid oxide fuel cells are less sensitive to fuel composition compared to other fuel cell and allows the use of conventional hydrocarbon fuel cells without any external reformer. In SOFC stack designs, the planar solid oxide fuel cell has received much attention as it is simpler to fabricate and the compact size of the fuel cell stack results in better mechanical strength. Recently, fuel cell research and development has received much attention due to the widening interest in this technology. Multikilowatt fuel cells having features of a practical power generation system have been operated for several thousand hours and have shown excellent performance. [2]

\subsection{Principle of Operation of a Fuel Cell}

A fuel cell converts the chemical energy of oxygen and hydrogen directly to electrical energy. The operating principle of a fuel cell is similar to that of a battery, which is an 
electrochemical combination of reactants to generate electricity. A fuel cell does not require recharging, it employs gases as reactants and operates as long as fuel and oxidants are supplied to the electrodes. Whereas a battery contains all the substances in the electrochemical oxidation-reduction reactions and therefore has limited capacity. Direct conversion of fuel energy to electricity is the key characteristic of fuel cell operation whereas in a conventional power system, the chemical energy is first converted to thermal energy, then to mechanical energy and finally to electricity.

The electricity generation mechanism of a fuel cell is similar to that of the electrochemical combustion. However, the reactants are made of two separate electrochemical reactions. The overall reaction in the fuel cell, like combustion, consists of the reduction of oxygen at the cathode and the oxidation of hydrogen at the anode. In a fuel cell the transfer of electrons takes place through the interconnect which also keeps the fuel and the oxidizer from mixing. Therefore in a fuel cell, chemical energy is directly converted into electrical energy without any intermediate steps.

A single fuel cell is composed of a cathode, electrolyte and anode where the fuel is fed to the anode and the oxidant is fed to the cathode. The electrolyte is an ion-conducting membrane that separates the oxidant and hydrogen and allows the conduction of ionic oxygen. When hydrogen reacts with oxygen at the anode/electrolyte interface, two electrons associated with the oxygen are replaced with hydrogen, producing electricity and water. The most commonly used fuel and oxidant in a SOFC are hydrogen and oxygen respectively. In the operation of a SOFC, the fuel (e.g., hydrogen) at the anode is oxidized and electrons are released to the external circuit. And the oxidant (e.g., oxygen) 
at the cathode is reduced and electrons accepted from the external circuit. The electron flow from the anode to the cathode through the external circuit produces electricity. These electrons are freely conducted back to the cathode where the incoming supply of oxygen is dissociated, hence sustaining the reaction. For this reaction to occur, the temperature of the fuel cell must be maintained above the activation temperature which is usually at least $600^{\circ} \mathrm{C}$.

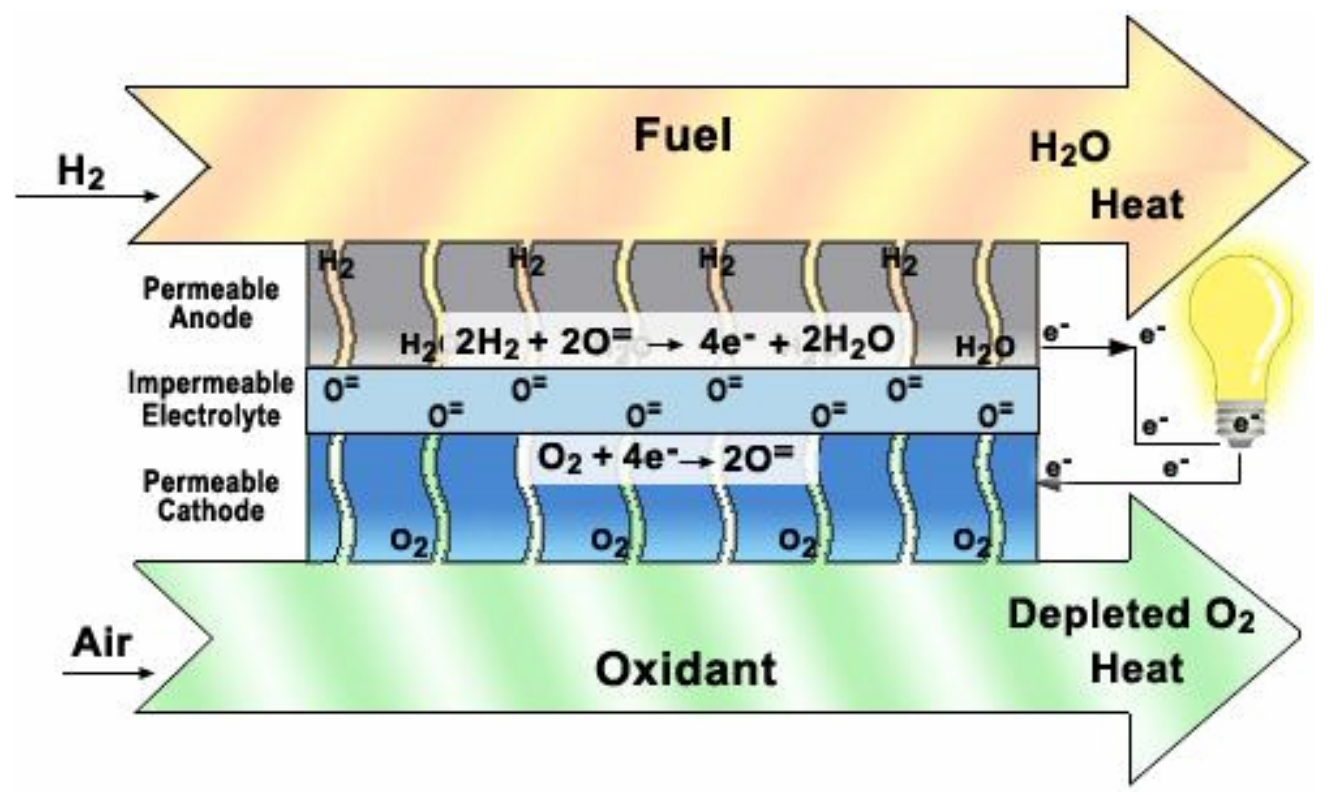

Figure 1: Solid Oxide Fuel Cell [16]

At the cathode/electrolyte interface, the reduction of oxygen in a SOFC based on an oxygen ion-conducting electrolyte is given as

$$
1 / 2 O_{2}+2 e^{-} \rightarrow O^{2-}
$$


At the anode/electrolyte interface, oxidation of hydrogen is given as

$$
\mathrm{H}_{2}+\mathrm{O}^{2-} \rightarrow \mathrm{H}_{2} \mathrm{O}+2 e^{-}
$$

Overall reaction

$$
\mathrm{H}_{2}+1 / 2 \mathrm{O}_{2} \rightarrow \mathrm{H}_{2} \mathrm{O}
$$

Water is produced when the oxide ions migrate from the cathode to the anode and reacts with hydrogen, which has to be removed from the system.

\subsection{Types of Fuel Cells}

Fuel cells are divided primarily by the type of electrolyte that is used. The electrolyte determines the kind of chemical reaction that takes place in the cell, the temperature range in which the cell operates, the catalyst needed and other factors. These characteristics, in turn, affect the application of the fuel cells. Depending on the temperature range at which the fuel cells operate, they can be broadly classified into high temperature fuel cells and low temperature fuel cells.

\subsubsection{High Temperature Fuel Cells}

In general, high temperature fuel cells are more efficient than low temperature fuel cells in generating electricity. The high temperature provides the benefit of increased 
efficiency but presents a problem for transportation application. Solid Oxide Fuel Cells (SOFCs), Phosphoric Acid Fuel Cells (PAFCs) and Molten Carbonate fuel cells (MCFCs) fall under the category of high temperature fuel cells.

\subsubsection{Solid Oxide Fuel Cells}

Solid oxide fuel cells use solid, non-porous ceramic compound as the electrolyte. The efficiency of converting fuel to electricity is expected to be around 50-60 percent. The fuel use efficiencies to capture and utilize the system waste heat could top 80-85 percent. The SOFCs operate at very high temperature around $1000^{\circ} \mathrm{C}$. High temperature operation reduces cost by removing the need for precious-metal catalyst and also allows to reform fuels internally which enables the use of a variety of fuels. The reactions at the electrode are

Electrochemical Equation

Cathode: $\quad 1 / 2 O_{2}+2 e^{-} \rightarrow O^{2-}$

Anode: $\quad \mathrm{H}_{2}+\mathrm{O}^{2-} \rightarrow \mathrm{H}_{2} \mathrm{O}+2 e^{-}$

Overall: $\quad \mathrm{H}_{2}+1 / 2 \mathrm{O}_{2} \rightarrow \mathrm{H}_{2} \mathrm{O}$

The oxygen ions migrate from cathode to anode and water is formed at the anode/electrolyte interface. The most commonly used cathode and anode materials are lanthanum manganite $\left(\mathrm{LaMno}_{3}\right)$ and Ni-YSZ. The usual electrolyte used is yittria stabilized zirconia (YSZ). 


\subsubsection{Phosphoric Acid Fuel Cells}

Phosphoric acid fuel cell (PAFC) is the first fuel cell to be used commercially. These fuel cells are typically used for stationary power generation, but some of them have been used in large vehicles such as city buses. PAFCs are 85 percent efficient when used for cogeneration of heat and electricity, but less efficient at generating electricity alone (37 to 42 percent). These fuel cells are typically large and heavy and require expensive platinum catalyst which increases the cost of the fuel cell. A typical phosphoric fuel cell costs around $\$ 4,000$ to $\$ 4,500$ per kilowatt. The electrode reactions are

Electrochemical Equation

Anode: $\quad \mathrm{H}_{2} \rightarrow 2 \mathrm{H}^{+}+2 e^{-}$

Cathode: $\quad 1 / 2 \mathrm{O}_{2}+2 \mathrm{H}^{+}+2 e^{-} \rightarrow \mathrm{H}_{2} \mathrm{O}$

Overall: $\quad \mathrm{H}_{2}+1 / 2 \mathrm{O}_{2} \rightarrow \mathrm{H}_{2} \mathrm{O}$

The electrolyte used in phosphoric acid fuel cells is liquid phosphoric acid which is contained in a Teflon-bonded silicon carbide matrix. The electrodes used are porous carbon containing a platinum catalyst. These fuel cells operate at a temperature of $205^{\circ} \mathrm{C}$ to $210^{\circ} \mathrm{C}$. The reaction is sustained by the transport of $\mathrm{H}^{+}$ions from anode to cathode.

\subsubsection{Molten Carbonate Fuel Cell}

Molten carbonate fuel cells (MFCSs) use an electrolyte composed of a molten carbonate mixture suspended in a porous and chemically inert ceramic lithium aluminum oxide $\left(\mathrm{LiAlO}_{2}\right)$. These fuel cells operate at a temperature of $650{ }^{\circ} \mathrm{C} . \mathrm{MCFCs}$ are developed for 
natural gas and coal based power plants which are used for electrical utility, industrial and military applications. Improvement in efficiency offers a significant cost reduction over phosphoric acid fuel cells. The efficiency of molten carbonate fuel cells reaches 60 percent. Due to high temperatures, the fuels are converted to hydrogen within the fuel cell itself by a process called internal reforming. The electrode reactions are

Electrochemical Equation

Anode: $\quad \mathrm{H}_{2}+\mathrm{CO}_{3}{ }^{2-} \rightarrow \mathrm{H}_{2} \mathrm{O}+\mathrm{CO}_{2}+2 e^{-}$

Cathode: $\quad 1 / 2 \mathrm{O}_{2}+\mathrm{CO}_{2}+2 e^{-} \rightarrow \mathrm{CO}_{3}^{2-}$

Overall: $\quad \mathrm{H}_{2}+1 / 2 \mathrm{O}_{2}+\mathrm{CO}_{2} \rightarrow \mathrm{H}_{2} \mathrm{O}+\mathrm{CO}_{2}$

Molten carbonate fuel cell uses carbon monoxide as a fuel input on the cathode side and hydrogen on the anode side. Materials used for anode are $\mathrm{Ni}-\mathrm{Al}-\mathrm{Cr}, \mathrm{Ni}-\mathrm{Al}$ and $\mathrm{Ni}-\mathrm{Cr}$ and the materials used for cathode are $\mathrm{NiO}-\mathrm{MgO}$. The major problem of the molten carbonate fuel cell is, during the operation of the fuel cell, the electrolyte has a corrosive nature.

\subsubsection{Low Temperature Fuel Cells}

Low temperature fuel cells have a quick start-up time and the weight of the fuel cell is lower than that of high temperature fuel cells. Most of the transportation fuel cells fall under the category of the low temperature fuel cells. The low temperature fuel cells are Alkaline Fuel Cells (AFCs), Proton Exchange Member or Solid Polymer Membrane Fuel Cells (PEMFCs or SPMFCs) and Regenerative fuel cells, which is comparatively a young fuel cell technology. 


\subsubsection{Alkaline Fuel Cells}

Alkaline fuel cells (AFCs) are considered to be one of the first fuel cells technologies developed. These fuel cells were widely used in the space program to produce electricity and water on the spacecraft. The electrolyte used in these fuel cells is a solution of potassium hydroxide in water and the electrodes used are nickel electrodes. A variety of non-precious metals are used as a catalyst at the anode and cathode. The operating temperature of the AFCs is around $23{ }^{\circ} \mathrm{C}$ to $70{ }^{\circ} \mathrm{C}$. The rate at which the chemical reaction takes place in the fuel cell is very high and the efficiency of the fuel cell is around 60 percent. The reactions at the electrode of AFCs are

Electrochemical Equation:

Anode: $\quad \mathrm{H}_{2}+2(\mathrm{OH})^{-} \rightarrow 2 \mathrm{H}_{2} \mathrm{O}+2 e^{-}$

Cathode: $\quad 1 / 2 \mathrm{O}_{2}+\mathrm{H}_{2} \mathrm{O}+2 e^{-} \rightarrow 2(\mathrm{OH})^{-}$

Overall: $\quad \mathrm{H}_{2}+1 / 2 \mathrm{O}_{2}+\mathrm{CO}_{2} \rightarrow \mathrm{H}_{2} \mathrm{O}$

The main disadvantage of this type of fuel cell is that it gets easily poisoned by carbon dioxide $\left(\mathrm{CO}_{2}\right)$. Even a small amount of $\mathrm{CO}_{2}$ in the air affects the cell operation, making it necessary to purify both hydrogen and oxygen used in the fuel cell. Susceptibility to poisoning affects the cell life which in turn adds to the cost of the fuel cell. 


\subsubsection{Proton Exchange Member (PEM) or Solid Polymer Fuel Cells (SPFCs)}

Proton exchange member (PEM) fuel cells have an advantage of low weight and volume over the other type of fuel cells and also offer high power density. The electrolyte used in the PEM fuel cells is solid polymer and carbon or nickel electrodes coated with Polytetraflouroethylene (PTFE) containing platinum catalyst are used. The fuel used is pure hydrogen supplied from storage tanks or onboard reformers. Solid polymer fuel cells operate at a temperature around $80^{\circ} \mathrm{C}$. As these fuel cells operate at a low temperature, they start quickly which results in less wear on the system components leading to better durability.

Electrochemical Equation:

Anode: $\quad \mathrm{H}_{2} \rightarrow 2 \mathrm{H}^{+}+2 e^{-}$

Cathode: $\quad 1 / 2 \mathrm{O}_{2}+2 \mathrm{H}^{+}+2 e^{-} \rightarrow \mathrm{H}_{2} \mathrm{O}$

Overall: $\quad \mathrm{H}_{2}+1 / 2 \mathrm{O}_{2} \rightarrow \mathrm{H}_{2} \mathrm{O}$

The platinum catalyst which is used to separates hydrogen's electrons and protons adds to the cost of the system. The platinum catalyst also causes poisoning due to carbon monoxide (CO) and therefore an additional reactor is needed to reduce the $\mathrm{CO}$ in the fuel. PEM fuel cells are primarily used for transportation applications, primarily in cars and buses. They are also used in some stationary applications. 


\subsubsection{Regenerative Fuel Cells}

Regenerative fuel cell is comparatively a young fuel cell technology which is still being developed. It provides excellent power instantly even at temperatures below freezing point. Regenerative fuel cell generates $75 \%$ of peak power at $25^{\circ} \mathrm{C}$ and $50 \%$ of power at $0^{\circ} \mathrm{C}$ and down to below $-20^{\circ} \mathrm{C}$. The electrolyte used in the fuel cell is sodium bromide. This type of fuel cell produces electricity from hydrogen and oxygen just like the other types of fuel cells. Regenerative fuel cells are used to power vehicles in a cleaner way and to make better use of domestic resources. A 50-kilowatt cell can power a lightweight car without any undesirable emissions. The regenerative fuel cell can be designed to operate in the reverse direction as an electrolyzer, where electricity is used to convert water back to hydrogen and oxygen. This fuel cell is an excellent energy source in situations where weight is a concern.

\subsubsection{Application of Fuel Cells}

Fuel cells offer several advantages when compared to conventional electric power generation systems. They provide substantially high power generation efficiency, low production of pollutants, minimal siting restrictions and potential for cogeneration. Due to various desirable characteristics of the fuel cells, they can be considered for applications ranging from large multimegawatt electric utility power plants to compact kilowatt space power systems. According to the economic studies, fuel cells can be produced and operated at costs competitive with other power generation systems. 
Fuel cells have been successfully used in stationary power installations for emergency power for hospitals, communications facilities, computer installations and factories. Direct methanol fuel cells are used in personal electronic devices like mobile phones and laptops. In transportation, fuel cells are used mostly in cars and buses but also in planes scooters, bicycles, trains, boats as well as in highway road signs. PEM fuel cells are used in landfills and waste water treatment plants where methane gas is converted into electricity. Military applications are expected to become a significant market for fuel cells as it provides power from land and sea transportation to portable devices used in the field.

\subsubsection{Literature Review}

The design of planar solid oxide fuel cells (SOFCs) is focused on the electrochemical performance and the mechanical integrity. Heat transfer and stress analyses are usually separated and then sequentially analyzed. The heat transfer is followed by the stress analysis and these stresses do not affect the heat transfer. However, with the maturaty of SOFC technology, the practical implementation is shifting its focus towards the stresses inherent in the fuel cell design. Therefore, the study of thermal stresses within solid oxide fuel cells is an essential aspect in the development of the fuel cell systems. Fuel cell modeling for the stresses can be categorized as two-dimensional and three-dimensional modeling.

Residual stress analysis of cylindrical solid oxide fuel cells was presented by Kato et. al., 1997. The residual stresses in the cylindrical SOFCs and the process temperatures 
were estimated using analytical modeling of the axisymmetric structure. From the analysis it is inferred that the axial stresses induced in the electrodes are high enough to break the structure under the assumed realistic conditions.

Busso E. P et. al., 1998 studied the residual stress generation during the sintering of the ceramic layers in an SOFC. This work investigated the stresses developed in the thin layer of ceramic structure when it was sintered to the rigid substrate under nonisothermal conditions. A correlation was developed between the residual stresses extracted from curvature measurements and analytical methods.

Lowrie F.L et. al., 2000 studied the room and high temperature failure mechanism in solid oxide fuel cell. The stability of yittria stabilized zirconia (YSZ) at elevated temperatures was investigated and there was evidence of crack initiation and propagation mechanisms. Constant load tests at operating temperatures revealed creep in the YSZ electrolyte which occurred due to grain boundary diffusion mechanism.

H. Yakabe et. al., 2001 constructed a three-dimensional model for a planar SOFC. Finite volume method was employed for calculating the temperature distribution, potential distribution and current density using a single-unit model. The stress distributions were calculated using the finite element program ABAQUS ${ }^{\mathrm{TM}}$ from the simulated temperature distributions in the electrolyte and the interconnect. From these results, the effects of cell size, operating voltage and thermal conductivity of the cell component were investigated. It was found that, co-flow pattern is advantageous to mitigate the steep temperature gradient and therefore to reduce the thermal stresses.

Thermal stress analysis in planar solid oxide fuel cells due to thermal expansion differences was explained by C.S Montross et. al., 2002. Stresses arise mainly due to temperature gradient, changes in the material properties, material reliability and 
differences in thermal expansion coefficients. In this literature, broad recommendations were made on the importance of reducing the differences in thermal expansion coefficients of the materials and the effects of size were examined. Two planar solid oxide fuel cell models with closed form solutions were used to investigate the thermal tensile and shear stresses.

Modeling and mitigation of SOFC failure was done by Jianmin Qu et. al., 2003. In this research a model was developed for simulating thermal spalling failure during steady state operation. A methodology was developed to establish a relationship between airflow and the thermal shock induced stresses within the cathode. Further, the effects of radiation on the temperature profile in a monolithic SOFC were studied and the location of failure within the P-E-N was predicted.

Mark Boersma et. al., 2003, presented a stress analysis for an operating SOFC stack under combined pressure loading and rejected heat due to stack operation. The finite element model was developed at Global Thermoelectric, Inc assisted by ANSYSTM technical support. For the stress analysis, the temperature gradient across the cell was used and the constraints on the bottom plate were set to allow frictionless expansion in the horizontal plane while fixing it in the vertical plane. As a result, design improvements and alterations were made by reducing the iterations and analyzing the problematic areas. The issues affecting the mechanical integrity of SOFCs were studied by Samuel T. Hagos et. al., 2003. Half cells made of yittria stabilized zirconia (YSZ) electrolyte were used. And this electrolyte which is coated with an anode and cathode was prepared for the residual stress analysis and to calculate the creep. Also the porous supported material was tested to fracture under thermally induced stresses. The results of the residual stresses 
measurements based on the curvature measurements were compared with the research from finite element stresses.

Jason LeMasters et. al., 2004 presented a thermal stress analysis of Linear Cellular Alloys (LCA) - based SOFCs. Approximate finite difference techniques were developed to analyze the temperature distributions resulting from a range cell geometries and materials of a hybrid solid oxide fuel cell. From these temperatures, the corresponding thermal stresses were calculated using ABAQUS ${ }^{\mathrm{TM}}$. The hybrid solid oxide fuel cell model was analyzed for manufacturing, start-up and steady state operating conditions.

Yakabe H et. al., 2004 evaluated the residual stresses for an anode- supported solid oxide fuel cell experimentally and numerically. X-ray diffraction method was employed to measure the residual stresses and it was found that the compressive stresses in the electrolyte were around $650 \mathrm{MPa}$ at room temperature which is high enough to cause failure.

\subsubsection{Objective}

The main focus in this research is to estimate the stresses in the components of a planar solid oxide fuel cell (SOFC). During the steady state operation of the fuel cell, air flows in the air channels over the cathode and fuel over the anode causing a non-uniform temperature distribution in the structure which in turn causes thermally induced stresses. Finite element analyses using ANSYS ${ }^{\mathrm{TM}}$ are carried out to accurately predict the stress levels in the components of the fuel cell. 
The planar type SOFC design has been used as it received much attention due to its simplicity to fabricate and also because it offers higher power density relative to the tubular type of SOFC. In the planar design, the electrolyte which is a flat plate is fabricated by tape-casting and the anode and cathode are applied to either sides of the electrolyte creating a P-E-N structure. An interconnect having gas channels is located above and below the P-E-N structure and glass seals are plugged at the outer edges of the interconnect-electrolyte intersection. The planar SOFC has been modeled by the use of mathematical models and finite element analysis by Yakabe et al., (2001). Yakabe developed a mathematical model for the electrochemistry of the fuel cell and this model was implemented into a thermo-fluid model created in STAR-CDTM which is a CFD program. The results of the STAR-CD ${ }^{\mathrm{TM}}$ program were then inserted into ABAQUS for thermal stress analysis. In the work by Keegan (2002), the electrochemistry model was based on a program called ASPEN ${ }^{\mathrm{TM}}$. The results from ASPEN ${ }^{\mathrm{TM}}$ were fed into STAR$\mathrm{CD}^{\mathrm{TM}}$ for thermo-fluid analysis, which in turn was used in ANSYS ${ }^{\mathrm{TM}}$ to model transient stress distribution. However, in this work, only thermal stress analysis is performed using ANSYS $^{\mathrm{TM}}$ with the help of calculated temperature distributions in the components from the computational fluid dynamics (CFD) codes developed by WVU CFD \& AMP Laboratory [10].

The purpose of the present work is to estimate the operating stresses in a five stack twodimensional model and a single three-dimensional model using ANSYS ${ }^{\mathrm{TM}}$. A coupled thermo-structural analysis is performed for the two-dimensional model and a static structural analysis for the three-dimensional model. In the stress calculation, the temperature profile from the CFD codes [10] was read into the ANSYS ${ }^{\mathrm{TM}}$ at the nodes 
which were interpolated within the elements. The plates of material in the twodimensional and three-dimensional models are constrained such that they can expand or contract but cannot rotate. This avoids gas leakage and connection problems and is more mechanically robust. Therefore, with the help of these analyses, the location of failure within the fuel cell can be predicted. 


\section{CHAPTER 2}

\section{SOLID OXIDE FUEL CELL}

\subsection{Introduction}

Solid oxide fuel cells, also called ceramic fuel cells have several advantages compared with other type of fuel cells. SOFCs operate at high temperatures and have all-solid-state construction, mainly ceramic. Due to these characteristics the fuel cell can be configured into compact and light weighted structures which cannot be achieved in fuel cells having liquid electrolyte. Components of the SOFC exhibit relatively low electrical conductivity, therefore the components must be fabricated very thin to reduce internal resistance losses. Other desirable characteristics of the fuel cell components are high strength, toughness and low cost. A solid oxide fuel cell basically consists of an electrolyte, conducting oxide ions sandwiched between two porous electrodes.

\subsection{Current Solid Oxide Fuel Cell Technology}

At present, four common configurations have been proposed and fabricated which satisfy these design requirements. They are - (1) tubular design, (2) monolithic design, (3) planar design and (4) segmented cell design. In the tubular solid oxide fuel cell design, a hollow cylinder with an electrolyte wall is present. Air flows through the center of the cylinder and the fuel passes over the outside. Unlike the other type of fuel cells, the tubular design eliminates the need for seals and allows thermal expansion. The cell is built up in layers on the cathode with an axial interconnect which allows the cell to be connected together in series. At elevated temperatures, the oxygen in the air ionizes and 
these ions flow through the electrolyte and combine with the fuel which is on the exterior of the cell. The electrons released due to electrochemical reaction, flow through an external circuit and produces electricity. The planar design consists of alternating flat plates of anode, electrolyte, cathode and the interconnect. A stack of anode, electrolyte and cathode is also referred as the PEN. The flat plates must be sealed at the edges to prevent the gas from escaping and also to withstand the stresses developed by the expansion of the interconnect and electrolyte. During the operation of the fuel cell, the oxygen ions are conducted from the cathode to the anode where they react chemically with the hydrogen. Due to the passage of these ions an electric charge is induced which is collected and conducted away from the cell. The monolithic design is similar to that of the planar solid oxide fuel cell design, however the electrolyte of the monolithic cell is corrugated to increase the efficiency. The PEN of the fuel cell is co-fired and layered with the interconnect. The monolithic design has the highest power density due to the close proximity of the interconnect layers. The segmented-cell-in-series design consists of a number of small cylindrical cell segments that are in contact with a planar metallic interconnect. The interconnect sheet electrically connect one cell segment to the other which are above and below as well as the cell segments on the same side of it which allows malfunctioning of a single cell without disabling the whole stack. 


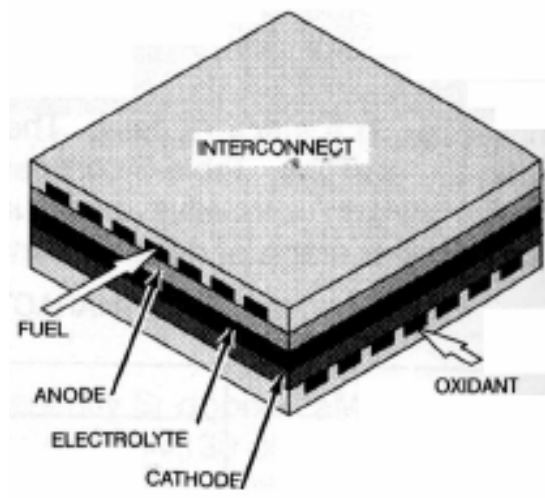

Planar Design

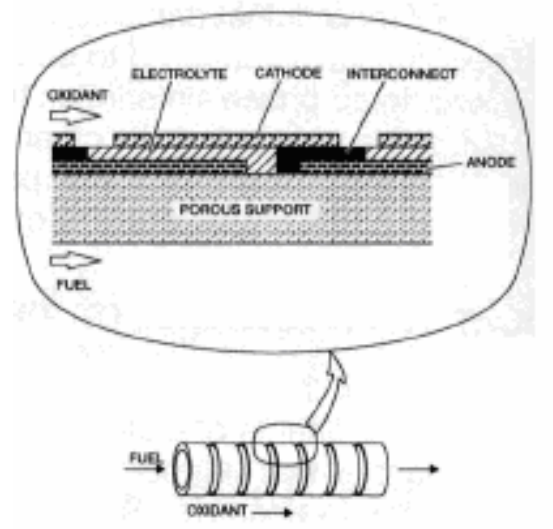

Segmented-cell-in-series Design

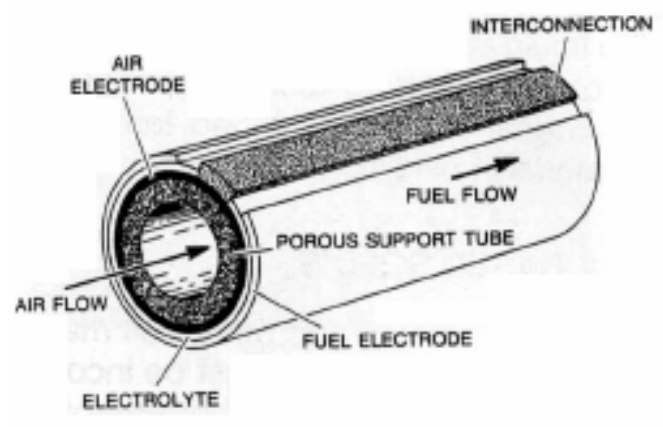

Seal-iess Tubular Design

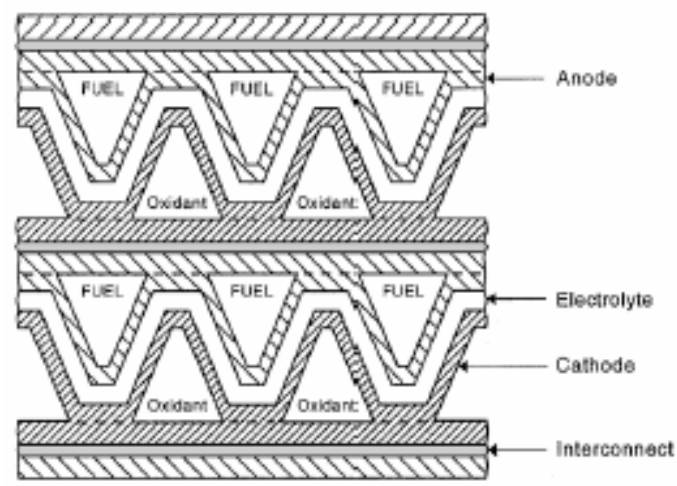

Monolithic Design

\section{Figure 2: Various Solid Oxide Fuel Cell Designs [2]}

\subsection{Components Of An SOFC}

The components of the SOFC perform specific functions and are fabricated from a variety of materials. The four components of the SOFC are

1. Anode

2. Electrolyte 


\section{Cathode}

4. Interconnect

\subsubsection{Anode}

The electrochemical oxidation of the fuel takes place at the anode/electrolyte region. A three component interface region is formed at the anode as it provides a reaction site for the fuel. Therefore the main function of the anode is that it must be stable in the fuel reducing environment and have sufficient electronic conductivity and catalytic activity for the fuel reaction. The other important properties the anode must possess are chemical and thermal compatibility with the other cell components from room temperature to higher temperatures at which the fuel cell is fabricated. Additionally the anode must be chemically stable, have sufficient porosity to allow transport of gas to the reaction site and the thermal expansion coefficient must match that of the other cell components to avoid cracking during fabrication and operation.

The above mentioned requirements are satisfied by many ceramics and metallic materials. The solid oxide fuel cells are operated at high temperatures; therefore the suitable metals are mainly nickel, cobalt and noble metals. The most commonly used metal is nickel (Ni) dispersed on Yittria stabilized Zirconia (YSZ) support (cermet). Nickel is primarily preferred due it its low cost and YSZ is used to maintain the porous structure of $\mathrm{Ni}$ at high temperatures and to provide anode thermal expansion coefficient close to that of the other cell components. 


\begin{tabular}{|c|c|}
\hline Thermal conductivity & $5.84 \mathrm{~W} / \mathrm{mK}$ \\
\hline Young's Modulus & $96 \mathrm{GPa}$ \\
\hline Thermal expansion coefficient & $12.5 \mathrm{e}^{-6} /{ }^{\circ} \mathrm{K}$ \\
\hline Failure Strength & $90 \mathrm{MPa}$ \\
\hline
\end{tabular}

\section{Table 1: The material properties of Ni-YSZ [2], [7], [10]}

\subsubsection{Cathode}

The main function of the cathode is to provide a reaction site for the electrochemical reduction of the oxidant. The key requirement of the cathode is that it must be stable in the oxidant oxidizing environment and have sufficient electronic conductivity and catalytic activity at operating conditions. The other properties that the cathode must posses are chemical and thermal compatibility with the other cell components, chemically stability in the oxidant environment, sufficient porosity to allow gas transport to the reaction sites, thermal expansion coefficient match with that of the other components and sufficient catalytic activity.

As the fuel cell operates at high temperatures, only noble metals and electronic conducting oxides can be used as cathode materials. Doped lanthanum manganite $\left(\mathrm{LaMnO}_{3}\right)$ is the most extensively used cathode material as it meets the requirement of thermal expansion match with other components. Also LaMnO3 is adequately compatible with Yittria stabilized Zirconia (YSZ) which is the electrolyte and has high electrical conductivity in oxidizing atmosphere. During the operation of the solid oxide 
fuel cell, LaMnO3 is stable in oxidizing atmosphere. Table 2 shows the typical mechanical properties of $\mathrm{LaMnO} 3$

\begin{tabular}{|c|l|}
\hline Thermal conductivity & $4 \mathrm{~W} / \mathrm{mK}$ \\
\hline Young's Modulus & $96.71 \mathrm{GPa}$ \\
\hline Thermal expansion coefficient & $11.2 \mathrm{e}^{-6} /{ }^{\circ} \mathrm{K}$ \\
\hline Failure Strength & $140 \mathrm{MPa}$ \\
\hline
\end{tabular}

Table 2: The material properties of LaMnO3 [2], [7], [10]

\subsubsection{Electrolyte}

The electrolyte of the solid oxide fuel cell separates the fuel from the oxidant and conducts ions between the cathode and the anode. The ions produced at the cathode are carried to the anode by the electrolyte and the charge is balanced due to the flow of the electrons completing the electric circuit in the fuel cell. The properties the electrolyte must possess are, stability in the oxidizing and reducing environments, ionic conductivity at operating conditions and impermeability to the reacting gases. As the SOFC operates at high temperatures, the electrolyte must be thermally and chemically compatible with the other components of the fuel cell at all temperatures. The other properties the electrolyte must posses are thermal expansion match with that of the other components of the cell, high mechanical strength and toughness. 
The most commonly used electrolyte material in the SOFC is Yittria stabilized Zirconia (YSZ). The alternative materials which are used at lower temperatures are Doped ceria $\left(\mathrm{CeO}_{2}\right)$ and Stabilized bismuthsesquioxide $\left(\mathrm{Bi}_{2} \mathrm{O}_{3}\right)$. YSZ is exclusively used as it possesses an adequate level of oxygen-ion conductivity and has a desirable stability in both the oxidizing and reducing environments. As YSZ is typically selected as the baseline material, the thermal expansions of the other cell materials are modified to match that of the electrolyte. Table 3 shows the typical mechanical properties of YSZ.

\begin{tabular}{|c|c|}
\hline Thermal conductivity & $2.16 \mathrm{~W} / \mathrm{mK}$ \\
\hline Young's Modulus & $200 \mathrm{GPa}$ \\
\hline Thermal expansion coefficient & $10.8 \mathrm{e}^{-6} /{ }^{\circ} \mathrm{K}$ \\
\hline Failure Strength & $177 \mathrm{MPa}$ \\
\hline
\end{tabular}

Table 3: The material properties of YSZ [2], [7], [10]

\subsubsection{Interconnect}

The primary function of the interconnect is that it connects the anode of one cell to the cathode of the other cell in an electrical series and also separate the fuel and oxidant in adjoining cells of a stack. The key requirement of the interconnect is that it must be stable both in oxidizing and reducing environments. It should also have sufficient conductivity to support electron flow during the operation of the fuel cell. The other properties the interconnect must possess are, impermeability to gases, chemical and thermal compatibility with the other cell components from room temperature to higher 
temperatures during operation and the thermal expansion must match that of the other cell components.

Lanthanum Chromite ( $\mathrm{LaCrO} 3)$ is the most commonly used interconnect material since 1970. The primary features of this material include high electronic conductivity in fuel and oxidant atmospheres, adequate stability in the fuel cell environment. Also the compatibility of $\mathrm{LaCrO} 3$ is reasonable with the other components of the solid oxide fuel cell. Permeation of oxygen through $\mathrm{LaCrO} 3$ is found to be very limited enhancing the efficient operation of the SOFC. The other interconnect materials that can be used are $\mathrm{CoCr}_{2} \mathrm{O}_{4}$ and $\mathrm{YCrO}_{3}$. Table 4 shows the typical mechanical properties of $\mathrm{LaCrO} 3$.

\begin{tabular}{|l|l|}
\hline Thermal conductivity & $6 \mathrm{~W} / \mathrm{mK}$ \\
\hline Young's Modulus & $60 \mathrm{GPa}$ \\
\hline Thermal expansion coefficient $\left(<1200^{\circ} \mathrm{K}\right)$ & $9.82 \mathrm{e}^{-6} /{ }^{\circ} \mathrm{K}$ \\
\hline Failure Strength & $73 \mathrm{MPa}$ \\
\hline
\end{tabular}

Table 4: The material properties of LaCrO3 [2], [7], [10]

\subsubsection{Edge Seals}

The edge seals prevent the gases flowing through the channels leaking in or out through the edges of the porous electrodes. The edge seals must allow thermal expansion coefficient match with the components of the fuel cell and provide high temperature service. The most commonly used edge seal material is YSZ cement. However, in this work, edge seals are not considered in the analysis. 


\subsection{Thermo-Electrochemical Behavior}

In the operation of the planar solid oxide fuel cell, fuel is passed from the channels at the anode and the oxidant is passed from the channel at the cathode. The SOFC has an oxygen-ion-conducting electrolyte which helps in oxidation and reduction of oxygen at the electrodes. Each planar cell is connected together in series and physically stacked on top of the other. During the operation of the fuel cell, various physiochemical hydrodynamic processes occur within the components of the cell. Electrochemical reactions occur at the interfaces between the electrolyte and the two electrodes. The air and fuel inlets are heated to high temperatures which help in the initiation of the electrochemical reactions. Heat transfer occurs in the solid and fluid region. Also, heat is generated at the electrolyte-electrode interface due to electro-chemical reactions and ohmic heating occurs within the electrolyte. Mass transfer occurs through the porous gas diffusion layers and an electric field potential occurs at the interfaces between the electrolyte and the electrodes. Local current distribution in the solid material is proportional to the gradient of the electrical potential. These physiochemical processes constitute a mathematical model which can be used to predict the temperature distribution using numerical methods.

\subsection{Thermal Stresses In Planar SOFC}

Thermal stresses play a very important role in the development of a reliable and a fuel efficient planar solid oxide fuel cell. Non-homogenous temperature distribution inside the fuel cell causes large internal stresses. Strict binding of the cell components generates mismatch in the thermal expansion coefficients of the components causing large stresses. 
Material properties like thermal conductivity and thermal expansion coefficient change with change in temperatures causing stresses due to the change in the material properties. When these thermally induced stresses are sufficiently high, mechanical damages such as spalling or micro-cracking can occur in the fuel cell.

\subsubsection{Stresses During Fabrication of Planar SOFC}

The most common fabrication technique of the planar solid oxide fuel cell is tape casting. In this method, slurry of ceramic powder dispersed in a solvent is uniformly spread onto a smooth surface and the volatile solvent is removed. The electrolyte stabilized Zirconia $\left(\mathrm{ZrO}_{2}\right)$ powders is made by tape casting where YSZ powder is used as the dispersant. The electrodes, Ni-YSZ anode and LaMnO3 cathode are sintered to the electrolyte at a temperature ranging from $1300{ }^{\circ} \mathrm{C}$ to $1500{ }^{\circ} \mathrm{C}$. After fabrication, the structure is cooled from the high sintering temperature to the room temperature. Due to slow cooling rates, visco-elastic creep is shown at a temperature above $1200{ }^{\circ} \mathrm{C}$ which entirely eliminates thermal expansion mismatch stresses. Therefore $1200{ }^{\circ} \mathrm{C}$ serves as a reasonable assumption for the stress-free temperature, but it is extremely dependent on the material selected. As the structure is cooled below $1200{ }^{\circ} \mathrm{C}$, residual stresses build up. Residual stresses in a planar SOFC are relatively low because the electrolyte is constrained only by the thin layers of anode and cathode.

\subsubsection{Stresses During Operation of Planar SOFC}

As planar SOFC is the most commonly used fuel cell, much research has been focused on the mechanical integrity during the operation of the fuel cell. Stresses during the 
operation of the fuel cell are mostly contributed by the mismatch of the thermal expansion co-efficients of the components, mechanically applied stresses, fatigue and thermal shocks. Failure in the fuel cell is not evaluated only based on catastrophic failure, but also on the cracking potential and hermetic joints which lead to losses in the efficiency of the planar SOFC. In the planar SOFC stack, mechanically applied stresses can be neglected as there are no external forces acting on the system and the weight of the components is negligible when compared to the strength of the structure. The material failure of the fuel cell due to the operating stresses must be analyzed separately for all the components. As the structure operates at a very high temperature range, failure can occur at the joint of the interconnect and the PEN, in the PEN, in the interconnect, in the interface of the electrolyte and anode or electrolyte and cathode. The maximum principle stress determines the failure in the ceramic.

Due to the intimate connection between the interconnect and the electrolyte, large stresses arise due to the constraint between the two components. Further stresses are also contributed by the cathode and the anode. In the planar SOFC, the electrodes fail before there is a significant effect on the overall structure. In this work, thermo-elastic stress analysis is performed using finite element analysis. The temperature distribution results of the WVU CFD \& AMP Laboratory code [10] were inserted into ANSYS ${ }^{\mathrm{TM}}$ for stress analyses of two-dimensional and three-dimensional planar SOFCs. The planar SOFC model is free to expand or contract in all directions, but the translation and rotation of the model is constrained. As the displacement at the joint of the PEN and interconnect is constrained, the stresses at the joint of these two materials are of great interest for the designing of a planar SOFC. The components of the structure are stacked one over the 
other, therefore bending effects are caused due to the contracting and expanding of the horizontal members. In addition the vertical members bend due to the shrinkage of the horizontal members. Magnitude of the stress is not dependent on the length of the model but depends on the $\mathrm{x}-\mathrm{y}$ dimensions and the material properties. Wider cells cause large stresses in the ceramic side of the joint. As the interconnect-PEN bond increases, the stresses within each component increase. Therefore, the operating stress is an important design parameter in the selection of the planar SOFC materials.

\subsection{Failure Criterion}

Theory of thermal elasticity states that, the stresses generated by non-uniform temperature field are proportional to the temperature gradient. Ceramic failure is defined as the point where the maximum principle stress exceeds the ultimate strength of the material. Stresses in $\mathrm{x}$-direction where the temperature is uniform will be uniform and in areas where there is a non-uniform temperature distribution i.e. in y-direction, the stresses will be maximum. Hence at these locations possible failure could occur. Elevated stresses are likely to be observed near the edges of cell because a large amount of mass is stacked at those particular regions, which includes the seals along with the cells and components. At elevated temperatures, the mechanical strength of the ceramics becomes low which would cause internal stresses and in turn lead to cracks or destruction of the material. At the inlets of the gases, large temperature gradient occurs and hence the structural analysis is focused on this area. Therefore, the failure limit is significantly dependent on the temperature. 


\section{CHAPTER 3}

\section{SOFC THERMAL MODEL}

\subsection{Introduction}

In this work, the temperature profile results from the thermal analysis for both the twodimensional and three dimensional models were given by Celik and Pakalapati, Computational Fluid Dynamics (CFD) Laboratory. With the help of these results the stresses in the SOFC were evaluated using ANSYS ${ }^{\mathrm{TM}}$. For the operation of reliable solid oxide fuel cells, evaluating the stresses in the components is very important. One form of stress in the SOFC is the thermal elastic stress which is caused due to the mechanical constraints, mismatch in thermal expansion coefficient among the components and the temperature distribution inside the fuel cell. Various reactions occurring across the planar components of the fuel cell, thermal energy transport, heat exchange, electrocatalytic reactions, mass transport owing to the oxygen ionic conduction across the electrolyte and property involved in current generation are significantly temperature dependent. Therefore local temperature plays an important role in determining local current density, which, in turn, determines the local heat flux. Temperature distribution is modeled by formulating the energy balance equations which describe the heat transfer processes occurring in the local heat balance.

The heat transfer processes in the SOFC are due to the heat released or absorbed arising from the electrochemical reactions, electrical resistances and the anode fuel chemistry. It also includes, heat conduction through the fuel cell components and the heat transfer between the cell components and the anode and cathode gas streams. There is heat 
exchange between the cell and the gas stream due to the combined effect of conductive heat transfer and a mass transfer which is associated with the exchange of reacting species at the cell temperatures. The other factors that affect the heat transfer processes are gas flow channel shape and size, gas flow configuration, gas inlet temperature, gas flow rate, cell area, voltage and pressure. The parameters of importance in the fuel cell process are delineated with the help of a physical model which also explains the relationship between these parameters using the basic laws like the conservation laws. In turn, a mathematical model is formulated from the assumptions made to set up the physical model. Hence, the accuracy of the assumptions made affects on the accuracy of the model in predicting the process variables.

\subsection{Mathematical Model}

The mathematical model constitutes the complete description of the physiochemical hydrodynamic processes taking place within the components of the solid oxide fuel cell. The physical and chemical properties that are considered are the electric potential field, the temperature field and sources in the temperature field and the specie equation. In this model, a general transport equation for a conserved scalar is derived for a multi-phase system. From this the temperature, electric potential, pressure field and specie equations are obtained by setting the scalar to be enthalpy and mass fraction respectively. The most commonly used three-dimensional generalized transport equation in computational fluid dynamics code [17] is

$\partial / \partial t\left(\varepsilon_{k} \rho_{k} \Phi_{k}\right)+\Delta .\left(\varepsilon_{k} \rho_{k} \bar{u}^{e f f} \Phi_{k}\right)=\Delta .\left(\varepsilon_{k} \Gamma_{\Phi}^{e f f} \Delta \Phi_{k}\right)+\varepsilon_{k} \rho_{k} S_{\Phi k}+F_{k l}$ 
where $\varepsilon$ is the volume porosity, $\Phi$ represents the enthalpy $\mathrm{h}, \mathrm{S}$ is the net generation or destruction, $\Gamma_{\Phi}{ }^{\text {eff }}$ is the effective diffusion/conduction coefficient, $\overline{\mathrm{u}}^{\text {eff }}$ is an effective pore volume averaged velocity, it includes the migration of ion velocity caused by the force acting on ions resulting from electric potential gradient. $k$ represents the $\mathrm{k}^{\text {th }}$ phase and $F_{k l}$ is the interfacial flux at the interface with the other phases.

\subsection{Model Equations}

\subsubsection{Electric Potential Field}

The electric potential field is determined by Ohm's law. The local current density distribution in the solid material is directly proportional to the gradient of the electric potential. The electric potential field [17] is given by

$$
\Delta \cdot i=\Delta \cdot\left(\sigma^{e f f} \Delta \Phi\right)=0
$$

where $\sigma^{\text {eff }}$ is the effective electric conductivity.

\subsubsection{Sources in Electric Potential Field}

There are step changes in the values of the electric potential across the electrodeelectrolyte interfaces. The sources in the electric field due electrochemical reactions are located near the Cathode/Electrolyte (C/E) and Electrolyte/Anode (E/A) interfaces [17]. They are given by the equations

$$
\Phi_{C}-\Phi_{E}^{s}=\Delta E_{C / E}=\Delta G_{C / E}^{\circ} / 2 F+R T / 2 F \ln \left(Y^{1 / 2}{ }_{O 2} / Y_{O=}\right)_{C}-\eta_{C}
$$




$$
\Phi_{E}^{n}-\Phi_{A}=\Delta E_{E / A}=\Delta G_{E / A}^{\circ} / 2 F+R T / 2 F \ln \left(Y_{H 2 O}^{1 / 2} / Y_{H 2} Y_{O=}\right)_{A}-\eta_{A}
$$

where $\mathrm{R}$ is the gas constant and $\eta_{\mathrm{C}}, \eta_{\mathrm{A}}$ are the anodic and cathodic activation polarizations respectively.

\subsubsection{Temperature Field}

The conduction equation for the mixture (solid and fluid) in the porous region is derived from the phase specific equation [17]. The multi-dimensional equation is

$\partial / \partial t\left(\rho C_{p} T\right)+\Delta\left(\varepsilon C_{p} u T\right)=\Delta(k \Delta T)-\Delta\left[\varepsilon k_{f} \Delta(\Delta T /\{1+\beta\})-(1-\varepsilon) k_{s} \Delta(\beta \Delta T /\{1+\beta\})\right]+S$

$\beta$ is the heat capacity ratio, $\Delta \mathrm{T}$ is the temperature differential between the solid and fluid phases.

In the solid region, the temperature difference or the volume porosity is assumed to be zero, then the above equation reduces to

$$
\partial / \partial t\left(\rho C_{p} T\right)=\Delta(k \Delta T)
$$

And for the porous regions, the mass averages of solid and fluid properties constitute the transport properties and $\mathrm{T}$ will be the mixed phase temperature. 


\subsubsection{Sources in Temperature Field}

Viscous dissipation due to friction, electrochemical heat generation and ohmic heat are the sources of heat generation mechanisms in the pore regions. The ohmic heat in the current conducting regions [17] is given by

$$
S_{p, \text { elec }}^{m}=\sigma_{p}^{\text {eff }} \Delta \Phi_{p} . \Delta \Phi_{p}
$$

Heating due to electrochemical reactions occur at the Electrolyte/Anode interface. Heat source due to reaction is given by

$$
S_{\text {reac }}=m_{\text {reac }} T \Delta s_{\text {reac }}
$$

\subsubsection{Specie Transport Equation}

The species transport equation [17] is given by

$$
\partial / \partial t\left(\varepsilon_{k} \rho_{k} x_{k}^{j}\right)+\Delta\left(\varepsilon_{k} \rho_{k} u x_{k}^{j}\right)=\Delta\left(\varepsilon_{k} \Gamma^{\text {eff }}{ }_{k} \Delta x^{j}{ }_{k}\right)+\varepsilon_{k} \rho_{k} S^{j}{ }_{k}
$$

here $\mathrm{x}_{\mathrm{k}}^{\mathrm{j}}$ represents the mass concentration of $\mathrm{j}^{\text {th }}$ species in $\mathrm{k}^{\text {th }}$ phase. The total diffusion resulting from concentration gradients is represented by the first term on the right hand side of the equation. It includes Maxwell-Stefan diffusion and Knudsen diffusion terms.

\subsubsection{Sources For The Specie}

In the specie, the source terms are located near the active region of the Electrode/Electrolyte interfaces [17]. The equations are given by 


$$
\begin{gathered}
\mathrm{S}_{\mathrm{o} 2}=\left(\mathrm{M}_{\mathrm{o} 2} \mathrm{I}^{\mathrm{s}} / 4 \mathrm{~F}\right) * 10^{-3} \\
\mathrm{~S}_{\mathrm{H} 2}=\left(\mathrm{M}_{\mathrm{H} 2} \mathrm{I}^{\mathrm{s}} / 4 \mathrm{~F}\right) * 10^{-3}
\end{gathered}
$$

$\mathrm{M}_{\mathrm{o} 2}$ and $\mathrm{M}_{\mathrm{H} 2}$ are the molecular weights (gm/gm-mole) of oxygen and hydrogen, $\mathrm{I}^{\mathrm{s}}$ is the current density $\left(\operatorname{amps} / \mathrm{m}^{2}\right)$ and $\mathrm{F}$ is the Faraday's constant (96493 col-sec/gm-mole).

\subsubsection{Numerical Model}

A numerical method is employed to solve the above mathematical model as it is impossible to solve the mathematical model analytically. Computational Fluid Dynamics (CFD) methods were used by WVU CFD \& AMP Laboratory [10] to solve the partial differential equations, which represent the laws of conservation. In the numerical analysis, initially the partial differential equations are reduced to a linear system of equations in terms of variable values at discrete points inside the calculation domain, and then the linear equations are solved to obtain a discrete solution. The general transport equation is discretized and used to solve the energy, specie, pressure and current equations. In the numerical analysis by WVU CFD \& AMP [10], finite volume method was employed for discretization. The derived transport equations were solved separately for each component and different modules were made to communicate with each other through boundary conditions. These individual modules of each component were combined and a code was developed to model the fuel cell. For details of the CFD results obtained for the simulations of SOFC refer the program developed by WVU CFD \& AMP [10]. 


\section{CHAPTER 4}

\section{TWO-DIMENSIONAL THERMAL STRESS ANALYSIS DURING OPERATION OF SOFC}

\subsection{Introduction}

The main purpose of the research is to evaluate the thermal stresses during the operating conditions of the two-dimensional and three-dimensional planar solid oxide fuel cells. Finding the stresses in the fuel cell is important as it helps to predict the failure during the operation of the cell. Therefore, in this research, effort has been made to develop twodimensional and three-dimensional models and predict the failure in the materials used accurately. The analyses were made in ANSYS ${ }^{\mathrm{TM}}$ using the temperature profiles from Computational Fluid Dynamics (CFD) codes developed by WVU CFD \& AMP [10]. Once the model was meshed using ANSYS ${ }^{\mathrm{TM}}$, the temperature profile, collected from the CFD results, was applied throughout the cell with adiabatic boundary conditions. Since ANSYS $^{\text {TM }}$ contains a wide variety of thermal and mechanical options, the model created was capable to a variety of different inputs and has an exposure to many different situations.

ANSYS ${ }^{\text {TM }}$ was used to solve for thermally induced stresses due to temperature variations under thermo- elastic conditions of the SOFC. For the two-dimensional analysis, a five stack co-flow planar SOFC was considered. The five stack fuel cell was sliced at 5 different places from the inlet to the outlet of the fuel cell and each of them was analyzed separately. The materials used are Lanthanum Chromite ( $\mathrm{LaCrO} 3$ ) for the interconnect, Nickel dispersed on Yittria stabilized Zirconia (Ni/YSZ) for the anode, Doped 
Lanthanum Manganite $\left(\mathrm{LaMnO}_{3}\right)$ for the cathode and Yittria stabilized Zirconia (YSZ) for the electrolyte. The SOFC model is analyzed using sequentially coupled analysis in ANSYS ${ }^{\mathrm{TM}}$.

\subsection{Finite Element Analysis Procedure}

In the sequentially coupled-field analysis in ANSYS ${ }^{\mathrm{TM}}$, we can couple two fields by applying the results from one analysis as input to the other analysis. In other words, it is a combination of analyses from different engineering disciplines which interact to solve a global engineering problem. The load transfer occurs external to the analysis and the loads are transferred explicitly using the physics environment. The base physics loads are not a function of other physics analyses and these loads are known as nominal boundary conditions. And coupled loads are the results of the other physics simulations. The term physics environment refers to both a file created containing all operating parameters for a particular physics analysis and to the file's content. A physics environment is an ASCII file which is created in ANSYSTM.

\subsection{Sequential Thermal-Stress Analysis}

In this work, the type of analysis used is a sequential thermal-stress analysis where the nodal temperatures from the thermal analysis are applied as loads in the subsequent stress analysis. Physics files can be used to perform the coupled-field analysis which is based on a single finite element mesh across the physics. The physics file is read to configure the database and then a solution is performed. After this, another physics field is read into the database and coupled-field loads are transferred where the second physics is solved. 
Coupling occurs by issuing commands to read the coupled loads from one physics to another across a node-node similar mesh interface.

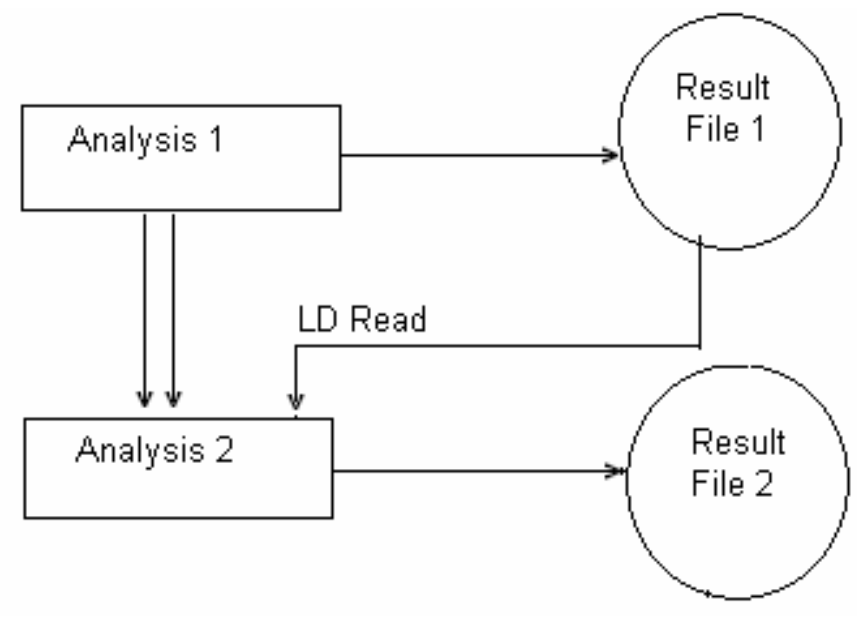

Figure 3: Data Flow for a Sequential Coupled-Field Analysis [18]

The data flow for the present sequential analysis is done with the indirect method which is ideal for one-way sequential coupling such as a typical thermal-stress analysis. Each database contains the appropriate solid model, elements, loads etc and the information is read from a result file into another database. The elements and the node numbers must be consistent between the database and the result file.

It is important that the element types across the physics environments are compatible, therefore they must maintain a consistent base geometry. However, the element type can change maintaining a constant geometry. For instance, thermal elements are required for a thermal analysis while structural elements are required to determine the stress in the 
model. It is important to note that only certain combinations of elements can be used for a coupled analysis. If the element type allows a degenerate geometry then the corresponding element type in the other physics must also allow the same degeneration geometry. A finite element mesh with higher order elements is generated to establish a physics environment, switching between the element orders. In the present model, a triangle element is used as a base geometry. The loads applied on the thermal physics environment are temperatures, surface film coefficient and surface heat flux and the structural model is constrained in the structural environment. A link is formed between the two physics environments in the coupled-field analysis which enables us to read the temperature results data from the thermal physics environment solution analysis and apply them as nodal loads for the structural environment's solution.

In the coupled analysis, firstly a linear steady state thermal analysis is performed. The model dimensions are based on a global coordinate system. By default, the global coordinate system is Cartesian, with $\mathrm{X}, \mathrm{Y}$ and $\mathrm{Z}$ axes. The materials used in the planar SOFC are isotropic in nature and the material property used in the thermal analyses is thermal conductivity. The nature of the material property is constant, therefore the steady state analysis is linear. This property is assigned to the model and the model is meshed. Nodal temperatures are applied as thermal loads to the mesh. These temperatures are applied as single loads individually in the two-dimensional model.

Convection which is a surface load is applied to account for the gas channels. The other load that is applied to the model is heat flux which accounts for the heat flow rate per area across the surface. Once the model is meshed, the SOFC model is solved, where the 
nodal temperatures interpolate and gives a temperature profile. This result which gives a temperature profile is stored as a file which can be later retrieved for the structural analysis, where the temperatures are applied as load.

Structural analysis with plane stress option is used to determine the stresses in the structure. A static analysis calculates the effects of steady loading conditions on a structure, while ignoring the effects caused by time-varying loads. The steady loading and response conditions are assumed, that is, the loads and the structure's response are assumed to vary slowly with respect to time. The material properties in the analysis are also linear and isotropic. The structural material properties of the components considered in the analysis are the Young's modulus $\left(E_{x}\right)$ and thermal expansion coefficient $\left(\alpha_{\mathrm{x}}\right)$.

As boundary condition, the model is constrained at required places and the temperature field from the thermal analysis is read into the structural analysis. This analysis is called implicit-to-explicit sequential solution. In the explicit phase, the temperature data is read from the result file of the thermal analysis, which is an implicit phase. This temperature data is applied as loads to the nodes of the model. For these thermal loads to take effect, the temperature dependent material is used which represents the thermo-elasticity of the material.

\subsection{Material Properties}

The material properties of the components (anode, electrolyte, cathode and interconnect) of the solid oxide fuel cell are listed below. The properties of the components used for the 
analysis are thermal conductivity, Young's modulus and thermal expansion coefficient. The heat transfer coefficients for the air channel and the fuel channel are $224 \mathrm{~J} / \mathrm{s}-\mathrm{m}^{\wedge} 2-\mathrm{K}$ and $32 \mathrm{~J} / \mathrm{s}-\mathrm{m}^{\wedge} 2-\mathrm{K}$ respectively.

\begin{tabular}{|c|c|c|c|}
\hline Materials & $\begin{array}{c}\text { Young's } \\
\text { Modulus } \\
(\mathrm{GPa})\end{array}$ & $\begin{array}{c}\text { Thermal expansion } \\
\text { Coefficient } \\
\left(10-6 /{ }^{\circ} \mathrm{C}\right)\end{array}$ & $\begin{array}{c}\text { Thermal } \\
\text { Conductivity } \\
(\mathrm{W} / \mathrm{mK})\end{array}$ \\
\hline $\begin{array}{c}\text { Interconnect } \\
(\mathrm{LaCrO3})\end{array}$ & 60 & 9.82 & 6 \\
\hline $\begin{array}{c}\text { Anode } \\
(\mathrm{Ni} / \text { YSZ) }\end{array}$ & 96 & 12.5 & 5.84 \\
\hline $\begin{array}{c}\text { Electrolyte } \\
(\text { YSZ })\end{array}$ & 200 & 10.8 & 2.16 \\
\hline $\begin{array}{c}\text { Cathode } \\
(\text { LaMno })\end{array}$ & 96.71 & 11.2 & 4.0 \\
\hline
\end{tabular}

Table 5: Properties of the components used in the analysis [2], [7], [10]

\subsection{Geometric Model}

For the two-dimensional analysis of the planar SOFC, a five stack co-flow model is used. The five stack model provided by WVU CFD \& AMP Laboratory [10], is a sandwich model where the fuel channel and air channel are layered between the interconnect and anode, and the interconnect and cathode respectively. Therefore to account for the stresses due to thermal expansion mismatch between the components in the twodimensional analysis, the model is sliced at six places along the width of the fuel cell from the inlet of the gases to the outlet of the gases throughout the model and each of it is analyzed separately. The shape and size of these six slices are based on the dimensions of the sandwich model provided by the WVU CFD \& AMP Laboratory. The six slices considered for the two-dimensional analysis are given below. 


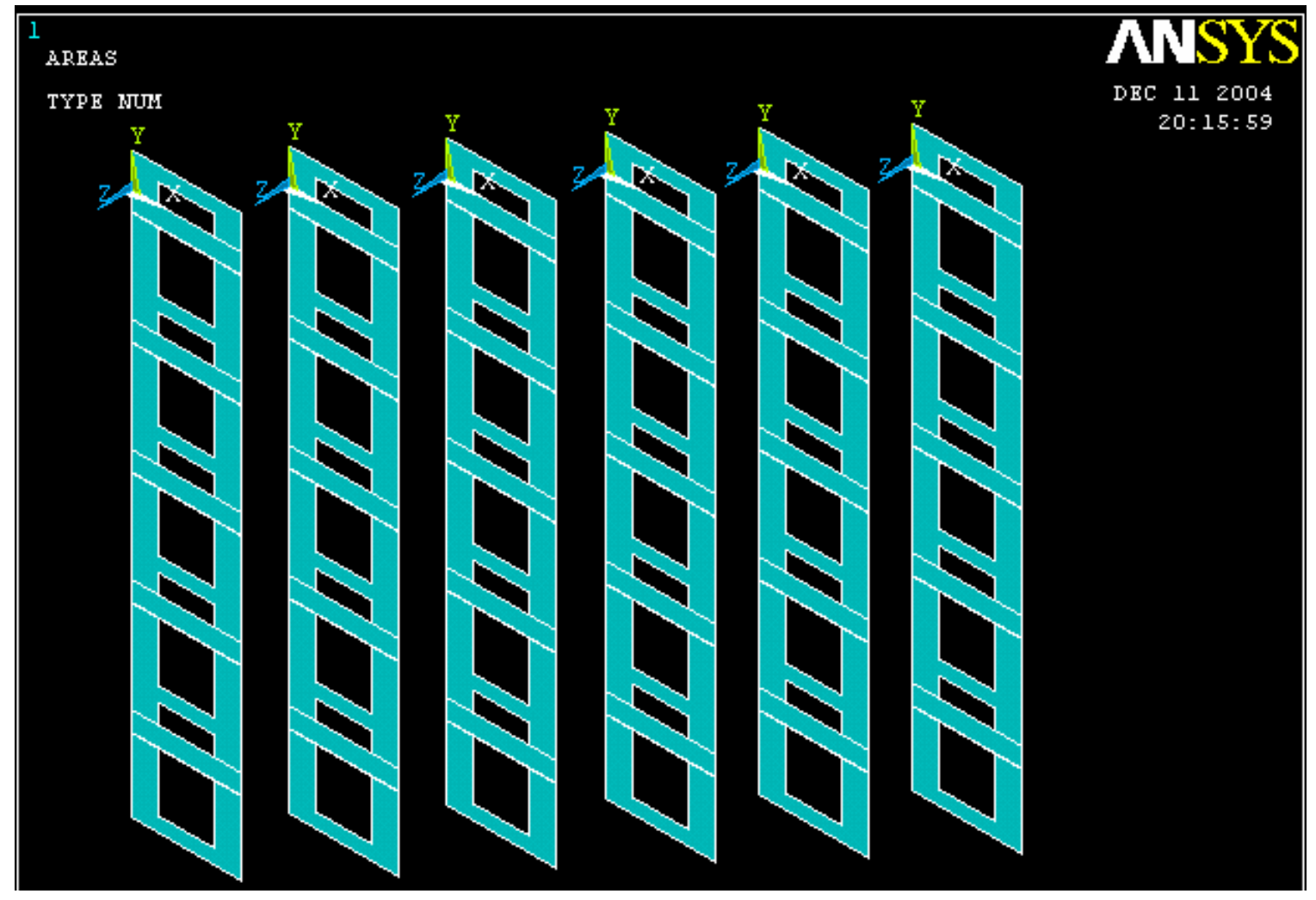

Figure 4: Two-dimensional view of the six parts of five stack SOFC

These six parts of the SOFC begin from the inlet of gases to the outlet of gases, from left to right. The total width of the fuel cell is $10 \mathrm{~cm}$ and the height is $5.785 \mathrm{~mm}$. The dimensions of the components in each of the slices are given below in the close-up view of the model. 


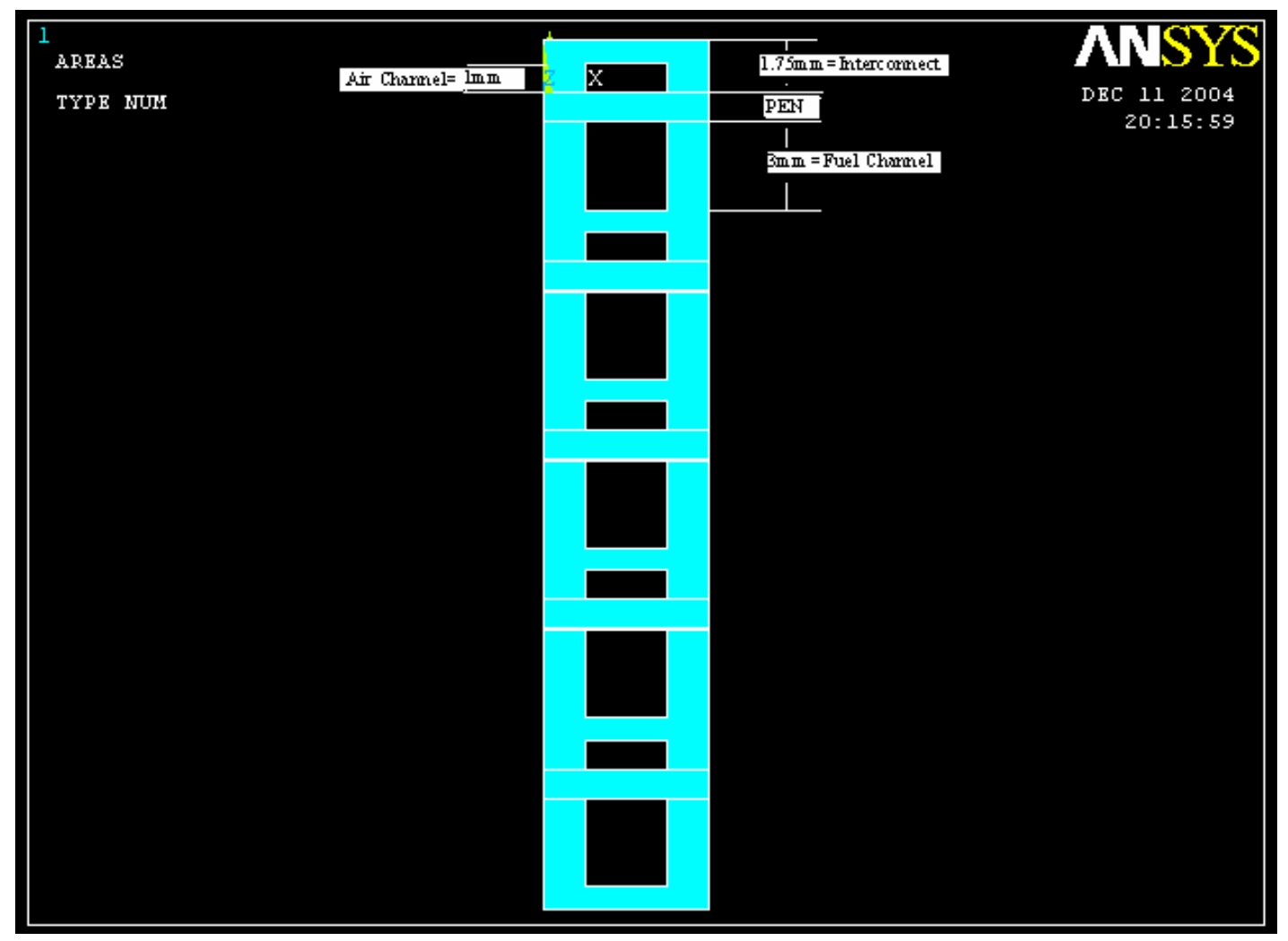

Figure 5: Close-up view of a single slice

The anode, electrolyte and the cathode constitute the PEN. The dimensions of these components are $1 \mathrm{~mm}, 0.01 \mathrm{~mm}$ and $0.02 \mathrm{~mm}$ respectively.

\subsection{Thermal Analysis}

In the sequential thermal stress analysis, the element type used for the thermal analysis is PLANE77. This element type has eight node thermal elements where the temperature has one degree of freedom. The material property which is thermal conductivity is assigned to the components of the fuel cell after the model is generated. 
The two-dimensional models are meshed using a triangular mesh. The six meshed models and the close-up view of a single slice are given below.

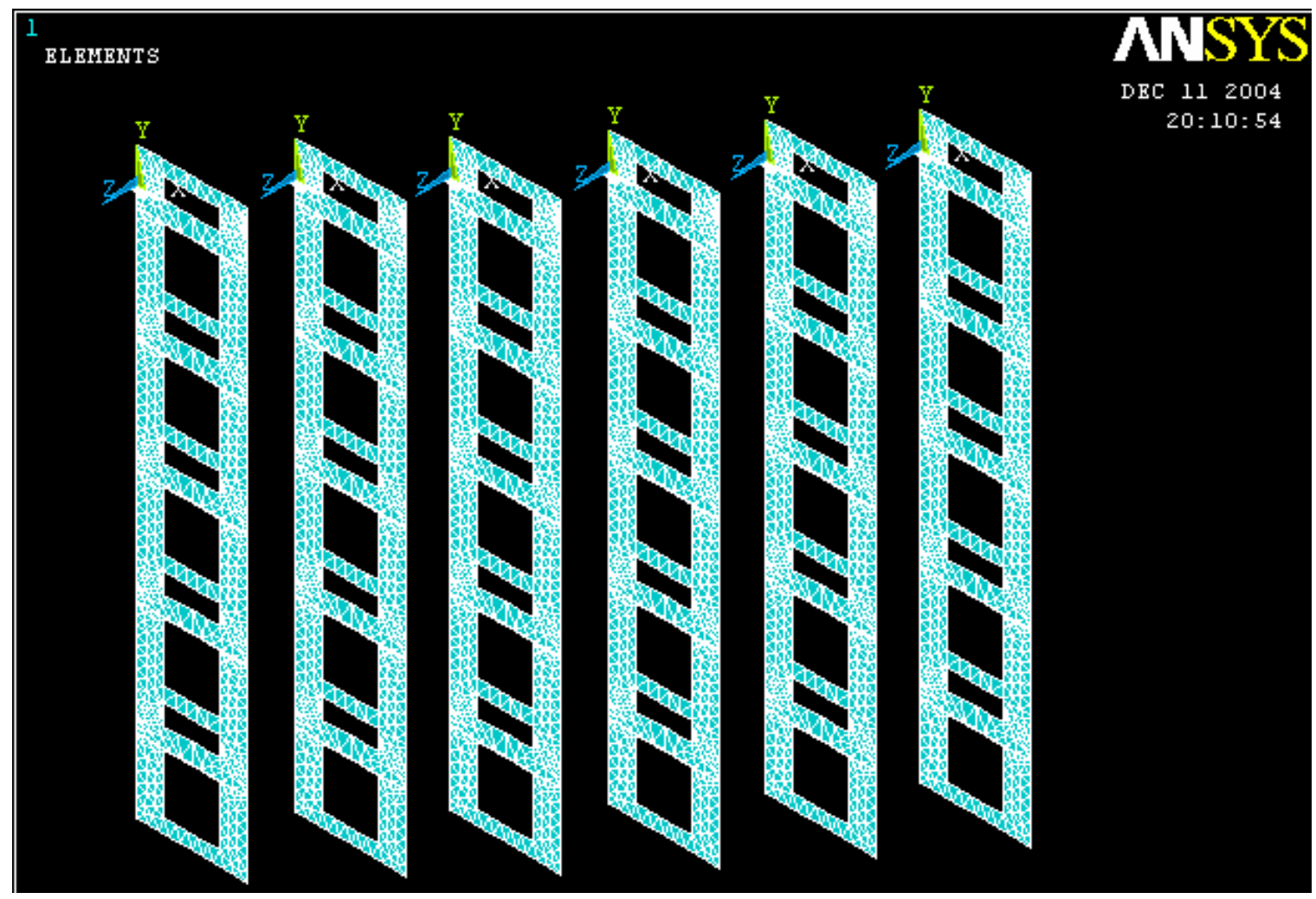

Figure 6: Five stack two-dimensional meshed models 


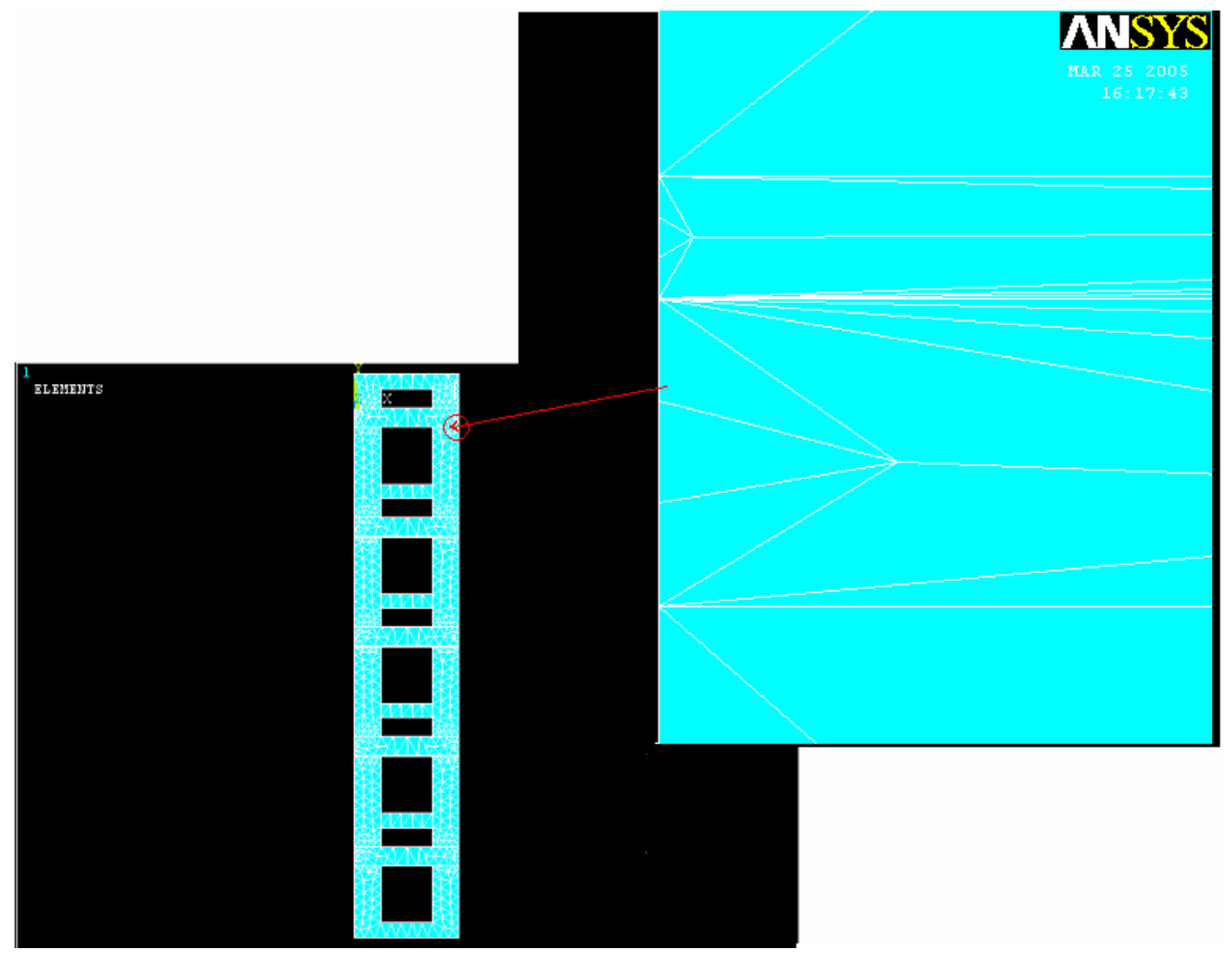

Figure 7: Close-up view of the mesh in cathode and electrolyte of the model

\subsubsection{Boundary Conditions}

From the temperature profile provided by the WVU CFD Laboratory, the highest nodal temperatures were located in each individual component and these temperatures are used as inputs for the coupled thermal-stress analysis in ANSYS ${ }^{\mathrm{TM}}$. Along the edges of the inner side of the interconnect where fuel and air are passed through the channels into the fuel cell, the heat transfer coefficients of the gases are imposed to account for convection. At the top and bottom of the five stack cell, the heat flux from the stack to the surroundings is zero, which represents a perfectly insulated boundary condition. 


\subsubsection{Results}

Once the boundary conditions are given to the model, firstly a thermal analysis is performed for each of the individual slices of the five stack fuel cell. The temperatures at nodes interpolate and we get a temperature distribution in the five stack fuel cell. The temperature distribution in each of the six slices starting from the inlet to the outlet of gases is given below individually.

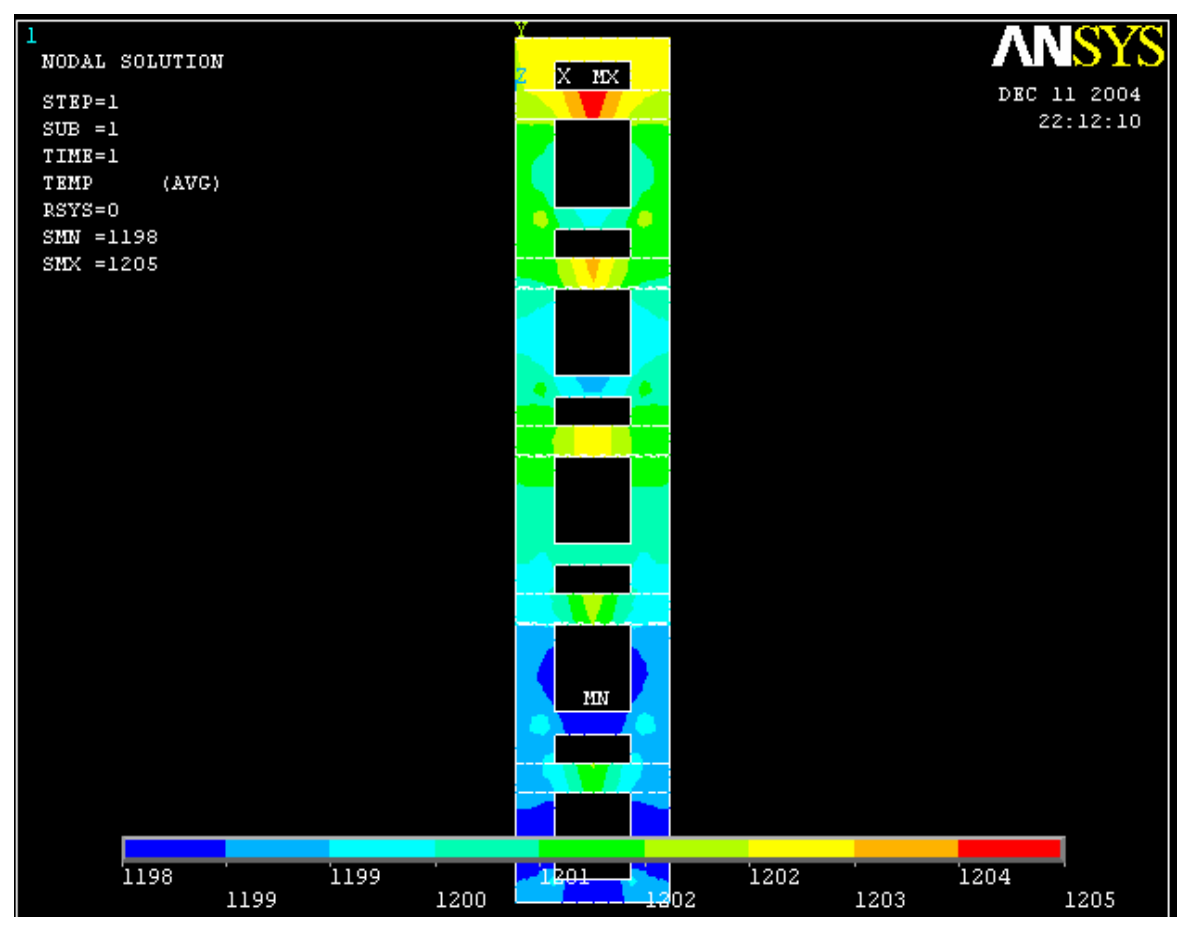

Figure 8: First slice (temperature profile at the inlet) 


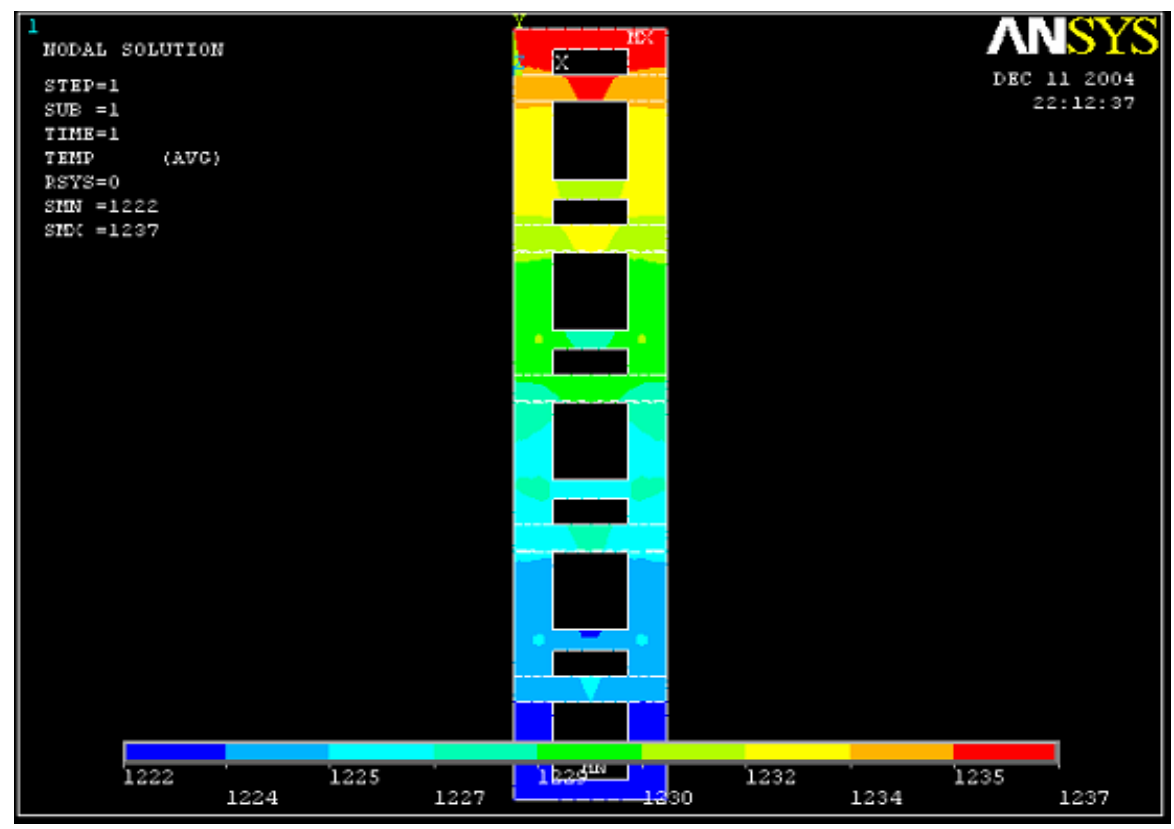

Figure 9: Temperature profile of second slice

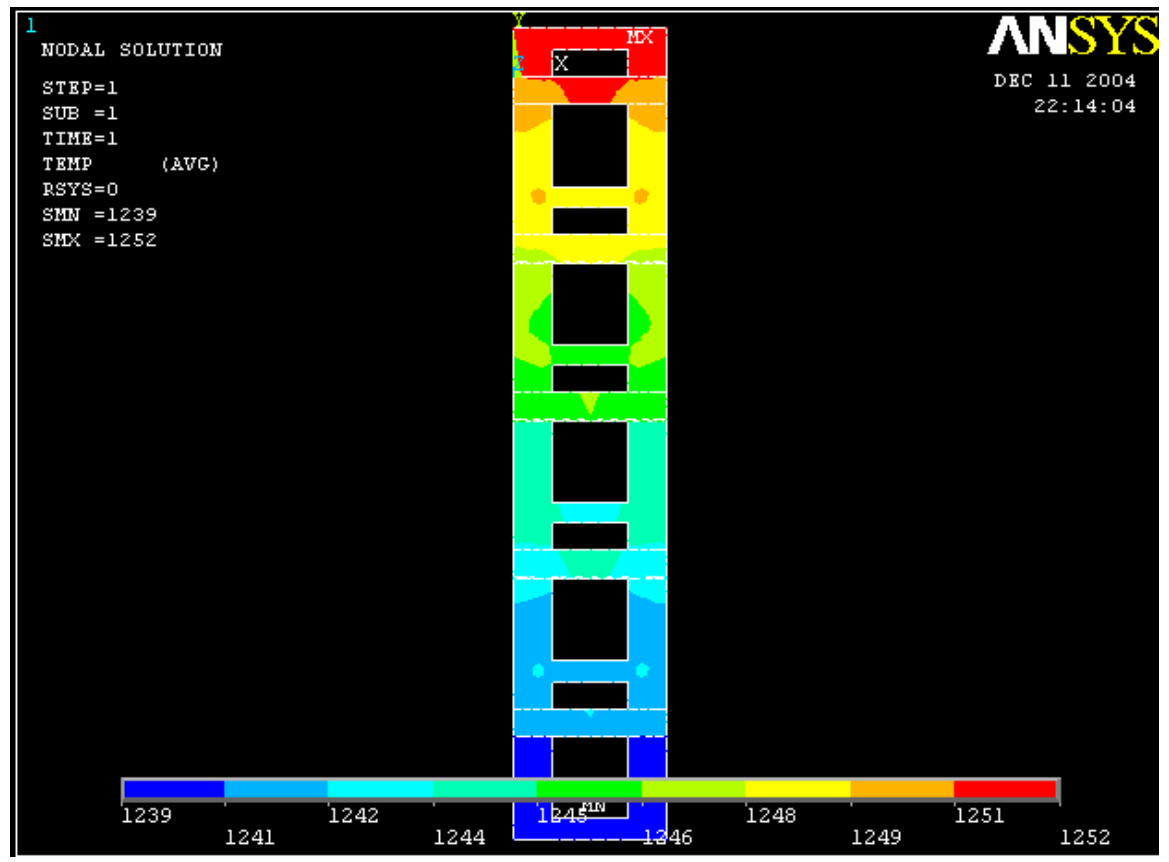

Figure 10: Temperature profile of third slice 


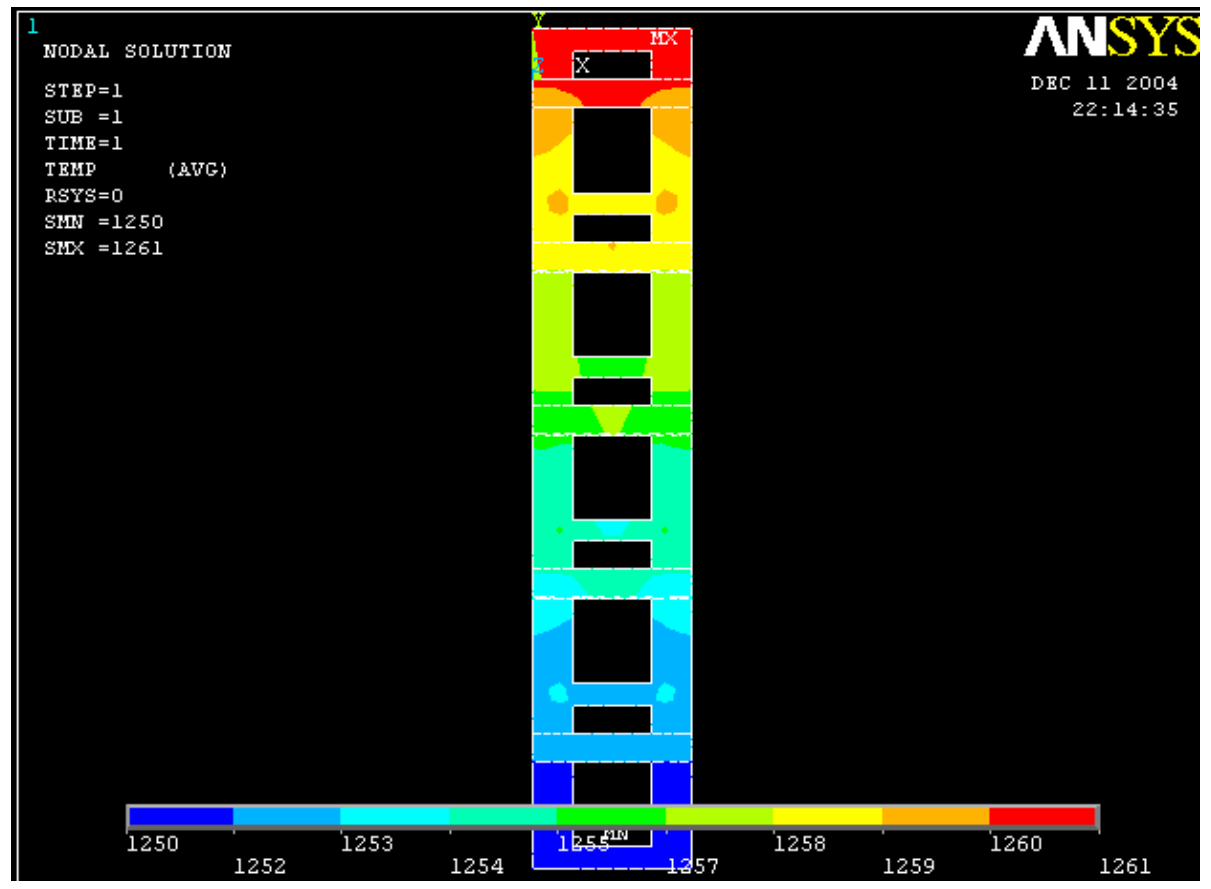

Figure 11: Temperature profile of fourth slice

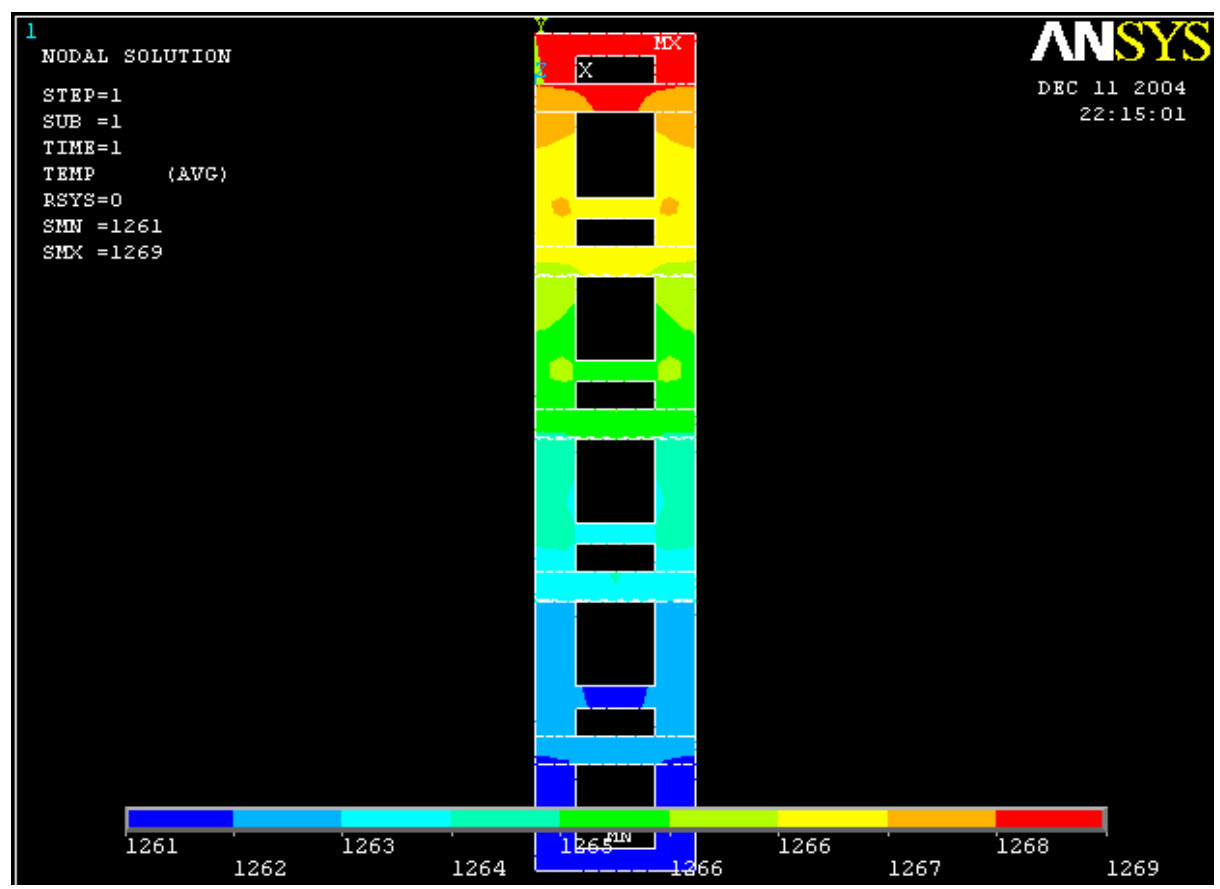

Figure 12: Temperature profile of fifth slice 


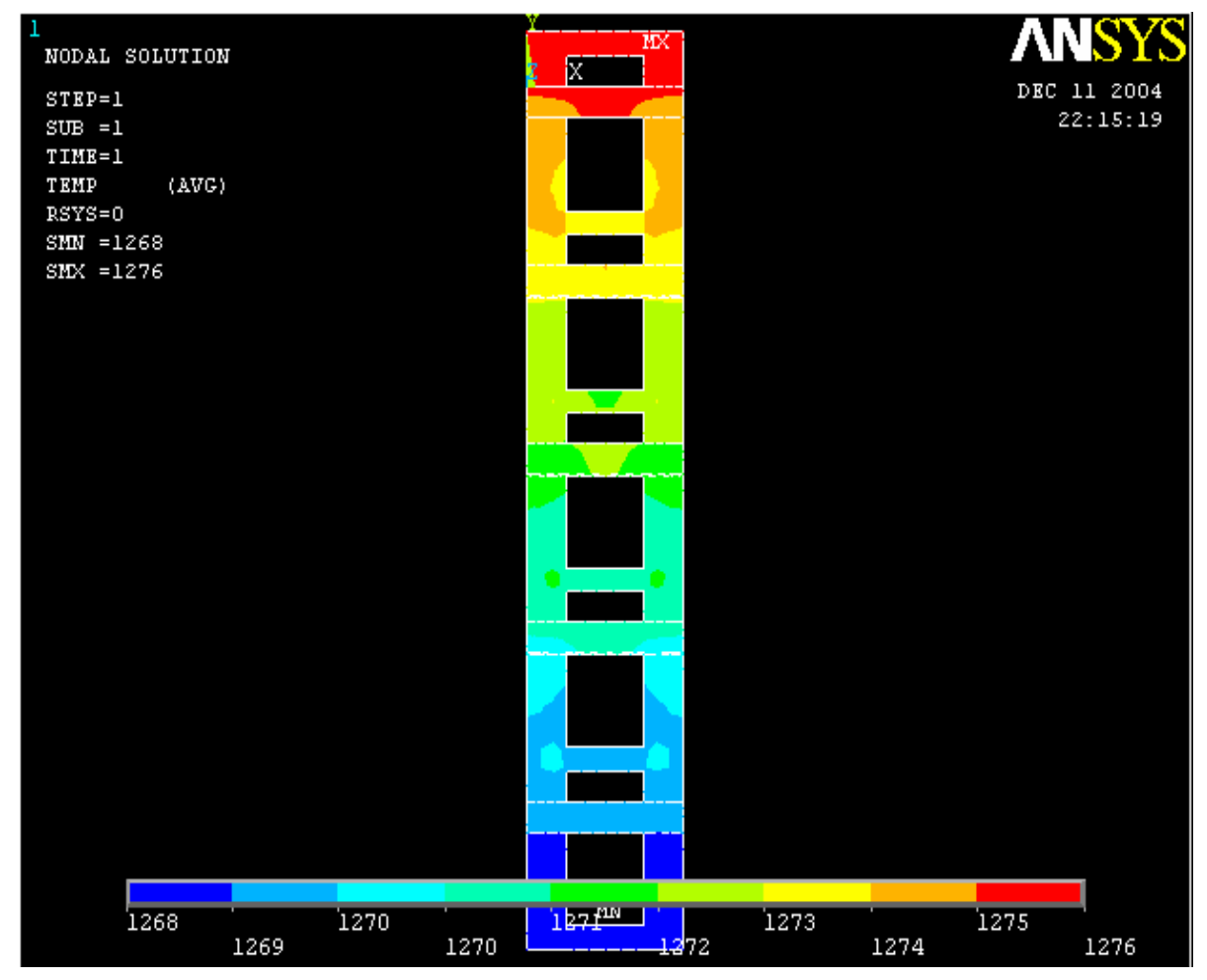

Figure 13: Sixth slice (temperature profile at the outlet)

As the five stack cell is meshed into a single cell, the temperature of the separator plate of each cell is communicated with the neighboring cell and similarly the temperatures of the PEN and the gas channels are communicated to the neighboring cells. From the above results, it is observed that the cell temperature decreases from top to bottom. The top cell of each slice has the highest temperature and the bottom cell operates at the lowest temperature. Due to the asymmetry in the fuel cell stack design leads to the nonuniformity in the temperature distribution.

The heat transfer coefficients of the gas channels vary because the cathode and anode have different mass flow rates. Therefore, the air gas channel provides the most cooling 
which in turn cools the cathode. From the figure below, we can see that the temperature at the anode is higher than the temperature at the cathode.

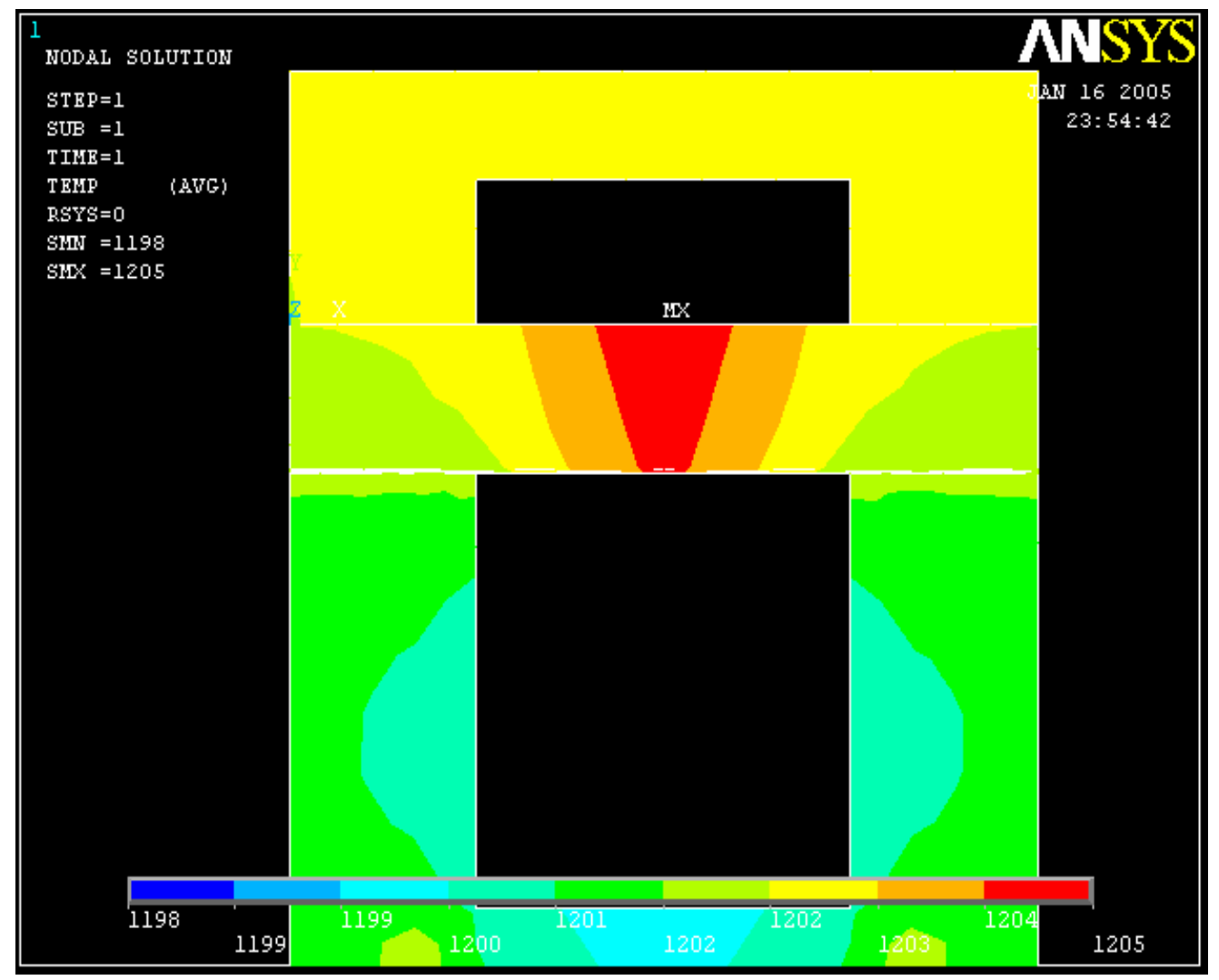

Figure 14: Close-up view of the temperature profile in the top half of first slice (at inlet of gases)

The temperature distribution in the PEN (cathode, anode and electrolyte) is observed to be linear in the five stack fuel cell. The temperature distribution in each of these components is given in the graphs below. 
Cathode

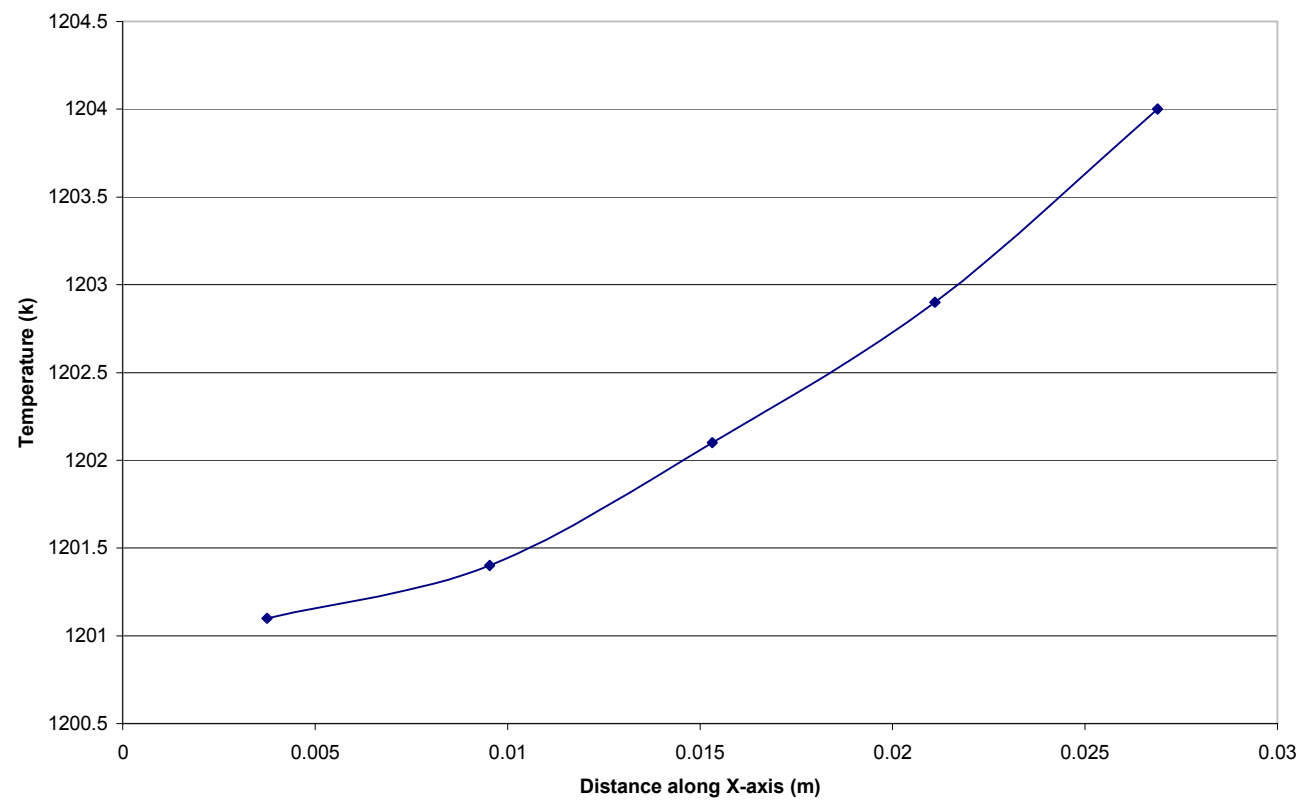

Figure 15: Temperature Distribution in Cathode

(from the bottom to the top of the fuel cell stack)

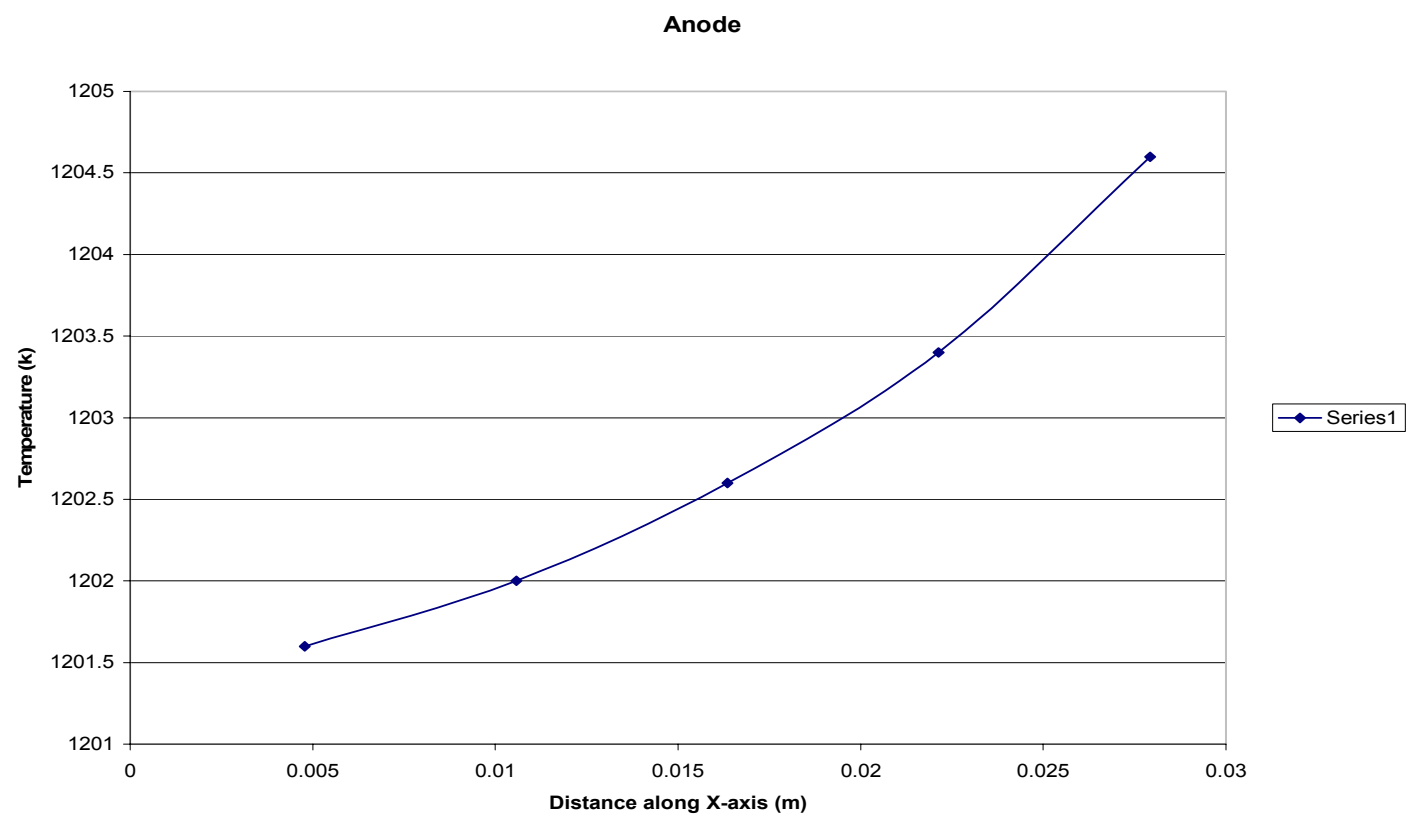

Figure 16: Temperature Distribution in Anode

(from the bottom to the top of the fuel cell stack) 


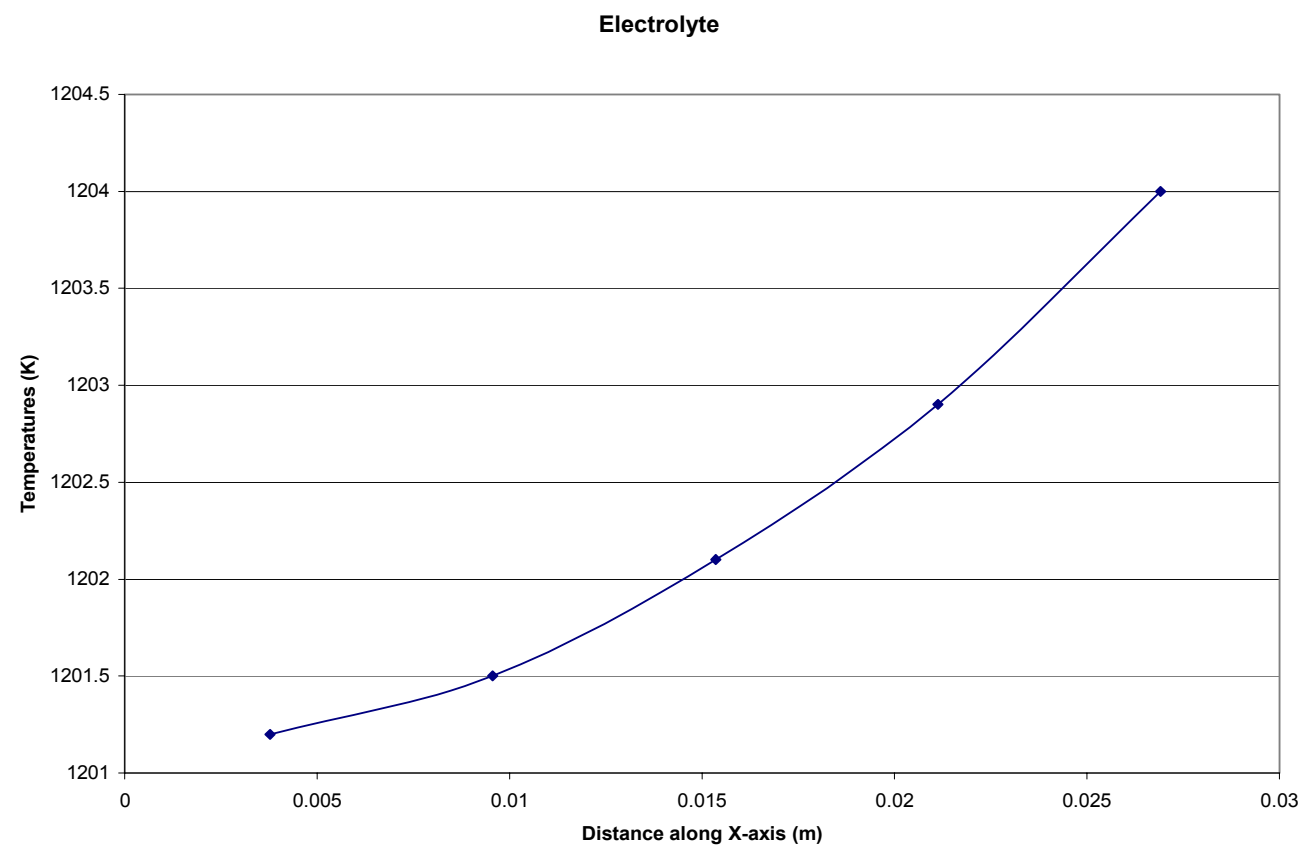

Figure 17: Temperature Distribution in Electrolyte (from the bottom to the top of the fuel cell stack)

\subsection{Stress Analysis}

Once the model is solved for the thermal analysis we return to the model creation preprocessor (PREP7) in ANSYS ${ }^{\mathrm{TM}}$. Then the element type is switched from thermal to structural and the structural element type used is PLANE82. Once the element type is switched, the structural material properties, which are, the Young's moduli and thermal expansion coefficients are assigned to the models. The thermal expansion coefficients of the materials used change with change in temperatures. Therefore the thermal expansion coefficients given to the six slices of the five stack fuel cell vary. Two models with different boundary constraints have been considered for stress analysis of the twodimensional model. 


\subsection{Boundary Conditions for the First Model}

As the element type used is compatible with that of the thermal model, the mesh involved in the structural analysis is also a triangular mesh which corresponds to that of the thermal model. For the structural boundary conditions, the temperatures from the thermal analysis are used as nodal loads, which are read into the structural model in ANSYSTM. And as boundary constraints, the six slices are fixed on the top and the bottom in the ydirection and the walls of the PEN in the five stack cell are also fixed in the y-direction on either sides i.e., zero displacement is given in the y-direction.

\subsubsection{Results of the First Model}

The present co-flow stack model has been chosen to capture the stresses due to the thermal expansion mismatch and the operational asymmetry inherent in the planar solid oxide fuel cell. A stack model connected in series is used to generate the desired voltage output and power. A stack model has been previously developed to study the stresses due to thermal expansion mismatch [1] and it was identified that the components of the coflow fuel cell model have minimum thermal stresses when compared to that of cross-flow and counter-flow arrangements.

Usually the stress at the edges in the y-direction is the most important as the peeling stress $\left(\sigma_{\mathrm{yy}}\right)$ is the largest component of stress. These regions of stress are indicative of the stresses in the entire fuel cell model. From the thermal analysis, it is noted that the PEN operates at a higher temperature than the interconnect, such that stress would develop. Therefore, the stresses for the interconnect and the PEN must be analyzed separately. The 
maximum principle stress determines the failure in the ceramic. In the elastic model [1] the high stress regions are shown at the bending point in the ceramic and at the joint of the interconnect and the PEN. However the higher stress is at the bending point of the ceramic than at the joint.

The operating stresses are caused due to the bending effects caused by the contraction and expansion of the horizontal membrane (y-direction) of the planar fuel cell. The stresses in the six slices from the inlet of gases to the outlet of gases are given below.

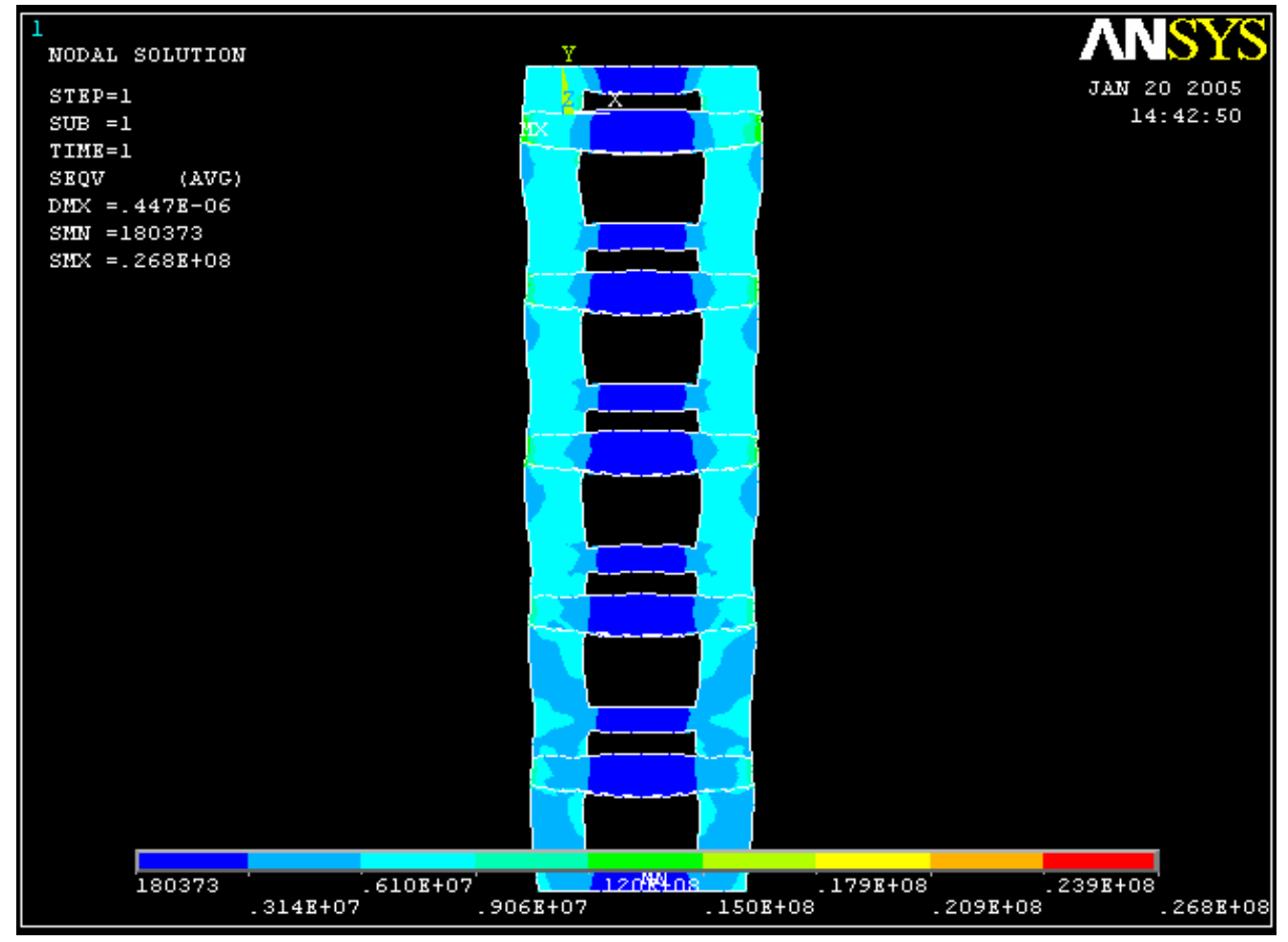

Figure 18: First slice (von Mises stresses near the inlet of gases of $1^{\text {st }}$ model) 


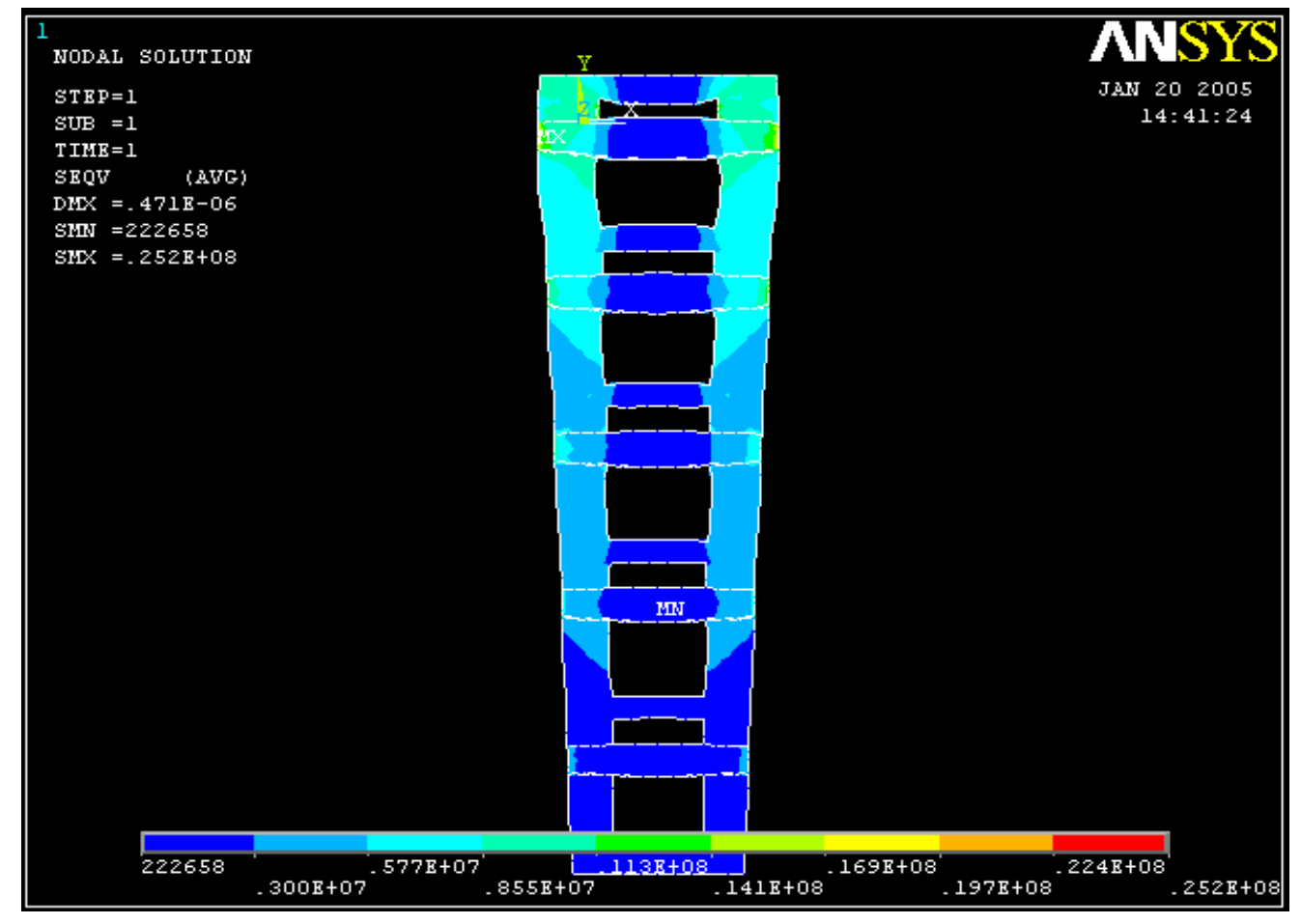

Figure 19: von Mises stresses in the second slice $\left(1^{\text {st }}\right.$ model $)$

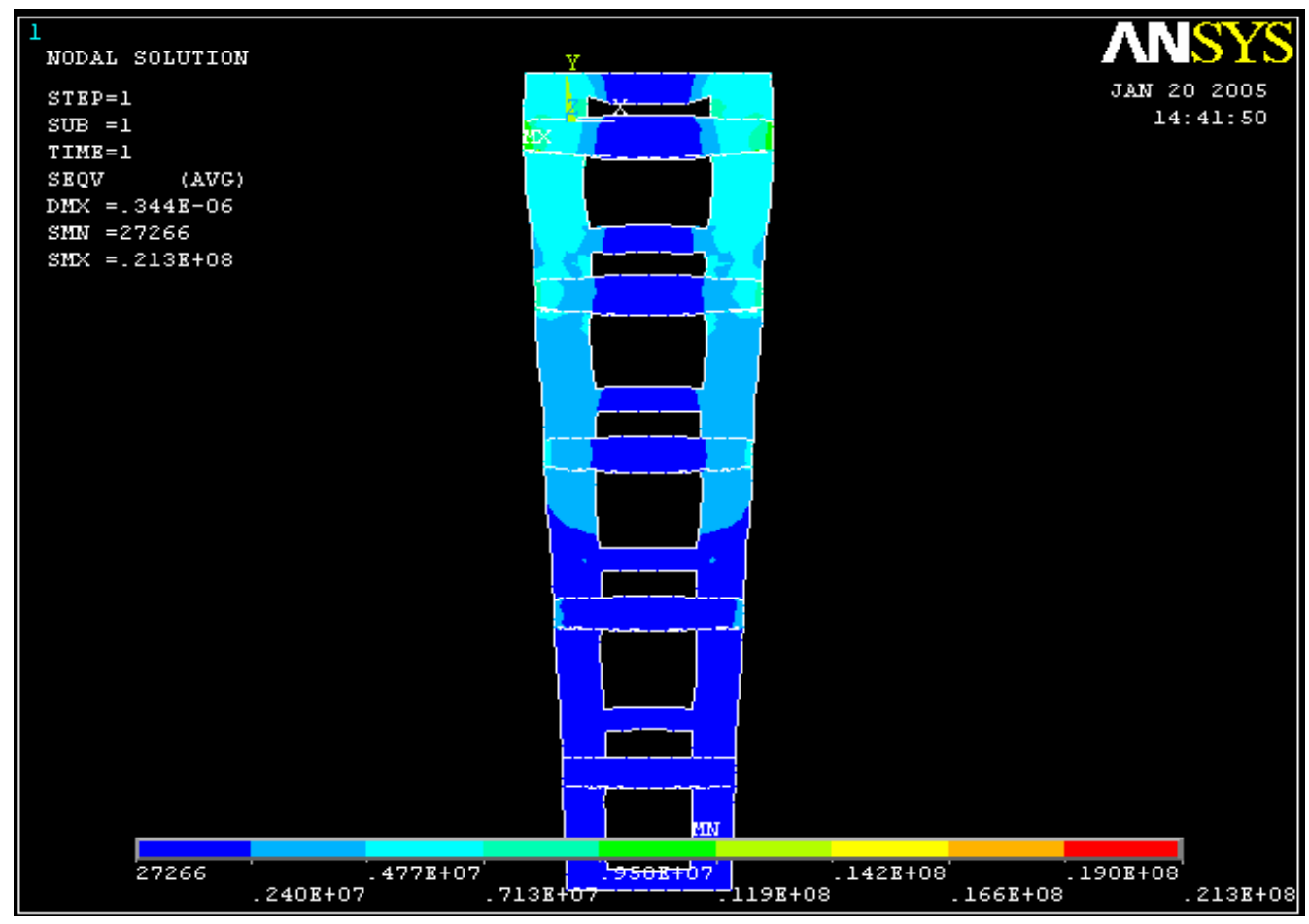

Figure 20: von Mises stresses in the third slice $\left(1^{\text {st }}\right.$ model $)$ 


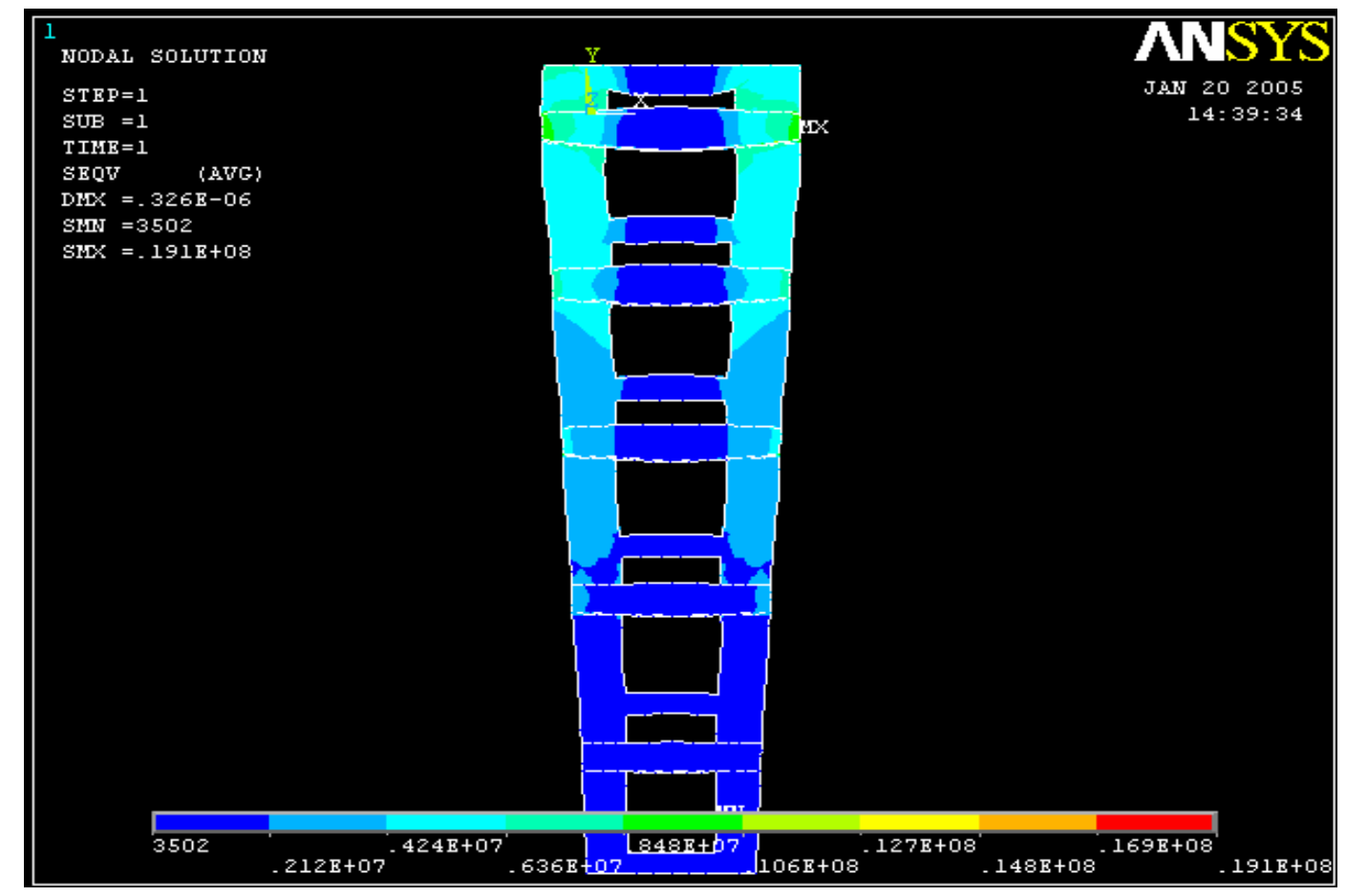

Figure 21: von Mises stress in the fourth slice $\left(1^{\text {st }}\right.$ model $)$

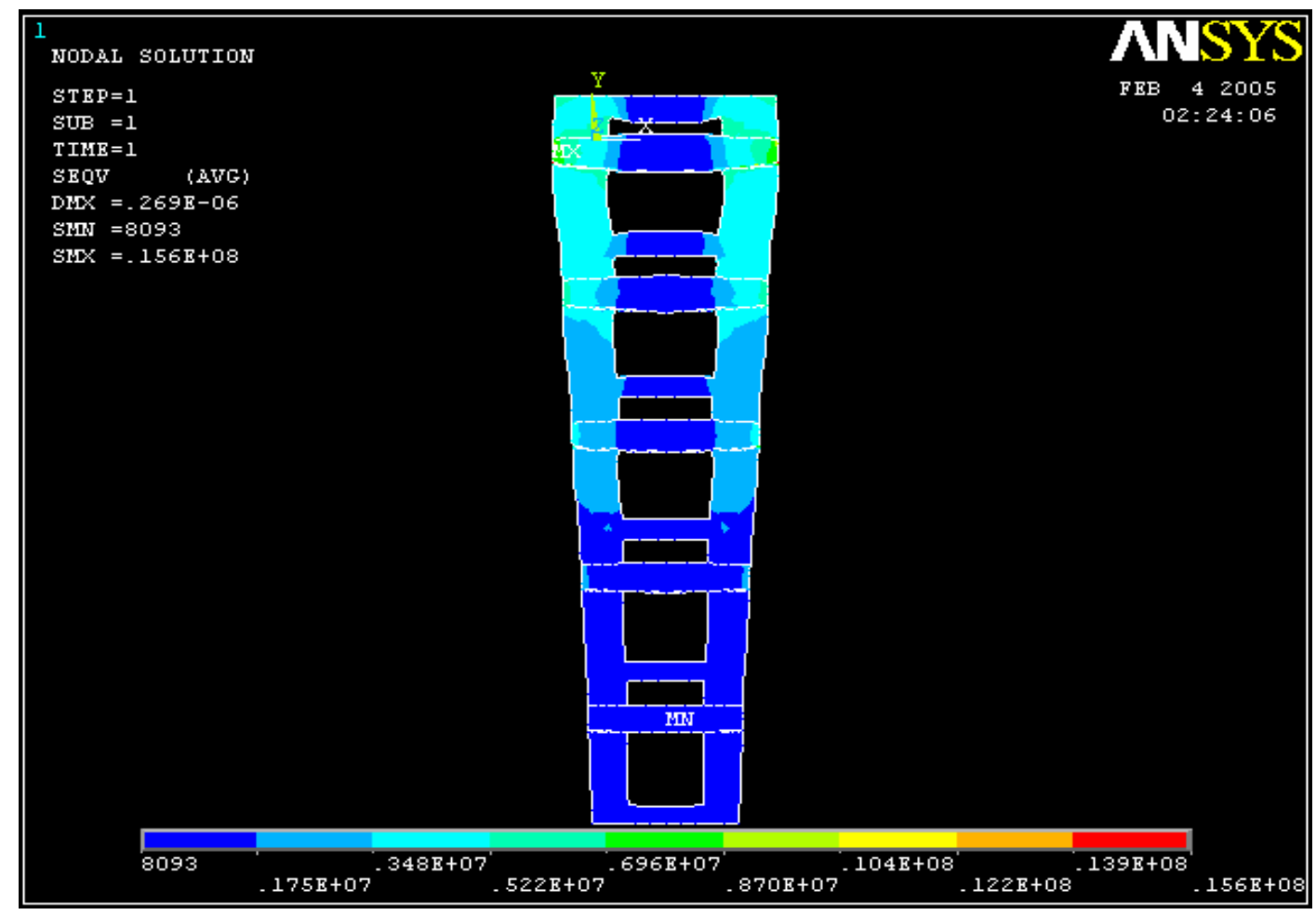

Figure 22: von Mises stresses in the fifth slice $\left(1^{\text {st }}\right.$ model $)$ 


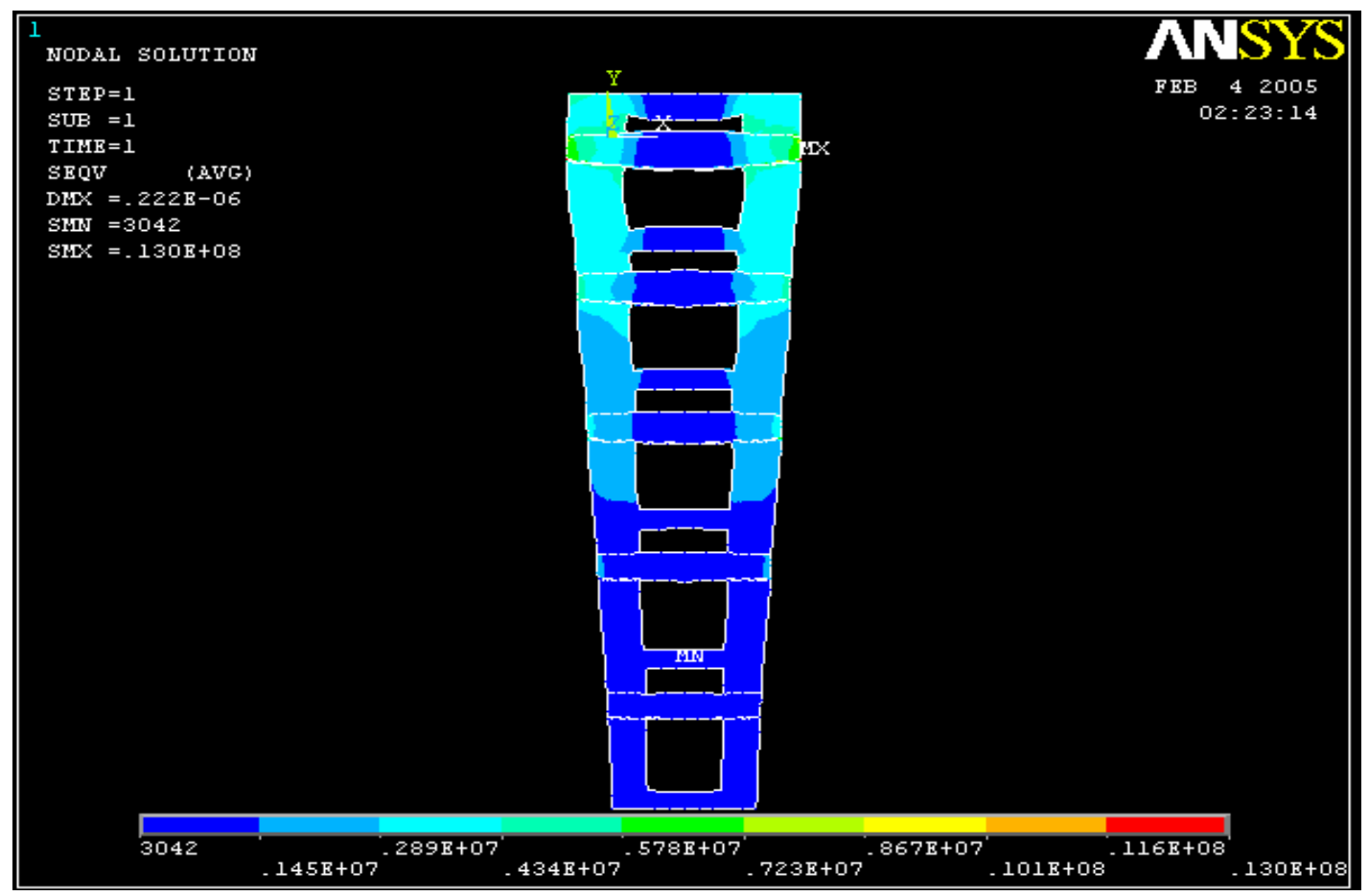

Figure 23: Sixth slice (Von Mises stresses near the outlet of gases of $1^{\text {st }}$ model)

During the steady state operation of a planar SOFC, the surface of the fuel cell which is allowed to expand and contract while constraining the curvature is in the state of compression (Jason LeMaster, Georgia Institute of Technology, 2004). The main source of stress is due to the difference in the thermal expansion coefficient between the lanthanum chromite interconnect and the YSZ electrolyte. The Ni-YSZ anode and the lanthanum manganite cathode are porous and have a lower elastic modulus when compared to that of the electrolyte. Therefore, they would not have a significant effect on the resulting stresses because of their compliance (C.S Montross et. al., 2002).

From the above results it was found that, stresses in the PEN and the interconnect are below their critical stresses. The maximum principle stresses for the ceramic materials is considered as they determine the failure in the components. The stresses found in the 
components are lower enough to avoid damage in the fuel cell. The maximum principle stress of 22.89 MPA found in the YSZ film was less then the critical stress of 275 MPA. The maximum stress in the interconnect is 11.5 MPA which is less than the critical stress of 186 MPA. The12.69 MPA stress found in the Ni-YSZ anode is less than its critical stress of 145 MPA. And the compressive stress found in the LaMnO3 cathode is 11.37 MPA which is less than its critical stress of 175 MPA.

At lower temperature the thermal expansion coefficient of the interconnect is lower than that of the PEN (Jason LeMaster, Georgia Institute of Technology, 2004). Therefore in the slices at the inlet of gases where the temperature is lower, due to the mismatch in the thermal expansion coefficients, the stresses are very high. As we move from the inlet to the outlet of gases, since the temperature in the fuel cell increases the mismatch in thermal expansion coefficient of the components of the fuel cell decreases. Therefore, in the slices towards the outlet of gases, the stresses are lesser when compared to the slices near the inlet of gases. The stresses in the slices at the inlet and at the outlet of gases is shown below. 

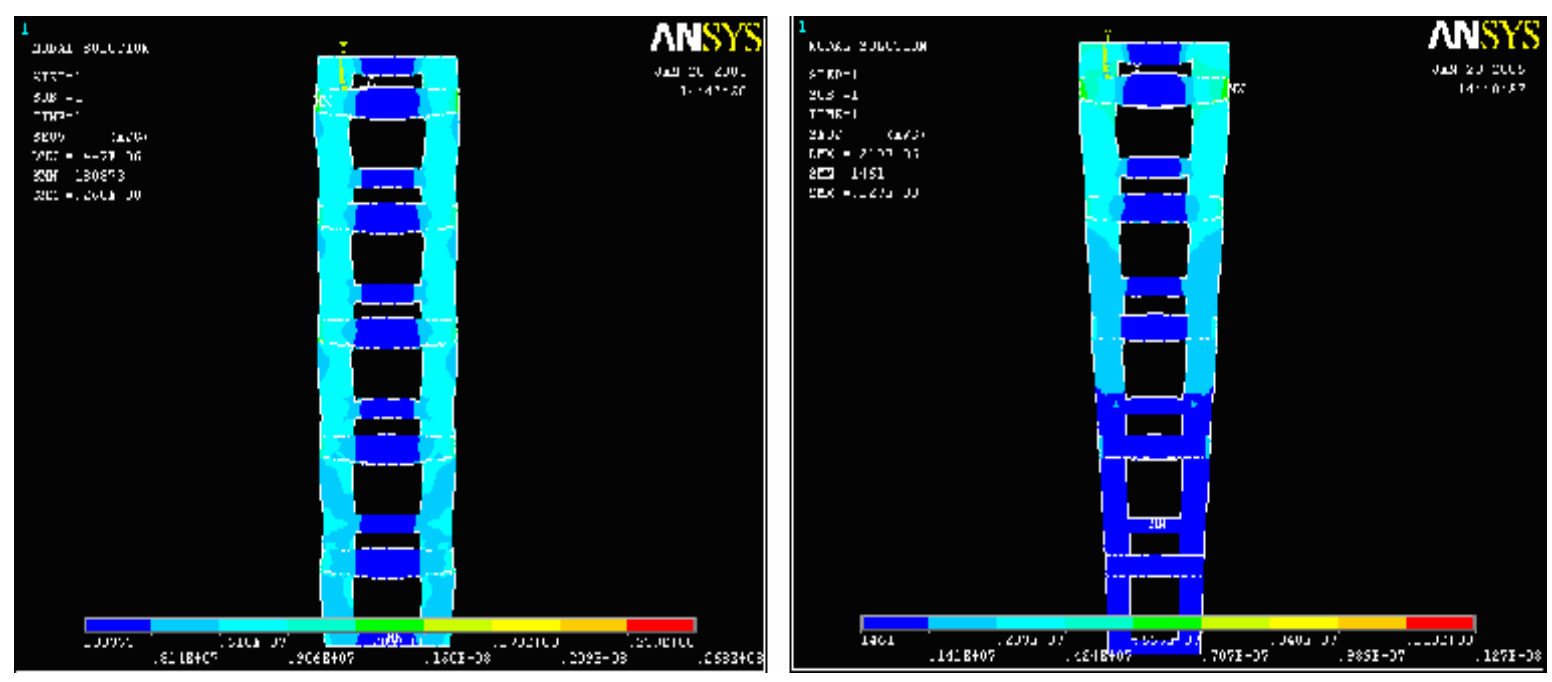

Figure 24: von Mises stress near the inlet of gases (left) and near the outlet of gases (right)

From the above figures we can see that the maximum stresses found in the fuel cell are near the inlet of air and fuel gases. Largest temperature gradient occurs near the inlet of gases where the highest stresses occur [6].

As the displacement of the PEN and the interconnect is constrained at the joint of the two materials, the stresses at the joint are of great interest in the design of the solid oxide fuel cell. The magnitude of the maximum stress is dependent on the $x-y$ dimensions and the material properties. Wider cells result in larger stresses in the ceramic side of the joint (Jason LeMaster, Georgia Institute of Technology, 2004). In the elastic study, the peeling stress $\left(\sigma_{\mathrm{yy}}\right)$ and the shear stress $\left(\sigma_{\mathrm{xy}}\right)$ increase approaching the free edge (Chiu \& Liou, 1994).

The stress is due to the asymmetry caused by the non-uniformity in the temperature distribution. The stresses in the YSZ electrolyte and the LaMnO3 increased from the center of the cell to the edge. As the failure of the fuel cell relies on the edge effects, the 
edges of the ceramic are focused. The figure below shows the compressive stress in the ceramic in the top part of the fuel cell near the inlet of air and fuel gases.

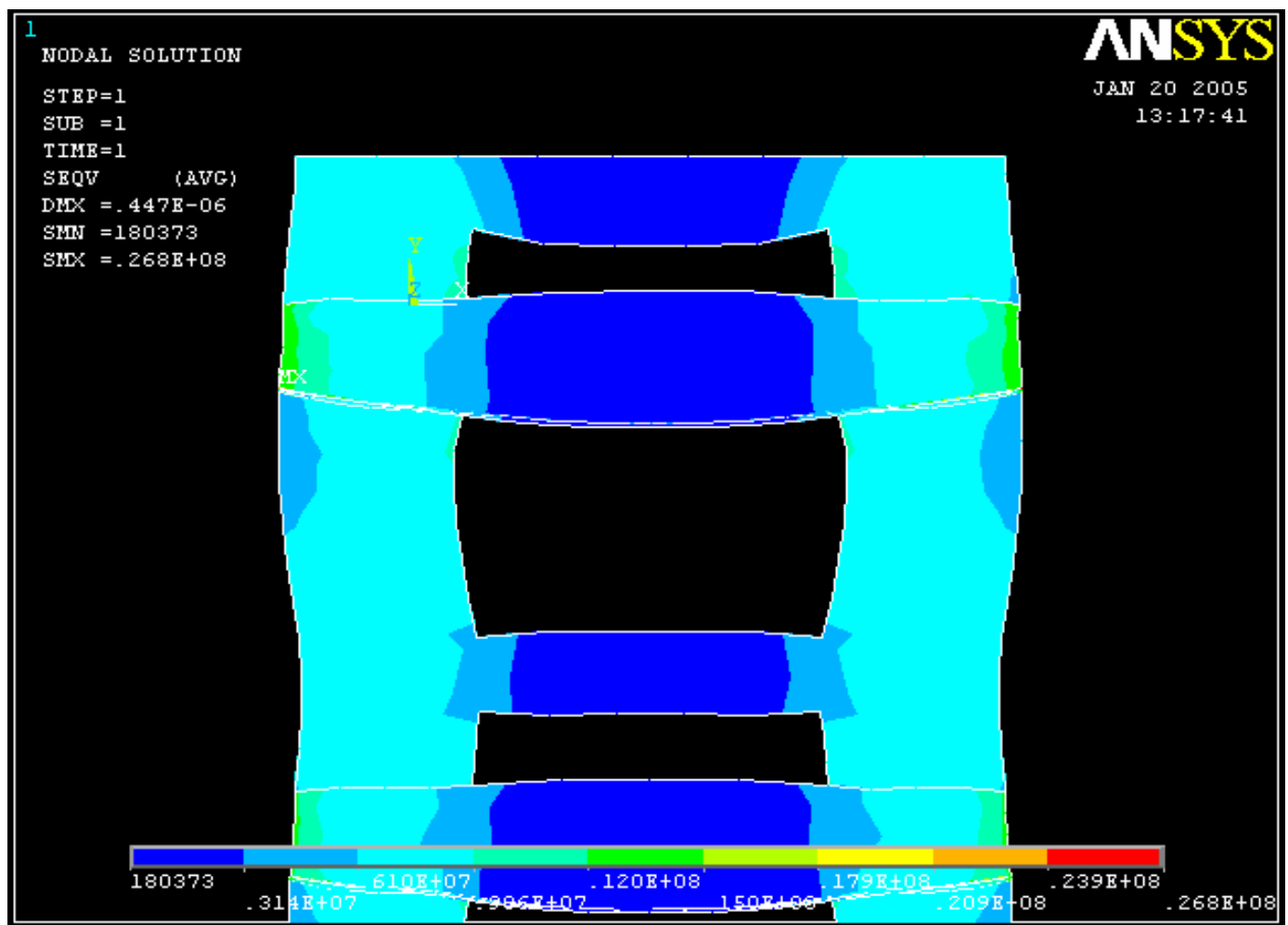

Figure 25: Von Mises stress in the top part of the fuel cell

(near the inlet of gases of the $1^{\text {st }}$ model)

At the edges, peeling stress $\left(\sigma_{\mathrm{yy}}\right)$ is the largest component of stress which predicts the cracking in the ceramic. Therefore the stresses in the y-direction along the edges are important. The location of the maximum stress found in the electrolyte near the inlet of air and fuel gases of the fuel cell is shown below. 


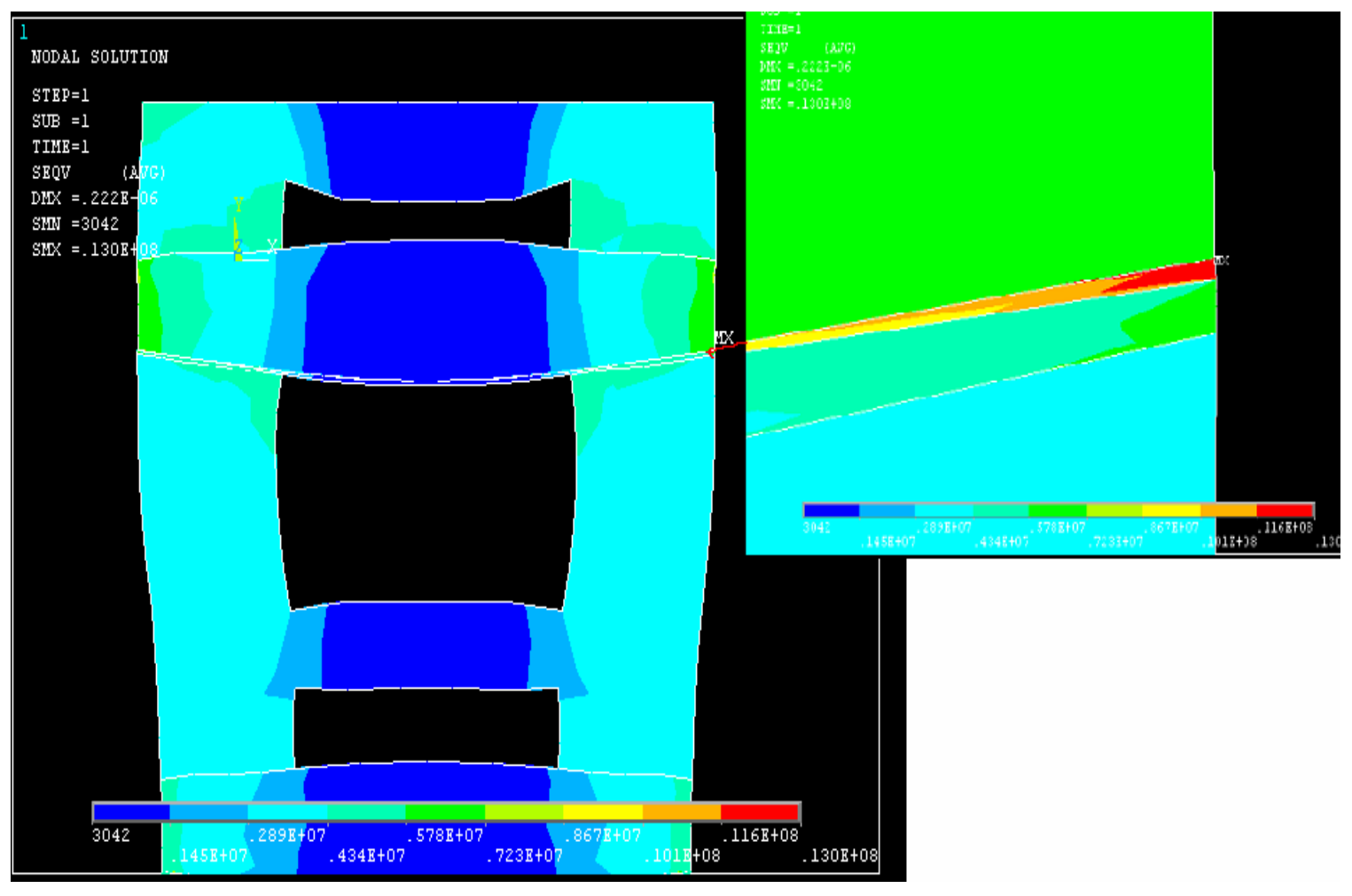

Figure 26: Stresses near the inlet of gases of the fuel cell $\left(1^{\text {st }}\right.$ model)

The critical stress relies on the edge of the ceramic. The difference in the thermal expansion coefficients (TECs) of the lanthanum chromite interconnect and the YSZ electrolyte near the inlet of gases of the fuel cell is $18.4 \%$, whereas the difference in TECs near the outlet of gases of the fuel cell is $9.07 \%$. Therefore, the maximum peeling stress $\left(\sigma_{\mathrm{yy}}\right)$ in the electrolyte near the outlet of gases of the fuel cell is $10.24 \mathrm{MPa}$ which is less when compared to the maximum peeling stress $\left(\sigma_{\mathrm{yy}}\right)$ near the inlet which is 22.89 $\mathrm{MPa}$. The maximum stresses near the outlet of gases in the fuel cell are given below. 


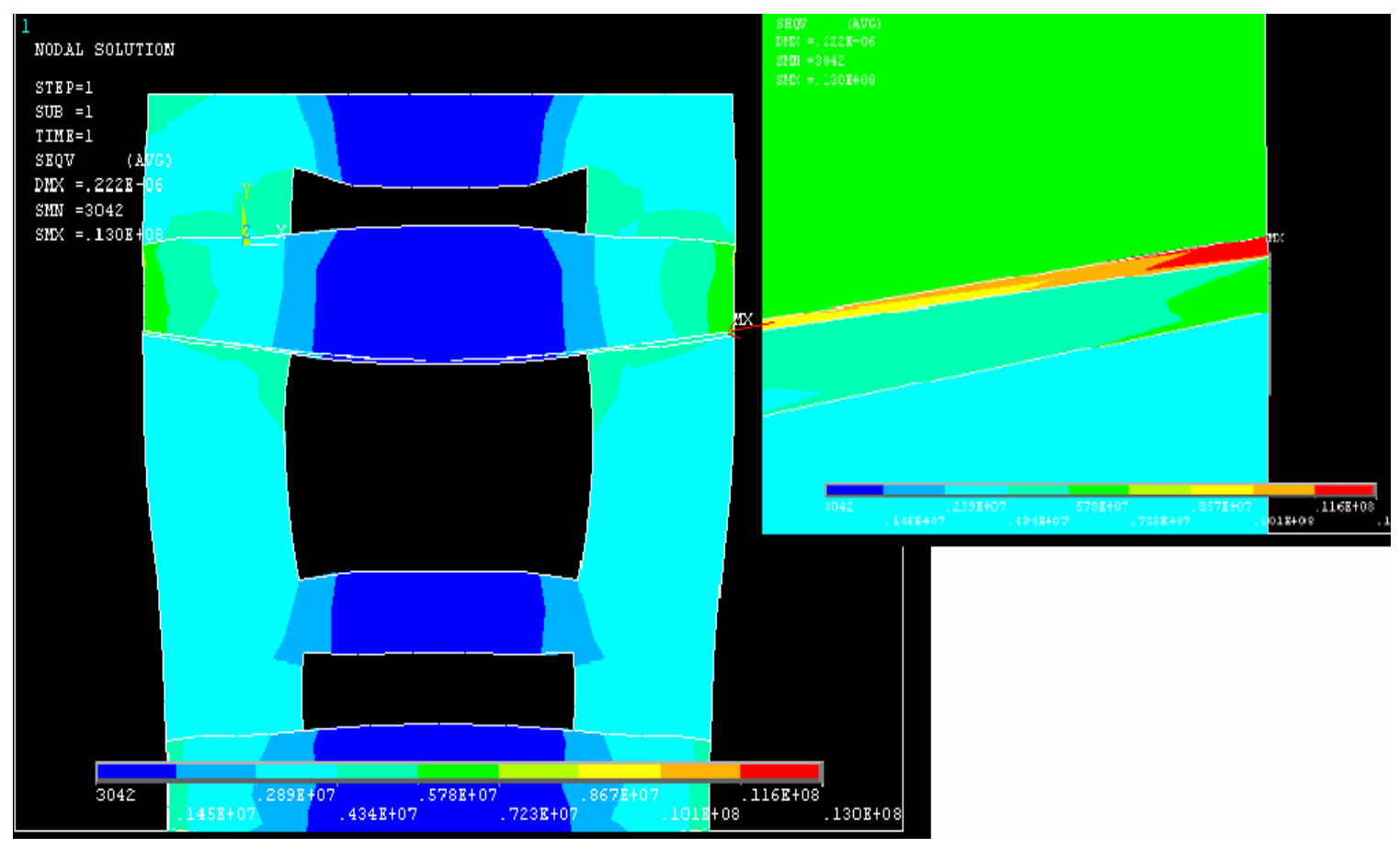

Figure 27: Stresses near the outlet of gases of the fuel cell $\left(1^{\text {st }}\right.$ model $)$

The ceramic fails when the maximum principle stress exceeds the critical stress. The maximum stress of the interconnect at the inlet of air and fuel gases of the fuel cell is 11.5 MPa which is less than the critical stress of lanthanum chromite which is $186 \mathrm{MPa}$. Therefore, the interconnect for this five stack two-dimensional model does not fail. Stress is maximum along the edges of the interconnect which is shown in the graph below. 


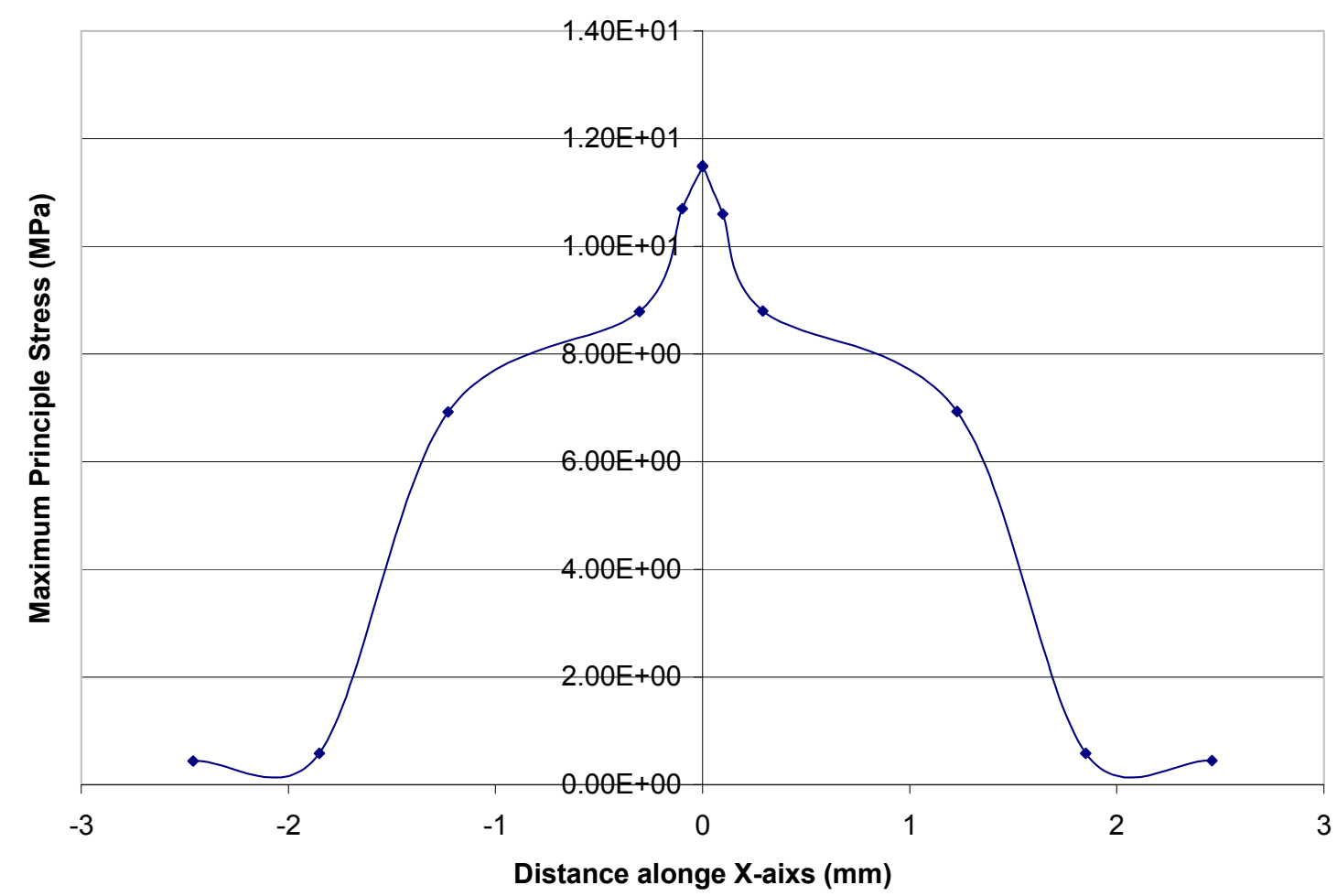

Figure 28: Maximum principle stress of $\mathrm{LaCrO3}$ interconnect near the inlet of gases (1 ${ }^{\text {st }}$ model)

The maximum principle stress in the electrolyte near the inlet of air and fuel gases is found to be $22.89 \mathrm{MPa}$ which is less than the critical stress. The maximum stresses are found near the corners of the material along the edges. The graph of the principle stress in the electrolyte is given below. 


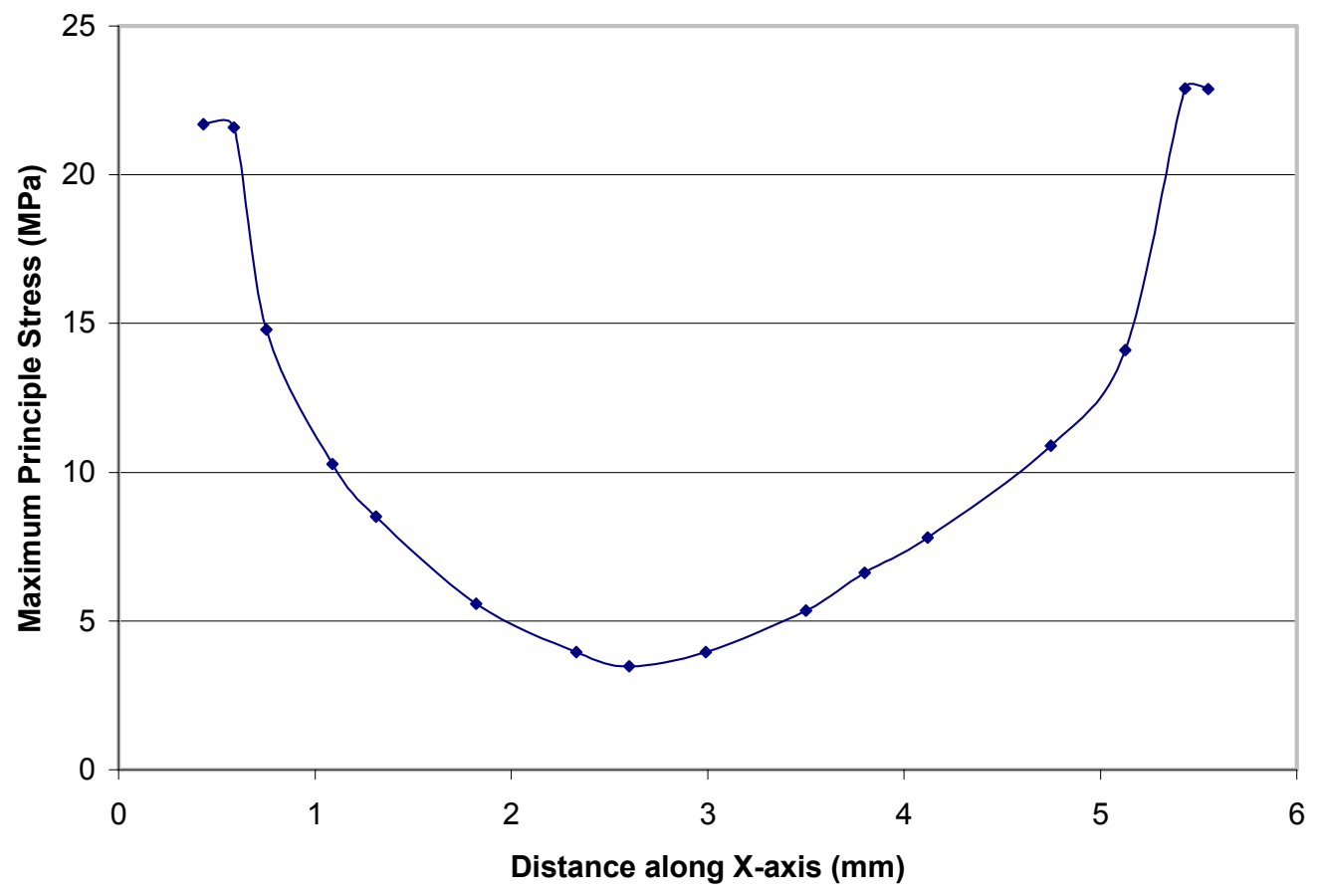

Figure 29: Maximum principle stress of the electrolyte $\left(1^{\text {st }}\right.$ model $)$

The maximum principle stresses found in the cathode and anode were found to be less than their respective critical stresses. The highest stress location in the ceramic is found along the edges. The graphs of the maximum principle stresses in the cathode and anode are given below. 


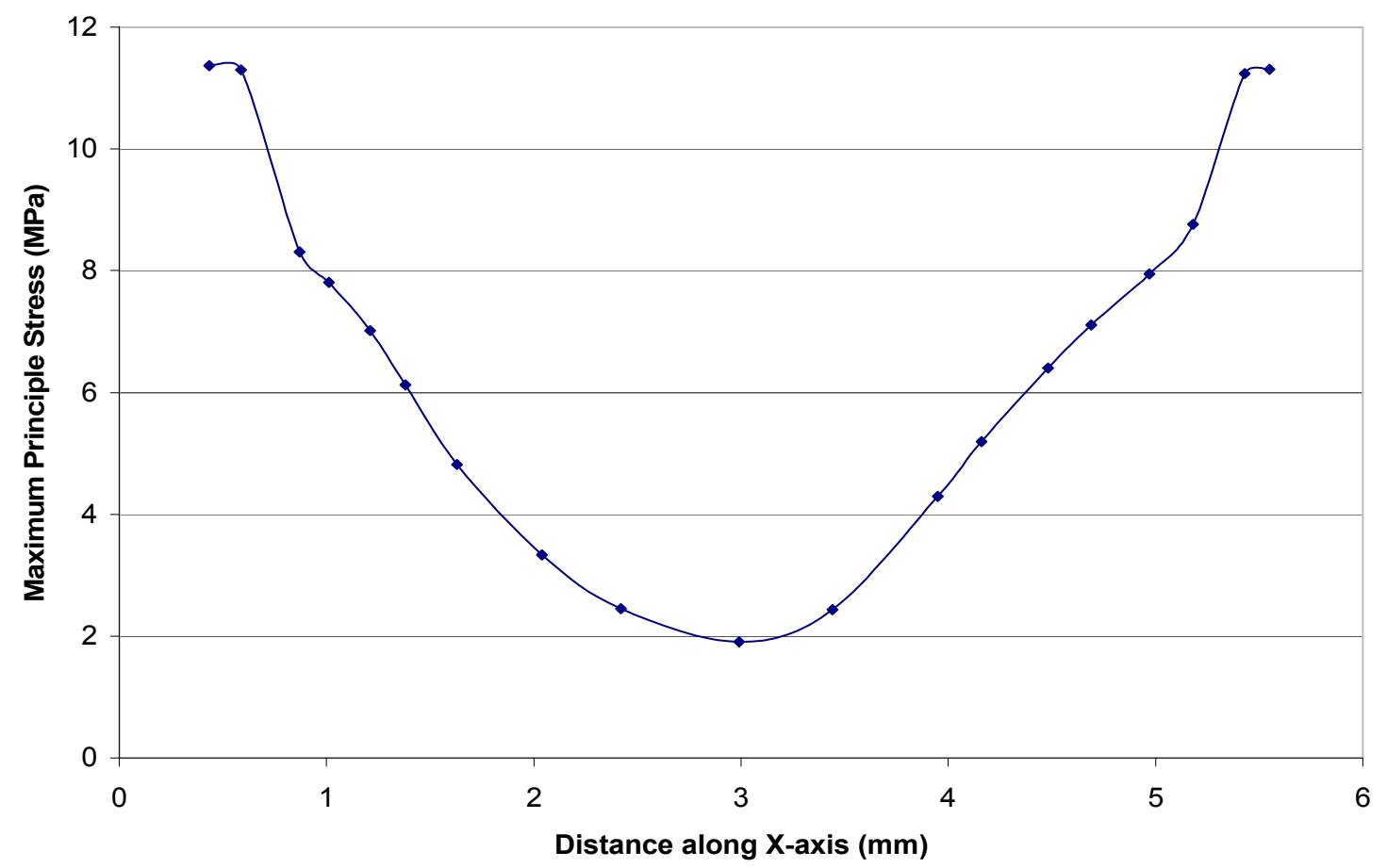

Figure 30: Maximum principle stress of the cathode $\left(1^{\text {st }}\right.$ model $)$

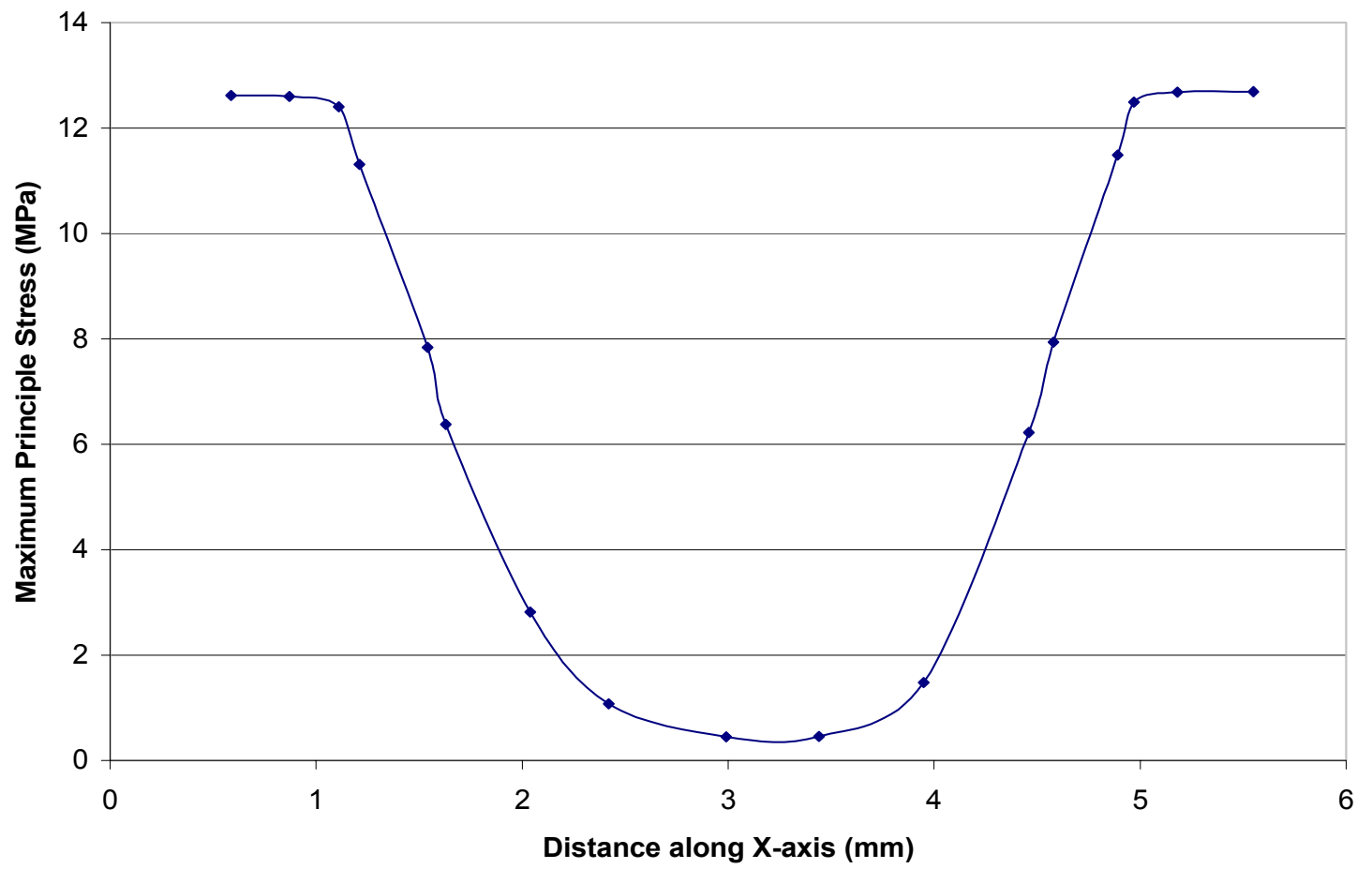

Figure 31: Maximum principle stress of the anode $\left(1^{\text {st }}\right.$ model $)$ 
From these graphs, we can infer that the stresses in the interconnect and PEN are high along the edges of the joint when compared to the center of the materials. These large components of stresses in the fuel cell are due to the difference in the TECs (thermal expansion coefficients) and the strength of the joint between the PEN and interconnect. The highest principle stresses found in the ceramic, i.e. cathode, anode and electrolyte and the interconnect is given below.

\begin{tabular}{|c|c|c|}
\hline Material & $\begin{array}{c}\text { Compressive Failure } \\
\text { Strength } \\
(\mathrm{MPa})\end{array}$ & $\begin{array}{c}\text { Calculated Compressive } \\
\text { Stress } \\
(\mathrm{MPa})\end{array}$ \\
\hline Interconnect (LaCrO3) & 186 & 11.5 \\
\hline Anode (Ni/YSZ) & 145 & 6.95 \\
\hline Electrolyte (YSZ) & 235 & 22.89 \\
\hline Cathode (LaMno $)$ & 175 & 11.37 \\
\hline
\end{tabular}

Table 6: Maximum principle stresses found in the PEN and interconnect $\left(1^{\text {st }}\right.$ model)

\subsection{Boundary Conditions for the Second Model}

The temperature results from the thermal model are read into the structural model as nodal loads similar to the first model. But different boundary constraints are given for this model. The bottom of the five stack model is fixed and the top part is left to expand freely without any constraint. This also prevents from the translation and rotation of the model. The bottom of the fuel cell is fixed along y-direction and a node on the left corner at the bottom of the stack is fixed along $\mathrm{x}$ and $\mathrm{y}$ axes. 


\subsubsection{Results of the Second Model}

In the second model, since the stack is constrained only at the bottom of the fuel cell, the fuel cell expands more uniformly from the bottom of the cell to the top of the stack. The von Mises stresses at the inlet of gases and outlet of gases are given below.

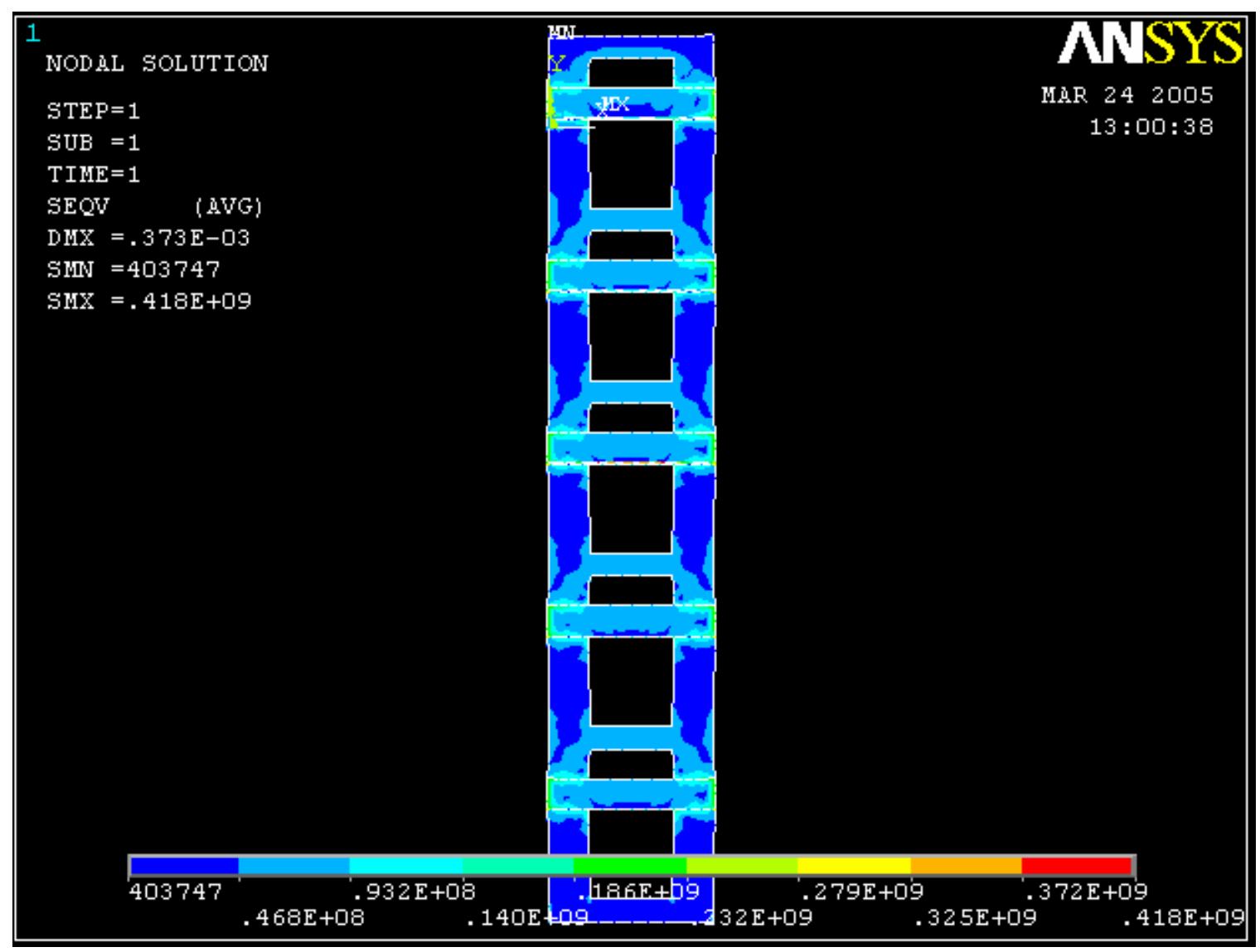

Figure 32: von Mises stresses at the inlet of gases $\left(2^{\text {nd }}\right.$ model $)$ 


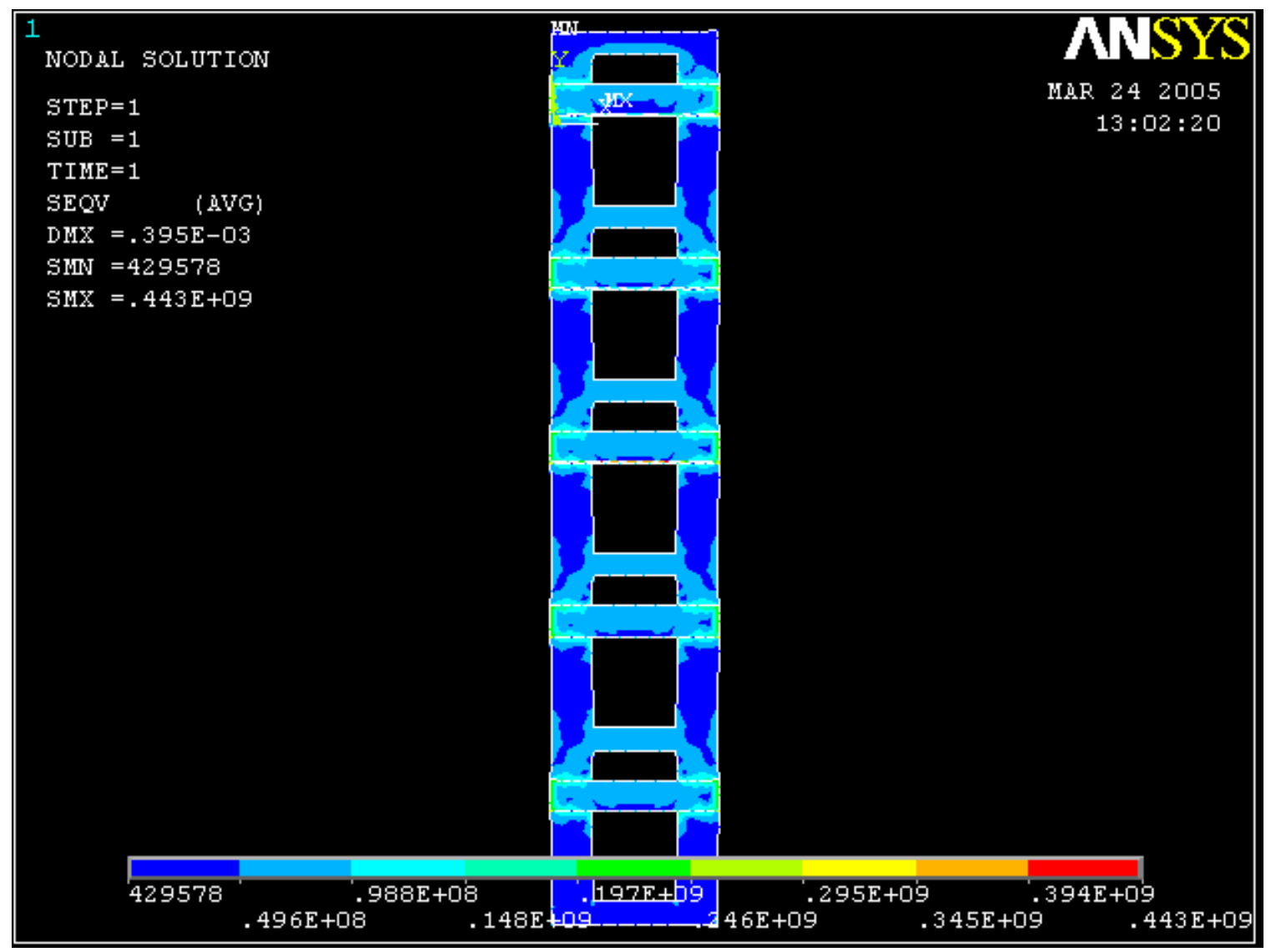

Figure 33: von Mises stresses at the outlet of gases $\left(2^{\text {nd }}\right.$ model $)$

Maximum principle stresses are found along the y-direction. The five stack model is partly under compression and partly under tension. The maximum compressive stress which is $57.2 \mathrm{MPa}$ is found in the electrolyte at the outlet of gases. The maximum tensile stress which is $60 \mathrm{MPa}$ is found near the outlet of gases. 


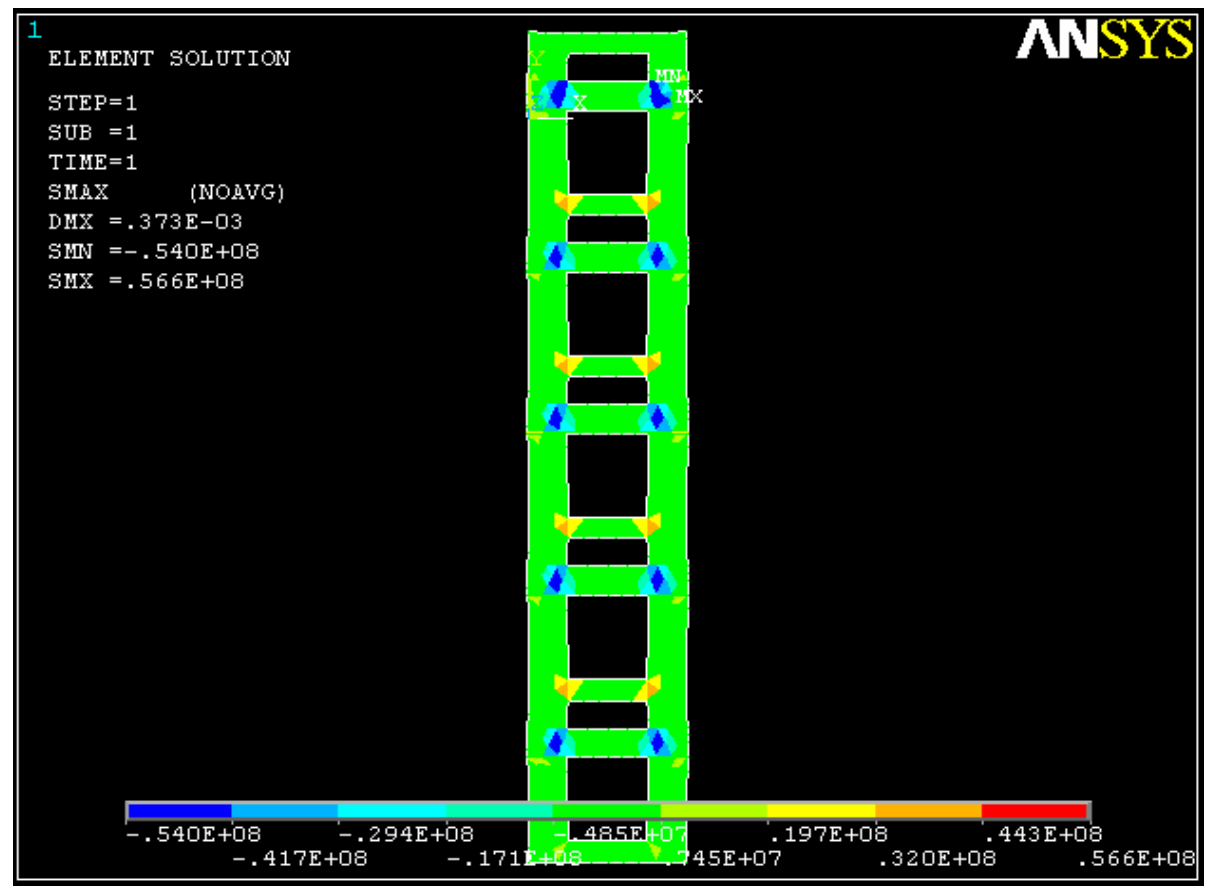

Figure 34: Maximum Principle Stress at the inlet of gases $\left(2^{\text {nd }}\right.$ model $)$

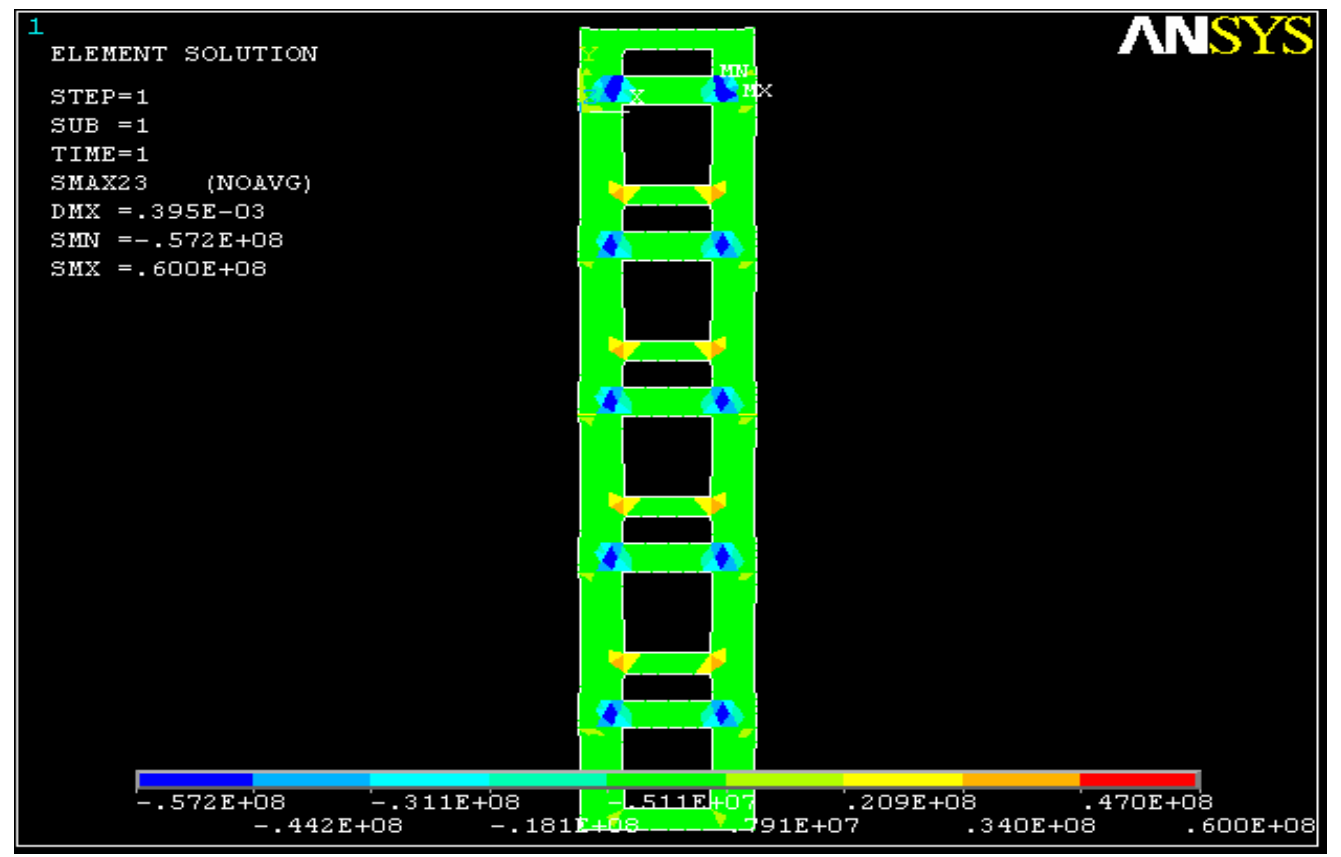

Figure 35: Maximum principle stresses at the outlet of gases $\left(2^{\text {nd }}\right.$ model) 


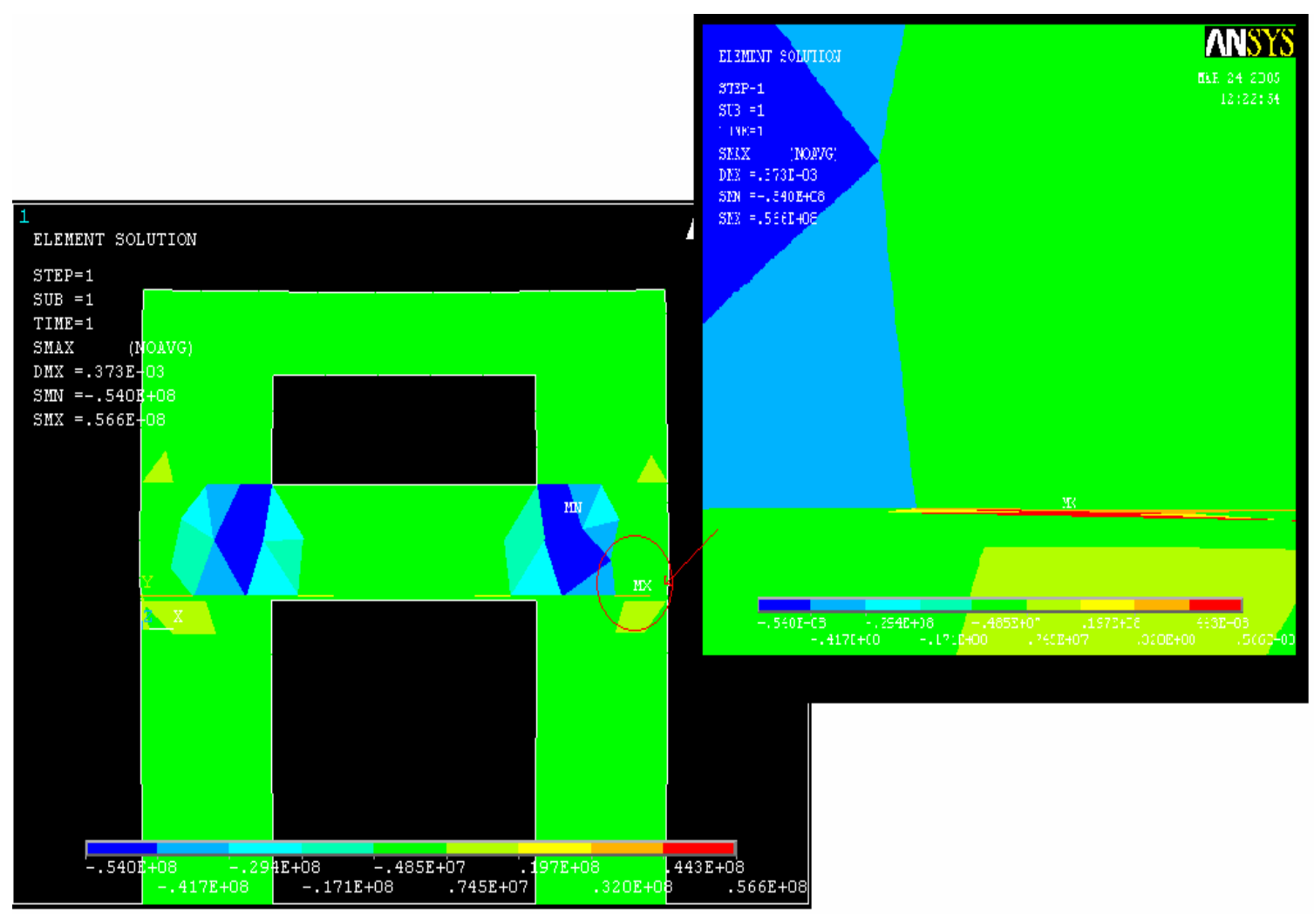

Figure 36: Zoom stresses at the inlet of gases $\left(2^{\text {nd }}\right.$ model)

From the stresses at the inlet of gases at the top of the stack, it can be seen that the maximum compressive stresses were found along the corners of the electrolyte and the maximum tensile stress is found in the PEN at the top of the stack. 


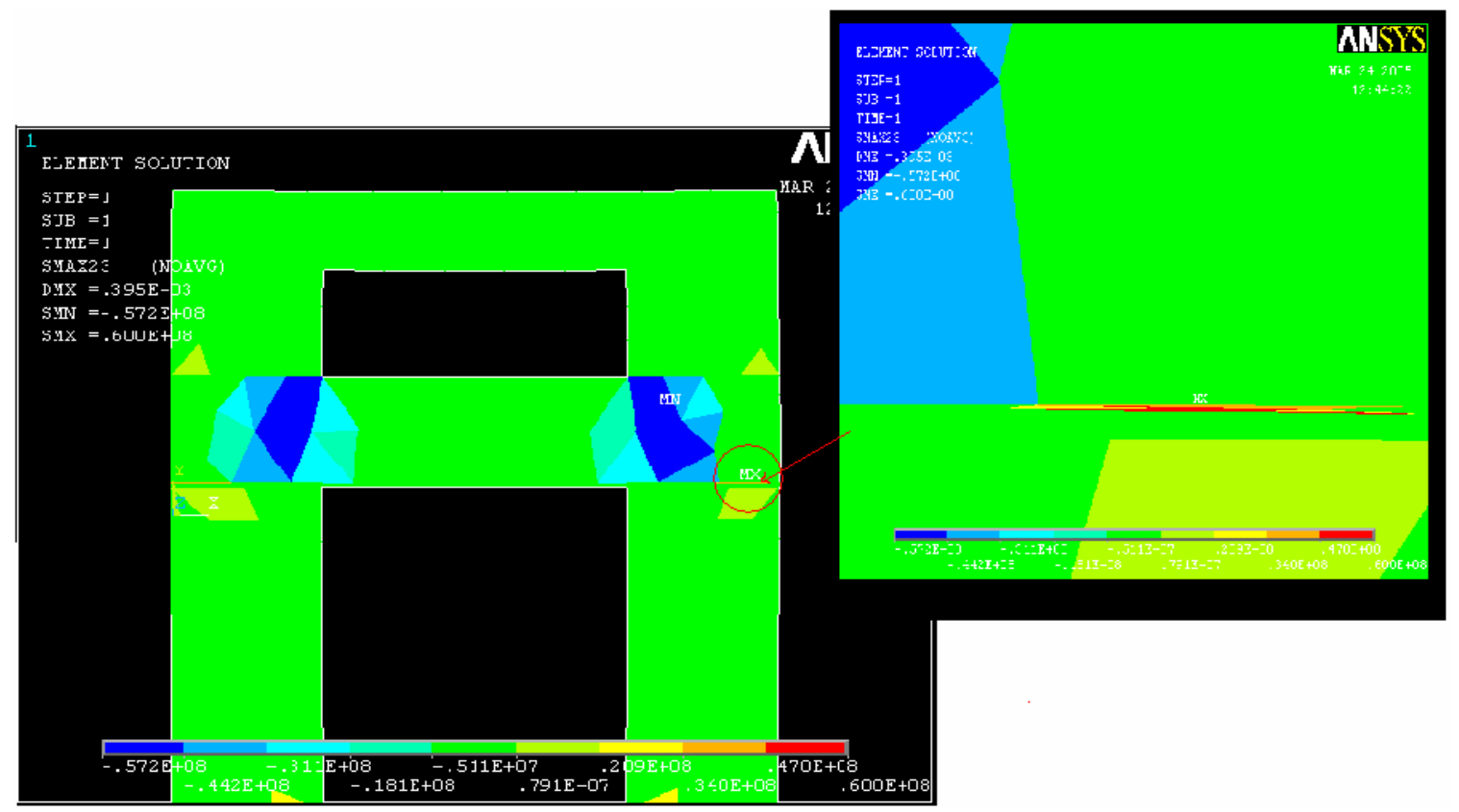

Figure 37: Zoom stresses at the outlet of gases $\left(2^{\text {nd }}\right.$ model $)$

A close-up view of the maximum stresses found near the outlet of gases is shown above.

From the stresses at the outlet of gases, it can be seen that the maximum stresses are found at the top of the stack, similar to the stress locations at the inlet of gases. 

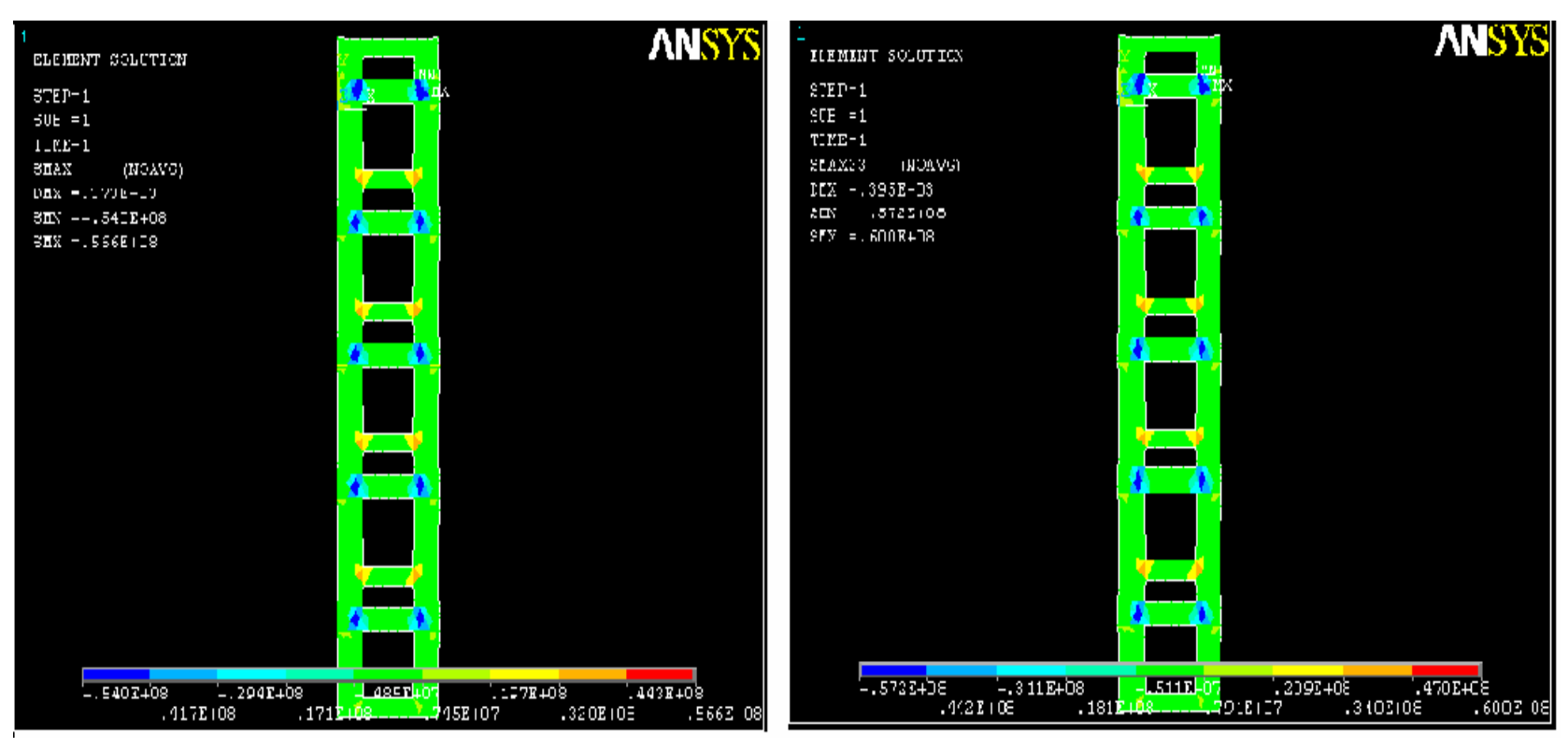

Figure 38: Maximum principle stresses at the inlet of gases (left) and outlet of gases (right)

The stress variations from the inlet of gases to the outlet of gases are more uniform in this model when compared to the first model. The maximum compressive stress at the inlet of gases in $54 \mathrm{MPa}$ and at the outlet of gases is $57.2 \mathrm{MPa}$. From this we can see that the variation in the compressive stresses from the inlet to the outlet of gases is only about $3 \mathrm{MPa}$. The stresses from the inlet to the outlet of gases are more uniform when compared to the first model. The maximum stresses found in this model are below the failure stresses, therefore this model does not fail.

Usually, fuel cell stack models are fixed at the bottom and are allowed to expand freely towards the top of the stack. Therefore the five stack fuel cell with these boundary constraints represents a more realistic model. 


\begin{tabular}{|l|c|c|c|c|}
\hline \multirow{2}{*}{ Material } & \multicolumn{2}{|c|}{$\begin{array}{c}\text { Failure Stress (MPa) } \\
{[25],[26]}\end{array}$} & \multicolumn{2}{c|}{ Calculated Stress (MPa) } \\
\cline { 2 - 5 } & Tensile & Compressive & Tensile & Compressive \\
\hline $\begin{array}{l}\text { Interconnect } \\
\left(\mathrm{LaCrO}_{3}\right)\end{array}$ & 73 & 186 & 23.31 & 35.45 \\
\hline $\begin{array}{l}\text { Anode } \\
(\mathrm{Ni} / \mathrm{YSZ})\end{array}$ & 90 & 145 & 33.9 & 42.36 \\
\hline $\begin{array}{l}\text { Electrolyte } \\
(\mathrm{YSZ})\end{array}$ & 177 & 235 & 57.2 & 60 \\
\hline $\left.\begin{array}{l}\text { Cathode } \\
(\mathrm{LaMnO}\end{array}\right)$ & 140 & 175 & 22.7 & 34.27 \\
\hline
\end{tabular}

Table 7: Maximum principle stresses found in the fuel cell (2nd model) 


\section{CHAPTER 5}

\section{THREE-DIMENSIONAL THERMAL STRESS ANALYSIS DURING OPERATION OF SOFC}

\subsection{Introduction}

The stresses in the solid part of the three-dimensional SOFC are calculated from the temperature profile provided by the WVU CFD \& AMP Laboratory [10] using finite element analysis. The materials used for the analysis are similar to that of the twodimensional analysis which are Lanthanum Chromite (LaCrO3) for the interconnect, Nickel dispersed on Yittria stabilized Zirconia (Ni/YSZ) for the anode, Doped Lanthanum Manganite $\left(\mathrm{LaMnO}_{3}\right)$ for the cathode and Yittria stabilized Zirconia (YSZ) for the electrolyte. Young's modulus and thermal expansion coefficient are the linear material properties assigned for the analysis. For the three-dimensional analysis, two models with different boundary constraints have been considered.

\subsection{Stress Analysis Using ANSYS ${ }^{\mathrm{TM}}$}

A static stress analysis, using ANSYS ${ }^{\mathrm{TM}}$, is performed to determine the stresses in the components of the fuel cell. The element type used for the three-dimensional model is SOLID45 which is an eight node linear brick element having three degrees of freedom at each node. The simulated temperature values were read into ANSYSTM at the nodes and interpolated to the calculated points within the elements. 


\subsubsection{Geometric Model}

The three-dimensional analysis was performed on a single stack cross-flow SOFC. The planar SOFC consists of interconnect, anode, electrolyte, cathode with the air flowing in the air channel over the cathode and the fuel flowing in the fuel channel over the anode. The dimensions of the fuel cell are $16 \mathrm{~mm}$ in the $\mathrm{x}$-direction, $7.5 \mathrm{~mm}$ in the y-direction and $16 \mathrm{~mm}$ in the $\mathrm{z}$-direction. There are five fuel channels and air channels in the solid oxide model. The width and height of the air channel and the fuel channel are $2 \mathrm{~mm}$. The geometry used for the three-dimensional analysis is given below.

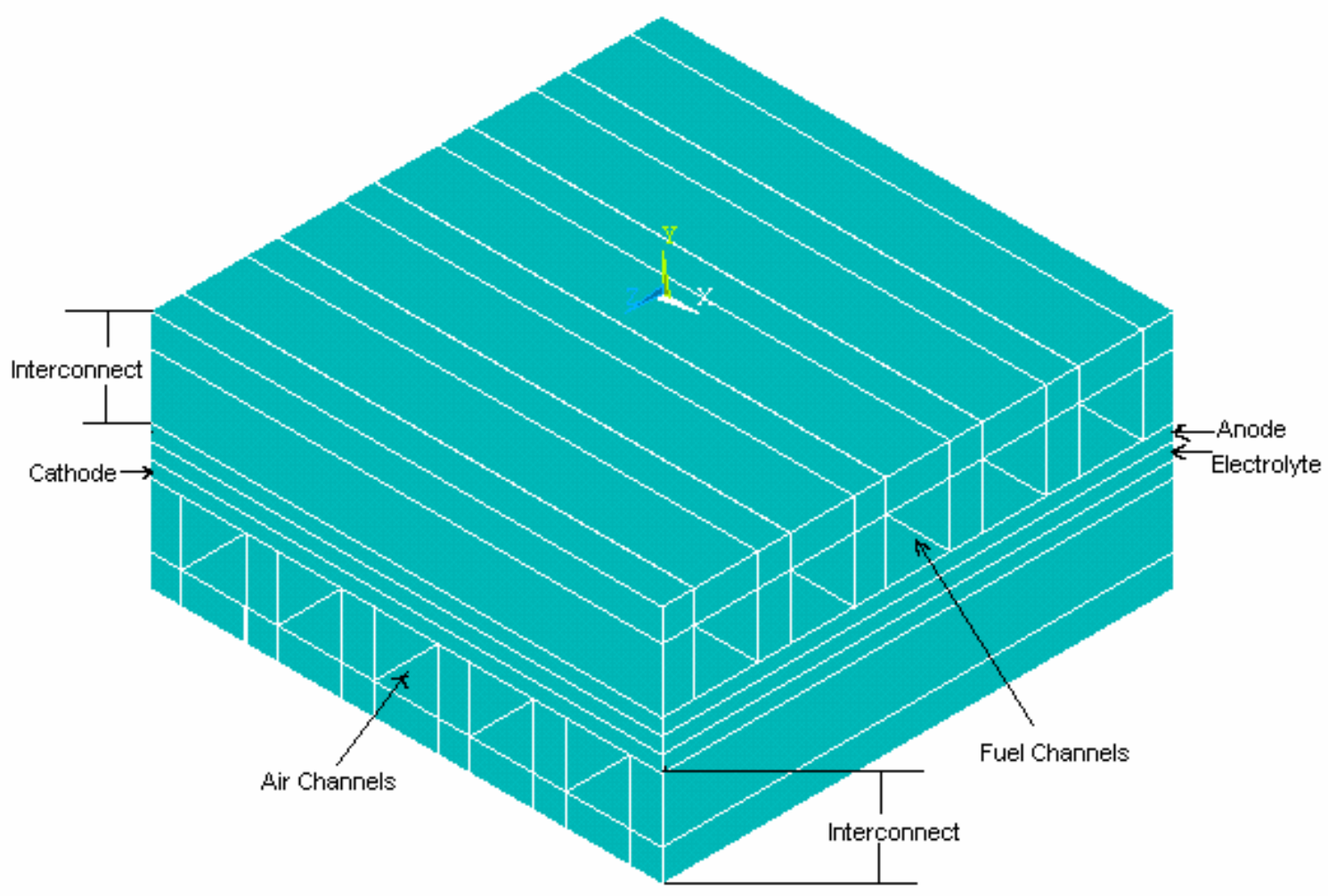

Figure 39: Three-dimensional view of a single stack cross-flow SOFC 


\subsubsection{Meshing Of The Three-Dimensional Model}

The mesh generated for the solid model in ANSYS ${ }^{\mathrm{TM}}$ is similar to that of the FORTRAN model created by the WVU CFD \& AMP Laboratory [10]. In this way, the nodal temperature data from the CFD analysis, which is included as a boundary condition for the three-dimensional analysis in ANSYS ${ }^{\mathrm{TM}}$, can be correctly transferred by matching the nodes from the FORTRAN model with that of the ANSYSTM model. Therefore a mapped mesh is used for meshing the three-dimensional solid model which has brick volume elements.

The element size in the solid model is controlled using manual size option in ANSYSTM which defines the number of divisions and spacing ratio on selected lines. Lines on the opposite edges of the areas in the $\mathrm{x}, \mathrm{y}$ and $\mathrm{z}$ directions are selected and the required number of element divisions are given respectively. Mapped meshing helps in transferring line divisions from one line to the opposite line and into the adjacent areas which have to be meshed. The number of elements given for each line in the x-direction and z-direction are 64, and 31 in the y-direction. The three-dimensional meshed model is given below. 


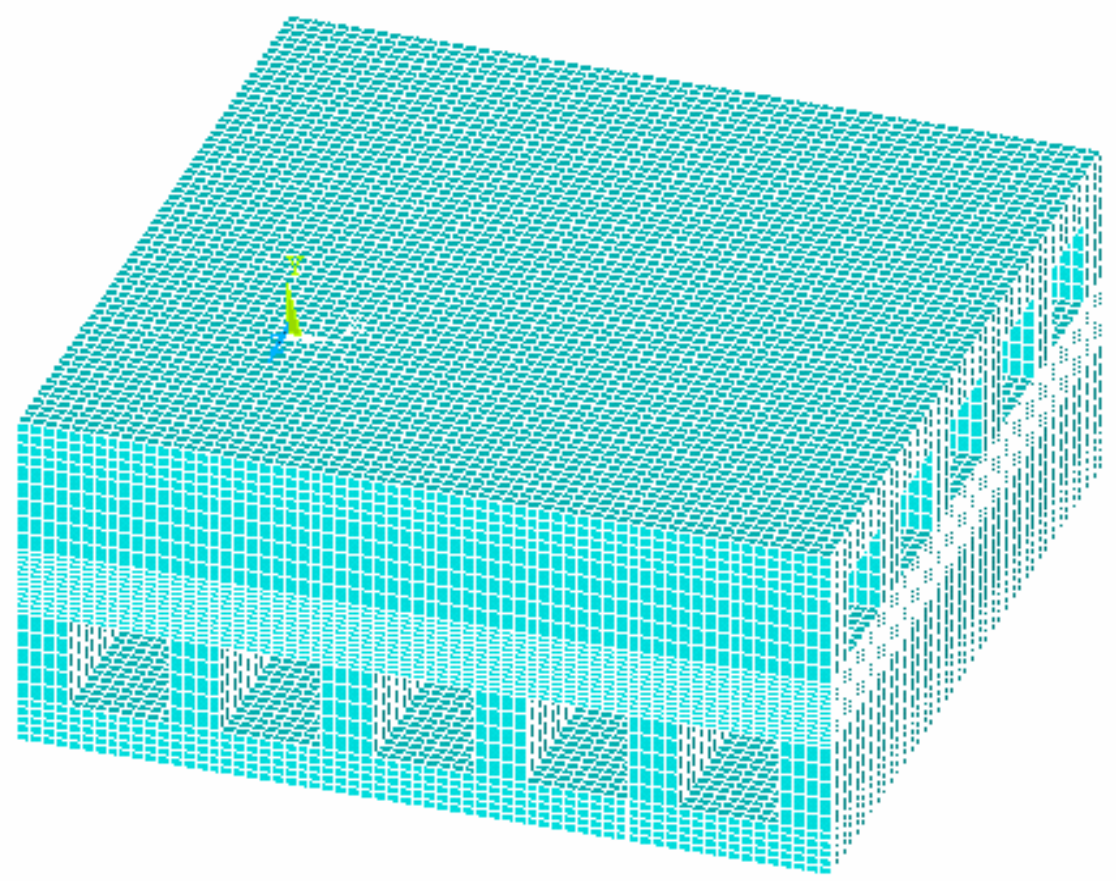

Figure 40: Three-dimensional meshed model

\subsubsection{Boundary Conditions}

The nodal temperature result provided by WVU CFD \& AMP Laboratory [10] is used as the boundary condition in the solid model. The temperature data file from FORTRAN is created in a tab-delimited text editor with the help of MATLAB and is read into a table array parameter in ANSYS ${ }^{\mathrm{TM}}$ as body load.

TABLE parameter is a special type of numeric array in ANSYSTM which calculates the values between the array elements through linear interpolation which are explicitly defined in the array. The index values in the table define the locations of the temperatures, with the first row of each plane having the y-coordinates and the first column having the x-coordinates. Each plane of data containing the row and column 
index values is repeated for the separate planes. For the present three-dimensional SOFC model, 64 rows, 31 columns and 64 planes are defined. The number of columns taken in this model is less than the number of columns in the model provided by WVU CFD \& AMP Laboratory [10] since ANSYSTM allows limited number of nodes. By using the command TREAD in ANSYS ${ }^{\mathrm{TM}}$, the temperatures data from the text editor is applies as body load on the solid model by selecting all the nodes of the model. The steady state temperature values from the FORTRAN code which are inputted in this manner are interpolated in ANSYS ${ }^{\mathrm{TM}}$ throughout the three-dimensional model.

\subsection{Boundary Constraints on the First Model}

For constraining the three-dimensional SOFC, a cantilever-like approach is used to prevent rotation and translation of the model without preventing the bending of the fuel cell caused due to the expansion of the components. The four corners of the model and the edges of the gas channels are constraints in the y-direction. Nodes are selected at the inlet and outlet of gases and constrained in the x-direction. Zero displacement is given to the model on the nodes in the z-direction. Results were checked to make sure the boundary conditions do not cause significant stress concentrations. After constraining the model this way the temperature data is inputted into ANSYS ${ }^{\mathrm{TM}}$ as body loads and a stress analysis performed. 


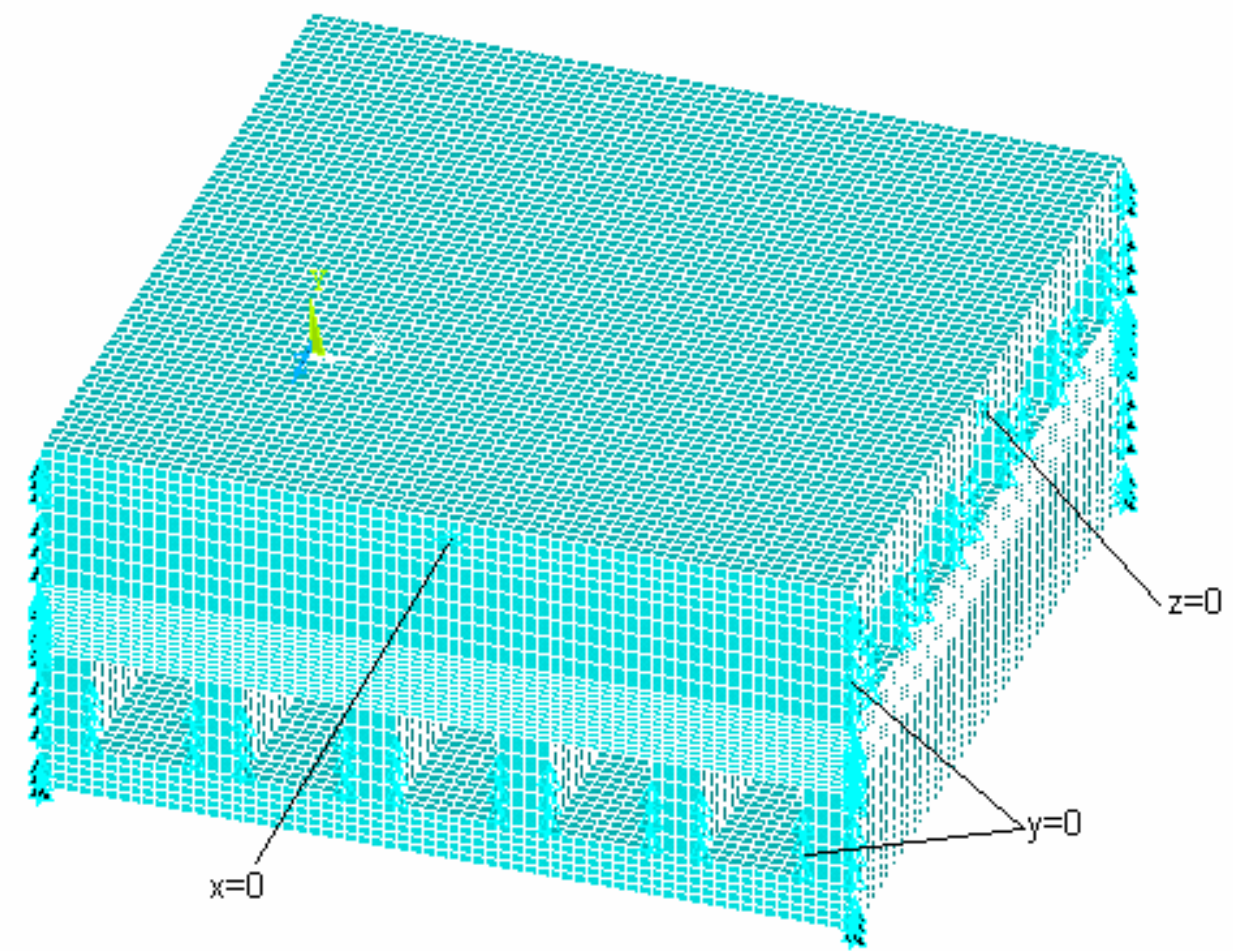

Figure 41: Boundary constraints on the three-dimensional SOFC ( $1^{\text {st }}$ model)

\subsubsection{Results of the First Model}

In the three-dimensional model, thermal stresses arise due to the temperature body loads and the thermal expansion mismatch of the components. Stresses in the y-direction are the most important as the peeling stress $\left(\sigma_{\mathrm{yy}}\right)$ is the largest component of stress found in the fuel cell. The greatest stresses in the fuel cell model are found at the joint and along the edges of the ceramic. From the contour plots of the maximum principle stress of the SOFC, the ceramic is found to be mostly under compression and the maximum stress is found in the electrolyte along the edge at the joint of the ceramic. 


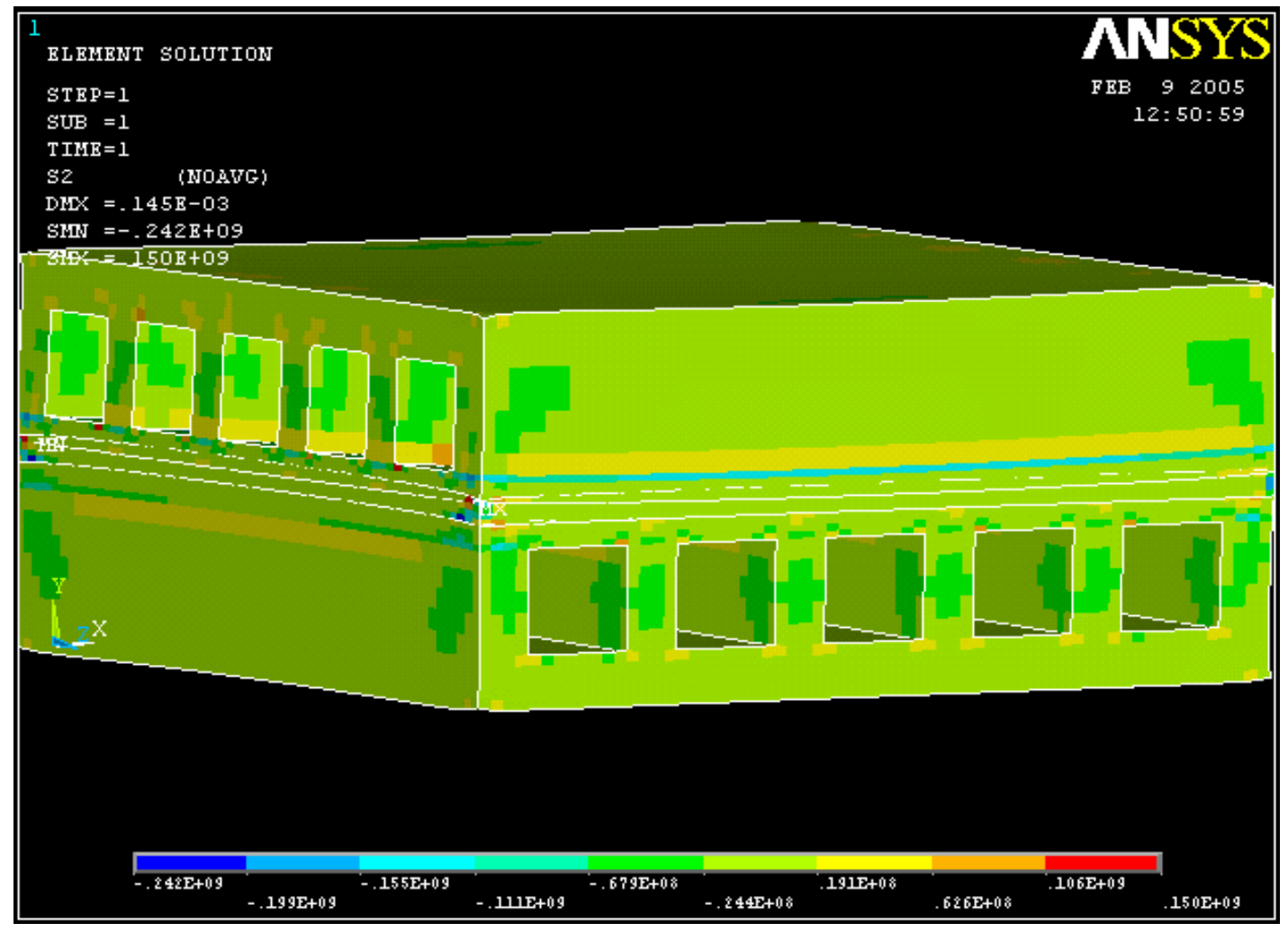

Figure 42: Maximum principle stress in the three-dimensional SOFC $\left(1^{\text {st }}\right.$ model $)$

The maximum compressive stress found in the electrolyte is $242 \mathrm{MPa}$ and the maximum tensile stress found in the electrolyte is $150 \mathrm{MPa}$. The tensile critical strength of the YSZ electrolyte is $177 \mathrm{MPa}$ whereas the compressive failure strength is $235 \mathrm{MPa}$. The maximum compressive stresses found in the anode and cathode are $137.25 \mathrm{MPa}$ and 123.39MPa respectively which are below their critical values. The maximum stress found in the interconnect is $68.59 \mathrm{MPa}$ which is less when compared to its critical stress value. Therefore, failure in the SOFC model is predicted as the compressive stress of the electrolyte is higher than the failure strength. 


\begin{tabular}{|c|c|c|c|c|}
\hline \multirow{2}{*}{ Material } & \multicolumn{2}{|c|}{$\begin{array}{c}\text { Failure Strength }(\mathrm{MPa}) \\
{[25],[26]}\end{array}$} & \multicolumn{2}{c|}{$\begin{array}{c}\text { Calculated Stress } \\
\text { [MPa) }\end{array}$} \\
\cline { 2 - 5 } & Tensile & Compressive & Tensile & Compressive \\
\hline $\begin{array}{c}\text { Interconnect } \\
(\text { LaCrO3) }\end{array}$ & 73 & 186 & 39.73 & 68.59 \\
\hline $\begin{array}{c}\text { Anode } \\
(\text { Ni/YSZ) }\end{array}$ & 90 & 145 & 88.58 & 137.25 \\
\hline $\begin{array}{c}\text { Electrolyte } \\
(\text { YSZ) }\end{array}$ & 177 & 235 & 150 & 242.06 \\
\hline $\begin{array}{c}\text { Cathode } \\
(\text { LaMno } 3)\end{array}$ & 140 & 175 & 85.9 & 123.39 \\
\hline
\end{tabular}

Table 8: Maximum stresses found in the three-dimensional model $\left(1^{\text {st }}\right.$ model $)$

\subsection{Boundary Constraints on the Second Model}

For constraining the second model, the bottom of the fuel cell is fixed along the corners in the y-direction. A node at the bottom of the model near the inlet of air and fuel gases is fixed along $\mathrm{x}, \mathrm{y}$ and $\mathrm{z}$ directions and a node in the $\mathrm{x}$-axis is fixed along the $\mathrm{z}$-direction. This model is less constrained when compared to the first model. The fuel cell is fixed only at the bottom and the top of the cell is left unconstrained which allowed it to expand freely and also the translation and rotation of the body is prevented. 


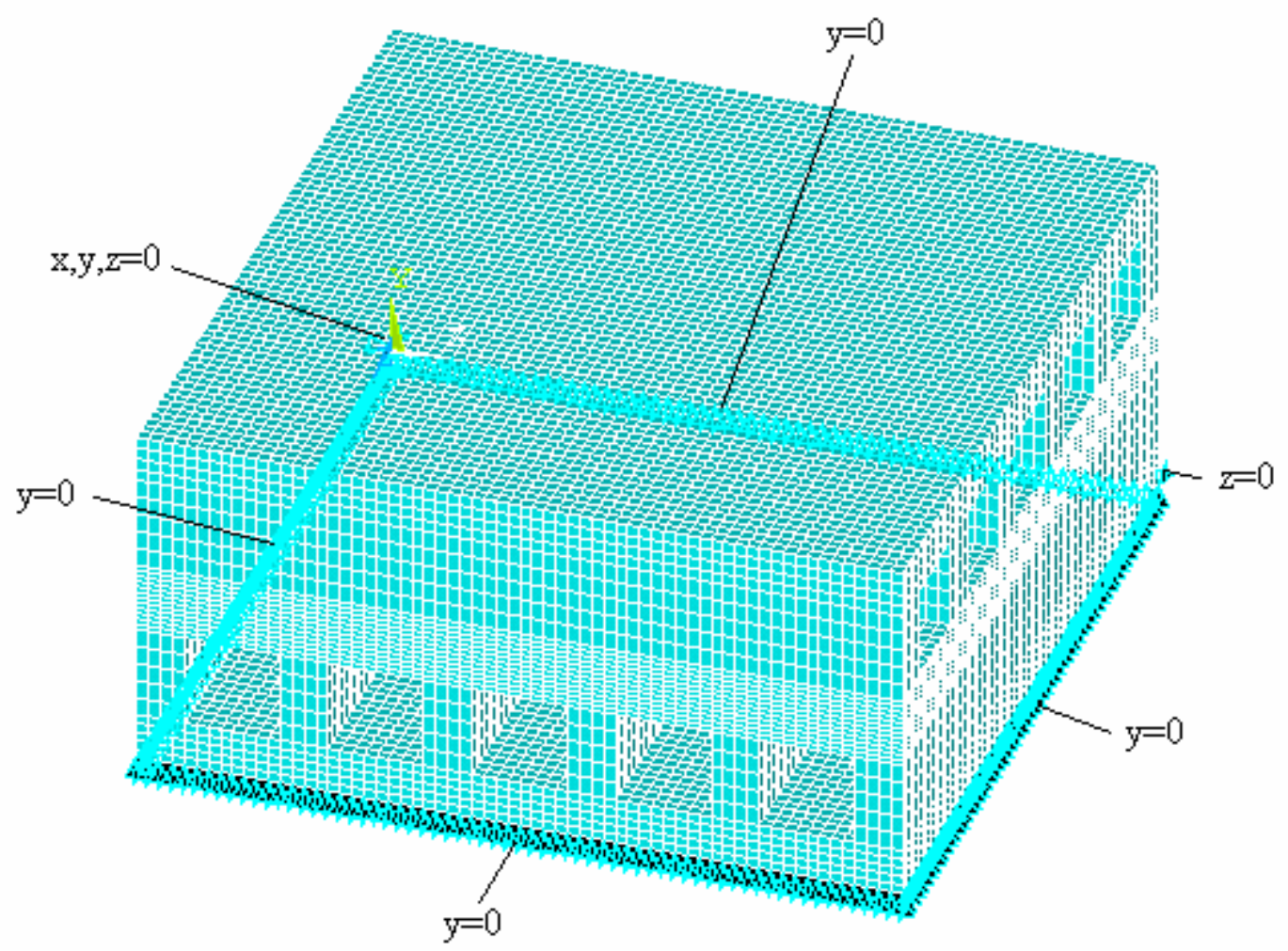

Figure 43: Boundary constraints on the three-dimensional SOFC $\left(2^{\text {nd }}\right.$ model $)$

\subsubsection{Results of the Second Model}

The stresses found in the model with these boundary conditions were lower than the stresses found in the first model. The model was more under compression than in tension. The maximum compressive stress was found in the electrolyte along the edge near the inlet of fuel and air channels. The maximum compressive stress found was $239 \mathrm{MPa}$ whereas the maximum tensile stress found was $135 \mathrm{MPa}$. The failure stress of the electrolyte material is around $235 \mathrm{MPa}$ which is close to the maximum principle stress found in the model. Therefore failure might not occur in the fuel cell model using these boundary constraints. 


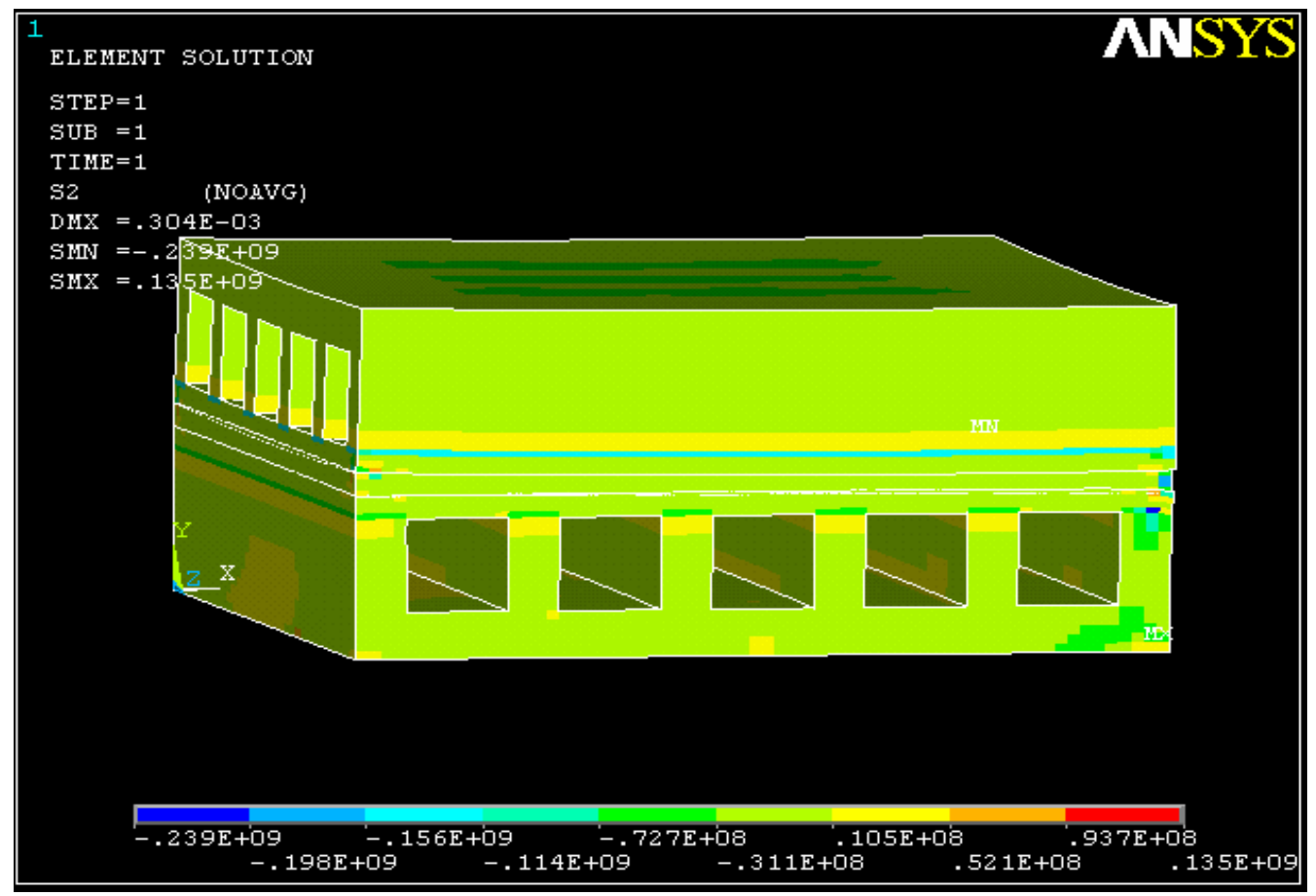

Figure 44: Maximum principle stress in the three-dimensional SOFC $\left(2^{\text {nd }}\right.$ model $)$

The maximum stresses found in the components of the three-dimensional model are given below.

\begin{tabular}{|c|c|c|c|c|}
\hline \multirow{2}{*}{ Material } & \multicolumn{2}{|c|}{$\begin{array}{c}\text { Failure Strength (MPa) } \\
\text { [25],[26] }\end{array}$} & \multicolumn{2}{c|}{$\begin{array}{c}\text { Calculated Stress } \\
\text { (MPa) }\end{array}$} \\
\cline { 2 - 5 } & Tensile & Compressive & Tensile & Compressive \\
\hline $\begin{array}{c}\text { Interconnect } \\
\text { (LaCrO3) }\end{array}$ & 73 & 186 & 34.31 & 63.45 \\
\hline $\begin{array}{c}\text { Anode } \\
\text { (Ni/YSZ) }\end{array}$ & 90 & 145 & 82.45 & 113.66 \\
\hline $\begin{array}{c}\text { Electrolyte } \\
\text { (YSZ) }\end{array}$ & 177 & 235 & 135 & 239 \\
\hline $\begin{array}{c}\text { Cathode } \\
\left(\text { LaMnO }_{3}\right)\end{array}$ & 140 & 175 & 76.82 & 91.7 \\
\hline
\end{tabular}

Table 9: Maximum stresses found in the three-dimensional model $\left(2^{\text {nd }}\right.$ model $)$ 
The principle stress of the three-dimensional model is compared with the steady state three-dimensional model by Jason LeMaster, 2004 [5].
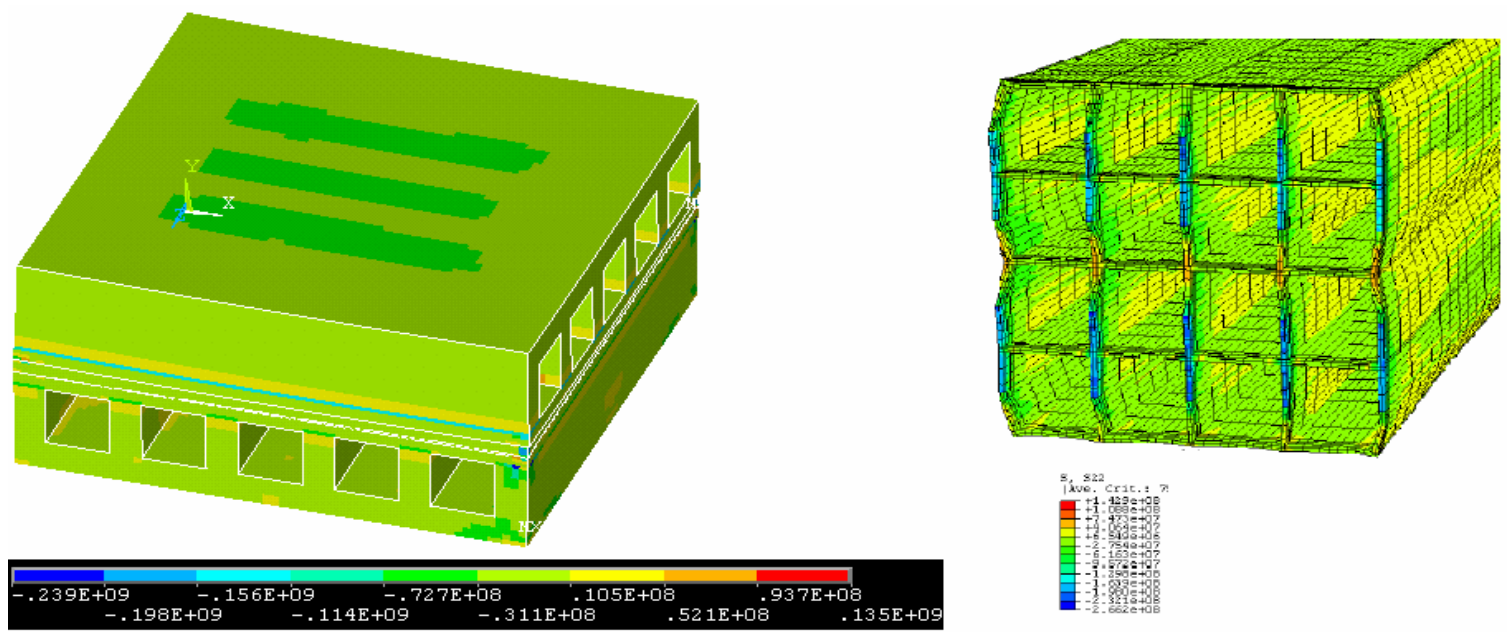

Figure 45: Comparison of the principle stresses with the model by Jason LeMaster, 2004 [5]

The maximum tensile stress found in the three-dimensional model is $135 \mathrm{MPa}$ whereas in the model by Georgia Institute of Technology the tensile stress is $142.9 \mathrm{MPa}$. And the maximum compressive stress in the present analysis was found to be $239 \mathrm{MPa}$ which is comparatively less than the model by Jason LeMaster, Georgia Institute of Technology, where the compressive stress found is $266.2 \mathrm{MPa}$. 


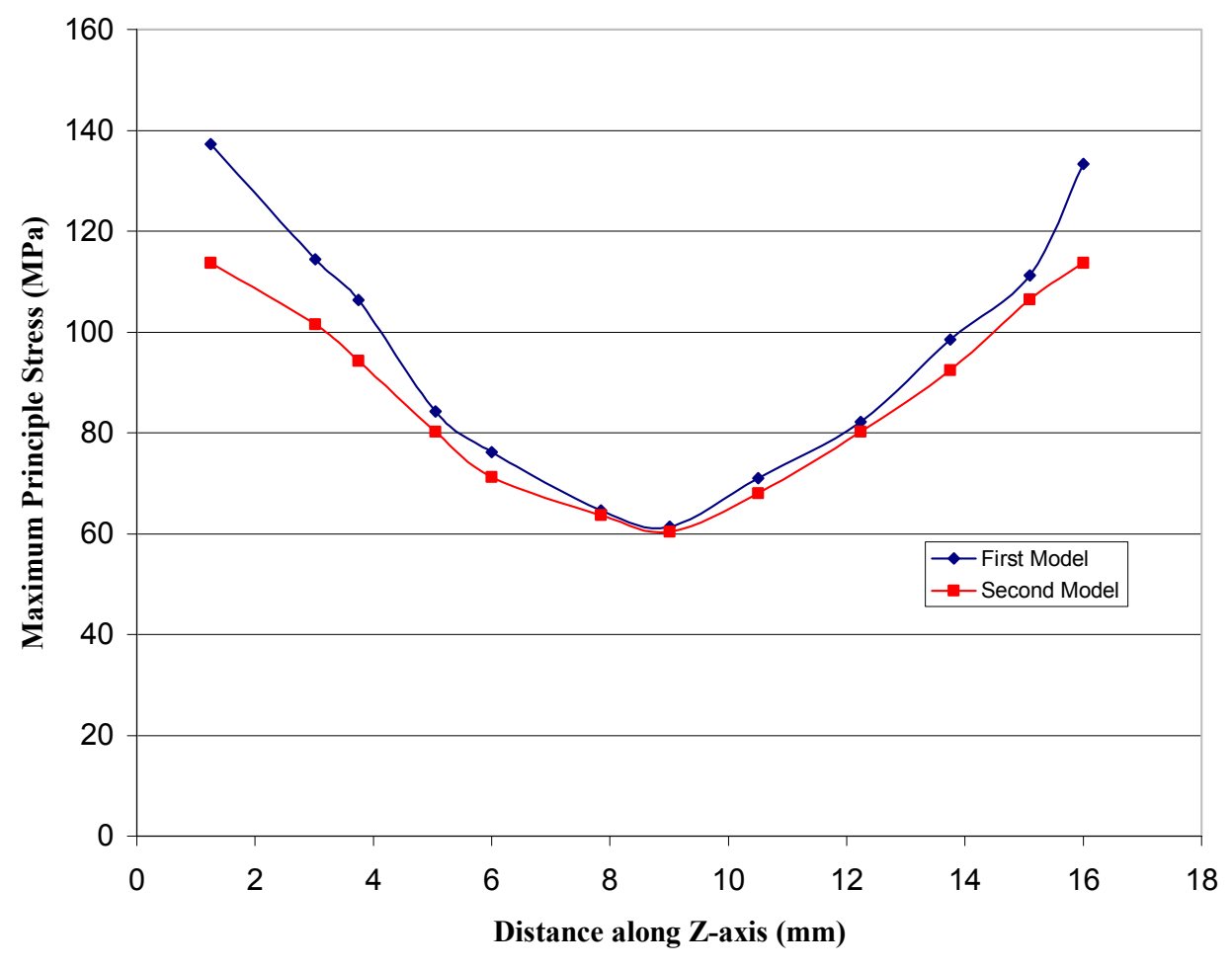

Figure 46: Maximum principle stresses in the Anode of the three-dimensional models

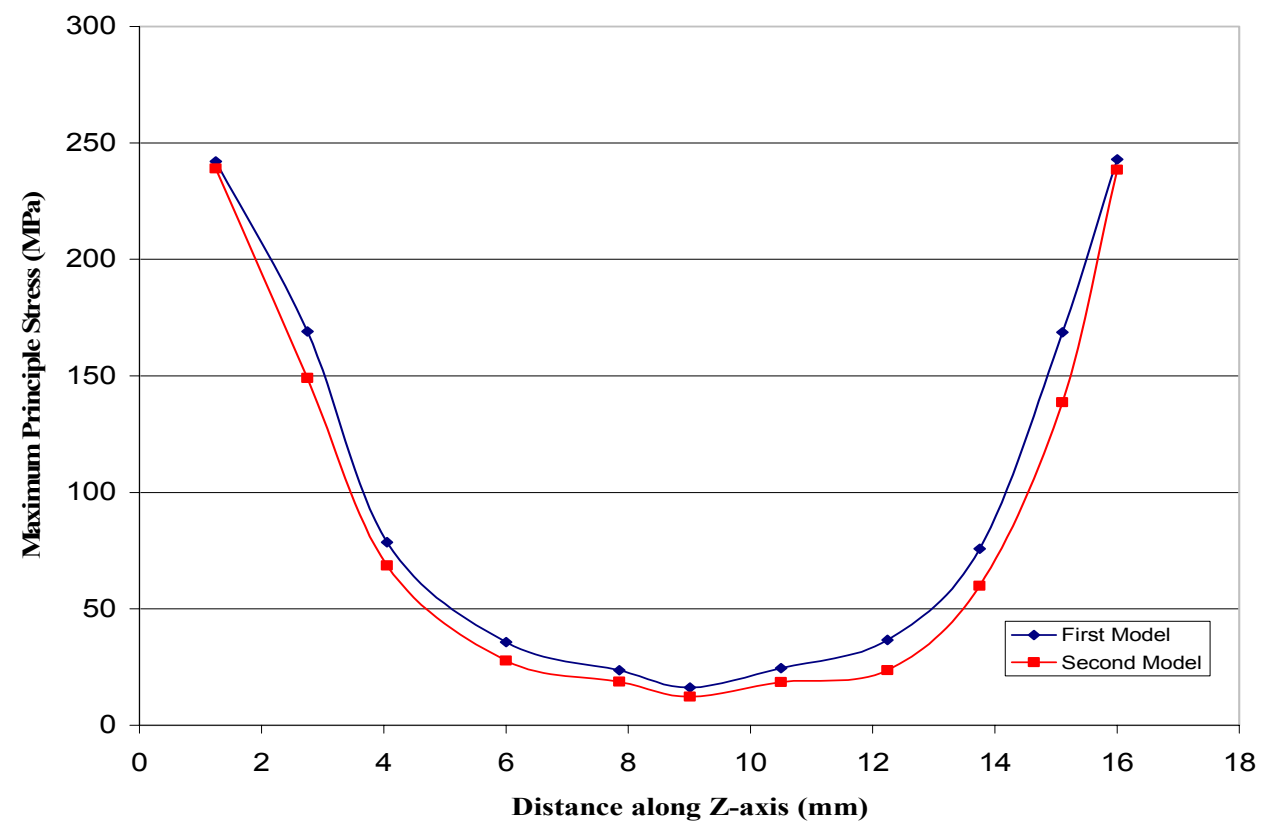

Figure 47: Maximum principle stresses in the Electrolyte of the three-dimensional models 


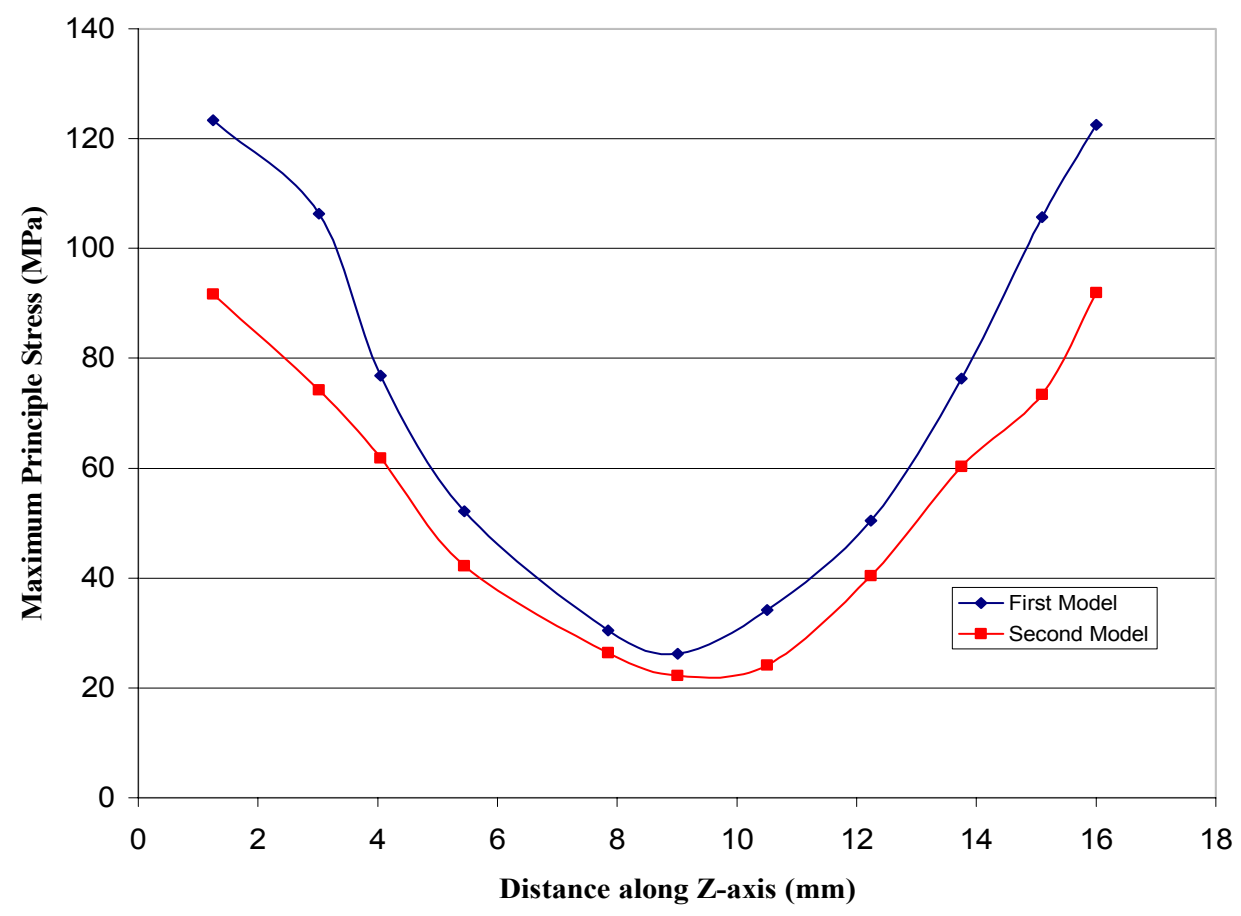

Figure 48: Maximum principle stresses in the Cathode of the three-dimensional models

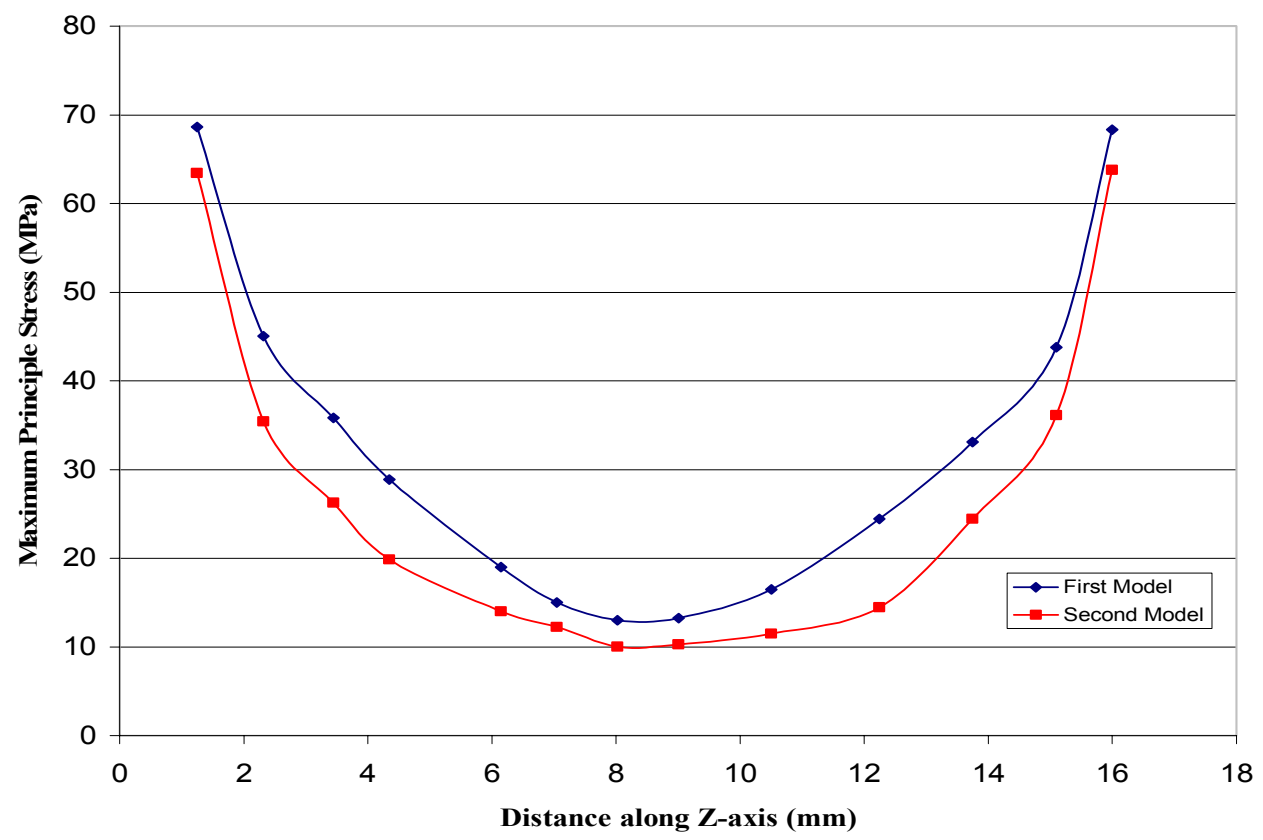

Figure 49: Maximum principle stresses in the Interconnect of the three-dimensional models 
From the above graphs, it can be inferred that maximum stress is found in the electrolyte. The principle stress of the electrolyte is very high when compared to the principle stresses in the other ceramics. The maximum stresses in the fuel cell increases from the center of the cell towards the edges. The stresses in the three-dimensional model arise at the joint of the PEN and the interconnect due to the mismatch in the thermal expansion coefficients of the components. 


\section{CHAPTER 6}

\section{CONCLUSIONS AND FUTURE WORK}

\subsection{Conclusions}

In this work, the thermal stress analysis of a two-dimensional five stack planar SOFC model and a single three-dimensional planar model has been performed using ANSYS ${ }^{\text {TM. }}$ The ultimate goal of this design is to determine the thermal stresses during operation of the solid oxide fuel cell models and identify the issues related to the failure of the models.

The stresses in the two-dimensional models remained below the failure stresses of the components of the fuel cell. The maximum stresses in the were found along the edges of the electrolyte at the inlet of gases, mainly due to the thermal expansion mismatch of the components and also since the displacement of the PEN and the interconnect is constrained at the joint of the two materials. The stresses found were large at the joint of the components and decay while approaching towards the center. Stresses were maximum at the inlet of fuel and air gases as largest temperature gradient occur at the inlet of gases. Whereas in the second model the stress distribution within the stack of each slice was more uniform from the bottom of the stack towards the top of the stack. The maximum principle stresses differed by $3 \mathrm{MPa}$ from the inlet of gases to the outlet of gases. The boundary constraints of second two-dimensional model are more realistic as a fuel cell stack is usually constrained only at the bottom and allowed to expand freely at the top of the stack. 
In the three-dimensional SOFC models, failure is predicted in the YSZ electrolyte of the first as the maximum principle stresses found in the component slightly exceed the failure strength. In the electrolyte, the maximum stress found at the edges of the component was substantially enough to lead to the failure of the model. These high stresses found in the components will cause the fuel and oxidizing gases to interact in an uncontrolled manner which will lead to the degradation in the efficiency of the fuel to electrical energy conversion and potentially in the failure of the whole system.

In the second three-dimensional model, the calculated stresses were below the failure stresses, therefore no failure is predicted. The maximum principle stresses in the second model were lower than that of the first model. The boundary constraints used in the second model are more realistic than the first model as a fuel cell is constrained only at the bottom and allowed to expand freely at the top of the cell. The second threedimensional model was compared with the model by Jason LeMaster, Georgia Institute of Technology and the maximum compressive stress found in the present work was less than the model by Georgia Institute of Technology. The components of the SOFC model in the present work are made of ceramic materials, whereas the model used by Georgia Institute of Technology has a metallic interconnect. Since the ceramic and metal have high variation of thermal expansion coefficients it could account for higher stresses. 


\subsection{Future Work}

In the present work, as a linear stress analysis is performed for both the two-dimensional and three-dimensional model the stresses are high. A non-linear analysis can be performed since an elastic- plastic model would give considerably lesser stresses.

The mechanical strength of the two-dimensional stack model and the single stack threedimensional model can be compared with experimental results. 


\section{REFERENCES}

1. C.S. Montross, H. Yokokawa and M. Dokiya (2002) "Thermal stresses in planar solid oxide fuel cells due to thermal expansion differences", British Ceramic Transactions, Vol 101, pp. 85-93.

2. Nguyen, Quang Minh (1995) "Science and technology of ceramic fuel cells". Elsevier Health Sciences.

3. Minh, Nguyen Q (1993) "Ceramic fuel cells", Journal of the American Ceramic Society, Vol. 76, pp. 563-588.

4. H. Yakabe, T. Ogiwara, M. Hishinuma, I. Yasuda (2001) "3-D model calculation for planar SOFC”, Journal of power sources, Vol. 102, pp. 144-154.

5. Jason LeMasters (2004) “Thermal Stress Analysis of LCA-Based Solid Oxide Fuel Cells", Georgia Institute of Technology.

6. Jianmin Qu (2003, July 31) "An Integrated Approach to Modeling and Mitigating SOFC Failure", NETL Conference Proceeding, Georgia Institute of Technology.

7. Thermal and Physical Properties of Materials for SOFC, PEFC (2004), http://unit.aist.go.jp/energy/fuelcells/english/database/thphy1.html.

8. Y. Lin and S.B. Baele "Numerical Simulation of the Performance of a Planar SolidOxide Fuel Cell Stack", National Research Council, Ottawa, Ontario.

9. Tanner, Cameron W., Virkar, Anil V., (2003) "A Simple Model for Interconnect Design of Planar Solid Oxide Fuel Cells", Journal of power sources, Vol. 113, pp. 44-56. 
10. Suryanarayana Raju Pakalapati (2003), “A Numerical Study of Current Distribution Inside the Cathode and Electrolyte of a Solid Oxide Fuel Cell', West Virginia University.

11. Ugur Pasaogullari and Chao-Yang Wang "Computational Fluid Dynamics Modeling of Solid Oxide Fuel Cells", Electrochemical Engine Center and Department of Mechanical and Nuclear Engineering, Pennsylvania State University.

12. A.C. Burt, I.B. Celik, R. S. Gemmen, A.V. Smirnov (2003) "Cell to Cell Performance Variation within a Stack", proceedings of Eighth International Symposium on Solid Oxide Fuel Cells, Paris, France, pp. 1487-1500.

13. A.C. Burt, I.B. Celik, R. S. Gemmen, A.V. Smirnov (2003) "Influence of Radiative Heat Transfer on Variation of Cell Voltage within a Stack", First International Conference on Fuel Cell Science, Engineering and Technology, Rochester, NY, 2003.

14. A.C. Burt, I.B. Celik, R. S. Gemmen, A.V. Smirnov and W.A. Rogers (2004) "Cellto-Cell Variations with Increasing SOFC Stack Size”, Second International Conference on Fuel Cell Science, Engineering and Technology.

15. A.C. Burt, I.B. Celik, R. S. Gemmen, A.V. Smirnov (2004) "A numerical study of cell-to-cell variations in a SOFC stack', Journal of Power Sources, Vol. 126, pp. 76-87.

16. Science at NASA, http://science.nasa.gov/headlines/y2003/18mar fuelcell.htm

17. Dr. Ismail Celik (2004) "Multi-dimensional modeling of solid oxide fuel cells", Mechanical and Aerospace Engineering, West Virginia University, Morgantown.

18. Sequentially Coupled Analysis, ANSYS ${ }^{\mathrm{TM}} 8.1$ Version. 
19. J. D. Carter, P. V. Hendriksen and M. Mogensen "Expansion on Reduction of Calcium Doped Lanthanum Chromite", Material Department, Riso National Laboratory, Denmark.

20. W. A. Meulenberg, S. Uhlenbruck, E. Wessel, H. P. Buchkrememer, D. Stover (2003) "Oxidation behaviour of ferrous alloys used as interconnecting material in solid oxide fuel cells", Journal of Materials Science, Vol. 38, pp. 507-513.

21. L. Meda, C. Bacaltchuk, H. Garmestani, K.H. Gahmen (2001) "Residual strain and texture in strontium-doped lanthanum manganite thin films", Journal of Material Science, Materials in Electronics, Vol. 12, pp. 143-146.

22. SECA Core Technology Program (2004) "Ceramic Interconnects/Coatings", SOFC Interconnection (IC) Technology Meeting, Argonne National Laboratory, Chicago IL.

23. Final Report to DOE NETL (2002) "Structural Limitations in the Scale-up of Anode Supported SOFCs", TIAX, LLC, Acorn Park, Cambridge, Massachusetts.

24. Andrei Fedorov, Comas Haynes, Jianmin Qu "An Intergrated Approach at Modeling and Mitigating SOFC Failure", Georgia Institute of Technology, National Energy Technology Laboratory.

25. Edgar Lara-Curzio and Miladin Radovic (2002) "Reliability \& Durability of Materials \& Components for Solid Oxide Fuel Cells", Metals \& Ceramics Division, Oak Ridge National Laboratory.

26. G. Qian, T. Nakamura, C. C. Berndt and S. H. Leigh (1997) "Tensile Toughness Test and High Temperature Fracture Analysis of Thermal Barrier Coatings", Elsevier Science Limited, Vol. 45, pp. 1767-1784. 
27. S. Bandopadhyay, N. Nagabhushana (2003) "Crack Growth Analysis of Solid Oxide Fuel cell Electrolyte", Office of Scientific and Technical Information, School of Mineral Engineering, University of Alaska, Fairbanks AK 99775.

28. San Ping Jiang, Siew Hwa Chan (2004) "A review of anode materials development in solid oxide fuel cells", Journal of Materials Science, Vol. 39, pp. 4405-4439.

29. Bent F., Sorensen, Soren Primdahl (1998) "Relationship between strength and failure mode of ceramic multilayers", Journal of Materials Science, Vol. 33, pp-5291-5300.

30. J. Hammer, S. Laney, F. Pettit \& G. Meier (2002) "Fundamental Studies of the Durability of Materials for Interconnects in Solid Oxide Fuel Cells", SECA Core Technology Program Review, University of Pittsburgh and Carnegie Mellon University.

31. K. Hilpert, W. J. Quadakkers and L. Singheiser (2003) "Interconnects", Handbook of Fuel Cells- Fundamentals, Technology and Applications, Vol. 4, pp.1037-1054.

32. S.C. Kung, T.L. Cable, T.A. Morris and E. A. Barringer (2000) "Performance of Metallic Interconnect in Solid-Oxide Fuel Cells", 2000 Fuel Cell Seminar, Portland, Oregon.

33. N. P. Brandon, D. Corcoran, D. Cummins, A. Duckett, K. El-Khoury, "Development of Metal Supported Solid Oxide Fuel Cells for Operation at 500-600 ${ }^{\circ}$ ", Journal of Materials Engineering and Performance, Vol. 13(3), pp. 253-256.

34. M. Mori, T. Yamamoto, H. Itoh, T. Watanabe (1997) "Compatibility of alkaline earth metal (Mg, Ca, Sr)-doped lanthanum chromites as separators in planar-type high temperature solid oxide fuel cells", Journal of Materials Science, Vol. 32, pp. 2423-2431. 
35. Willem Joseph Quadakker, Javier Piron-Abellan, Vladimir Schemet (2004) "Metallic Materials in Solid Oxide Fuel Cells", Materials Research, Vol. 7, pp. 203-208.

36. J. Ilasvsky, C. C. Brendt (1998) "Thermal expansion properties of metallic and cermet coatings", Surface and Coatings Technology, Vol. 102, pp. 19-24. 


\section{Appendix A}

Sequentially coupled analysis using ANSYSTM for two-dimensional SOFC

\begin{tabular}{|c|c|c|}
\hline \multicolumn{3}{|l|}{ /PREP7 } \\
\hline \multicolumn{3}{|c|}{ ET,1,PLANE77 } \\
\hline \multicolumn{3}{|c|}{$\mathrm{K}, 0,0,0$} \\
\hline \multicolumn{3}{|c|}{$\mathrm{K}, 0,0.001,0$} \\
\hline \multicolumn{3}{|c|}{$\mathrm{K},, 0,0.00175,0$} \\
\hline \multicolumn{3}{|c|}{$\mathrm{K}, 0.00555,0.00$} \\
\hline \multicolumn{3}{|c|}{$\mathrm{K},, 0.00555,0.001,0$} \\
\hline \multicolumn{3}{|c|}{$\mathrm{K},, 0.00555,0,0$} \\
\hline \multicolumn{3}{|c|}{$\mathrm{K}, 0.0041625,0,0$, } \\
\hline \multirow{3}{*}{\multicolumn{3}{|c|}{$\begin{array}{l}\mathrm{K}, 0.0041625,0.001,0, \\
\mathrm{~K}, 0.001387,0.001,0, \\
\mathrm{~K}, 0.001387,0,0,\end{array}$}} \\
\hline & & \\
\hline & & \\
\hline LSTR, & 1 & 2 \\
\hline LSTR, & 2 , & 3 \\
\hline LSTR, & 3 & 4 \\
\hline LSTR, & 4, & 5 \\
\hline LSTR, & 5 & 6 \\
\hline LSTR, & 6 , & 7 \\
\hline LSTR, & 7 & 8 \\
\hline LSTR, & 8 & 9 \\
\hline LSTR, & 9, & 10 \\
\hline LSTR, & 10, & 1 \\
\hline $\mathrm{K},-. .00$ & 0,0 & \\
\hline KDELE & 11 & \\
\hline $\mathrm{K}, 0,-.0$ & 1,0 & \\
\hline $\mathrm{K}, 0,-0$ & 0101 , & \\
\hline $\mathrm{K}, 0,-0$ & 01035 & \\
\hline $\mathrm{K}, 0.00$ & $55,-0$. & 01035,0 \\
\hline $\mathrm{K}, 0.00$ & $55,-0$. & 0101,0 \\
\hline $\mathrm{K}, 0.00$ & $55,-0$. & 01,0, \\
\hline LSTR, & 1 , & 11 \\
\hline LSTR, & 11 , & 12 \\
\hline LSTR, & 12 , & 13 \\
\hline LSTR, & 13 & 14 \\
\hline LSTR, & 14 & 15 \\
\hline LSTR, & 15 & 16 \\
\hline LSTR, & 16 , & 6 \\
\hline LSTR, & 6 & 1 \\
\hline LSTR, & 11 & 16 \\
\hline LSTR, & 12 & 15 \\
\hline $\mathrm{K}, 0,-0$ & 0475 , & \\
\hline $\mathrm{K}, 0.00$ & $387,-($ & 0475 \\
\hline $\mathrm{K}, 0.00$ & 387, & 003 \\
\hline
\end{tabular}


$\mathrm{K}, 0.001387,-0.00416,0$,

KDELE， 20

$\mathrm{K}, 0.00416,-0.00375,0$,

$\mathrm{K}, 0.00416,-0.00475,0$,

$\mathrm{K}, 0.00555,-0.00475,0$,

FLST,2,6,3,ORDE, 2

FITEM,2,17

FITEM,2,-22

KDELE,P51X

$\mathrm{K},, 0,-0.0061,0$,

$\mathrm{K}, 0.01387,-0.0061,0$,

KDELE, 18

$\mathrm{K}, 0.001387,-0.0061,0$,

$\mathrm{K}, 0.001387,-0.0051,0$,

$\mathrm{K}, 0.00416,-0.0051,0$,

$\mathrm{K},, 0.00416,-0.0061,0$,

$\mathrm{K}, 0.00555,-0.0061,0$,

$\mathrm{K}, 0.00416,-0.00435,0$,

$\mathrm{K},, 0.001387,-0.00435,0$,

$\mathrm{K}, 0.001387,-0.00135,0$,

FLST,2,9,3,ORDE, 2

FITEM,2,17

FITEM,2,-25

KDELE,P51X

$\mathrm{K}, 0,-0.005785,0$,

KDELE, 17

$\mathrm{K}, 0.01387,-.001035,0$,

KDELE, 17

$\mathrm{K},, 0.001387,-0.001035,0$,

$\mathrm{K},, 0.001387,-0.004035,0$,

$\mathrm{K}, 0.00416,-0.004035,0$,

$\mathrm{K},, 0.00416,-0.001035,0$,

$\mathrm{K}, 0,-0.005785,0$,

$\mathrm{K},, 0.001387,-0.005785,0$,

$\mathrm{K},, 0.001387,-0.004785,0$,

$\mathrm{K}, 0.00416,-0.004785,0$,

$\mathrm{K}, 0.00416,-0.005785,0$,

$\mathrm{K}, 0.00555,-0.005785,0$,

LSTR, 13, 21

LSTR, 21, 22

LSTR, 22, 23

LSTR, 23, 24

LSTR, 24, 25

LSTR, 25, 26

LSTR, 26, 14

LSTR, 14, 20

LSTR, 20, 19 


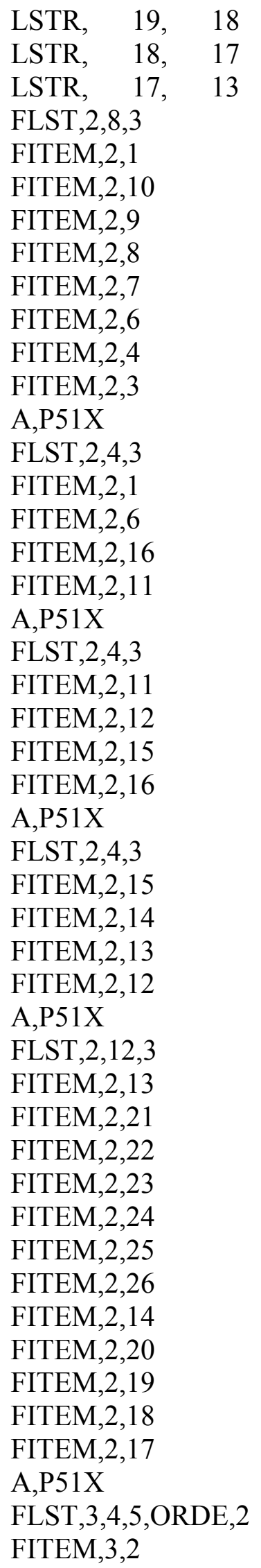


FITEM,3,-5

AGEN,5,P51X, , , ,-.005785, , ,0

FLST,2,4,3,ORDE,4

FITEM,2,89

FITEM,2,-90

FITEM,2,93

FITEM,2,-94

KDELE,P51X

ADELE, 21

FLST,2,4,3,ORDE,4

FITEM,2,89

FITEM,2,-90

FITEM,2,93

FITEM,2,-94

KDELE,P51X

FLST,2,4,4,ORDE,4

FITEM,2,112

FITEM,2,-113

FITEM,2,115

FITEM,2,-116

LDELE,P51X

FLST,2,6,3,ORDE,2

FITEM,2,89

FITEM,2,-94

KDELE,P51X

FLST,2,2,4,ORDE,2

FITEM,2,111

FITEM,2,117

LDELE,P51X, , ,1

K, ,0.001387,-0.027925,0,

KDELE, 91

KDELE, 89

$\mathrm{K}, 0,-0.027925,0$,

$\mathrm{K}, 0.00555,-0.027925,0$,

LSTR, 88, 89

LSTR， 89， 91

LSTR, 91, 97

LSTR, 97， 91

LSTR， 97， 96

LSTR, 96, 92

LSTR， 92， 90

LSTR, 90, 87

FLST,2,2,4,ORDE,2

FITEM,2,113

FITEM,2,115

LDELE,P51X

FLST,2,8,3 
FITEM,2,88

FITEM,2,89

FITEM,2,90

FITEM,2,87

FITEM,2,95

FITEM,2,96

FITEM,2,97

FITEM,2,98

A,P51X

/PREP7

FLST,2, 121,4,ORDE,4

FITEM,2,1

FITEM,2,-114

FITEM,2,116

FITEM,2,-122

LOVLAP,P51X

FLST,2,21,5,ORDE,2

FITEM,2,1

FITEM,2,-21

AGLUE,P51X

FLST,2,3,4,ORDE,3

FITEM,2,6

FITEM,2, 10

FITEM,2,115

LGLUE,P51X

FLST,2,3,4,ORDE,3

FITEM,2,22

FITEM,2,26

FITEM,2,125

LGLUE,P51X

FLST,2,3,4,ORDE,3

FITEM,2,46

FITEM,2,50

FITEM,2,128

LGLUE,P51X

FLST,2,3,4,ORDE,3

FITEM,2,68

FITEM,2,72

FITEM,2,132

LGLUE,P51X

FLST,2,3,4,ORDE,3

FITEM,2,96

FITEM,2,100

FITEM,2,138

LGLUE,P51X

FLST,2,3,4,ORDE,3

FITEM,2,90 


FITEM,2,94
FITEM,2,136
LGLUE,P51X
FLST,2,3,4,ORDE,3
FITEM,2,112
FITEM,2,114
FITEM,2,116
LGLUE,P51X
FLST,2,6,4,ORDE,6
FITEM,2,19
FITEM,2,-20
FITEM,2,28
FITEM,2,-29
FITEM,2,32
FITEM,2,123
LGLUE,P51X
FLST,2,5,4,ORDE,5
FITEM,2,37
FITEM,2,40
FITEM,2,52
FITEM,2,56
FITEM,2,130
LGLUE,P51X
FLST,2,5,4,ORDE,5
FITEM,2,59
FITEM,2,62
FITEM,2,74
FITEM,2,78
FITEM,2,134
LGLUE,P51X
FLST,2,5,4,ORDE,5
FITEM,2,81
FITEM,2,84
FITEM,2,96
FITEM,2,100
FITEM,2,138
LGLUE,P51X
FLST,2,5,4,ORDE,5
FITEM,2,103
FITEM,2,106
FITEM,2,118
FITEM,2,122
FITEM,2,139
LGLUE,P51X
MPTEMP,,,,,,
MPTEMP,1,0
MPDATA,KXX,1,,6




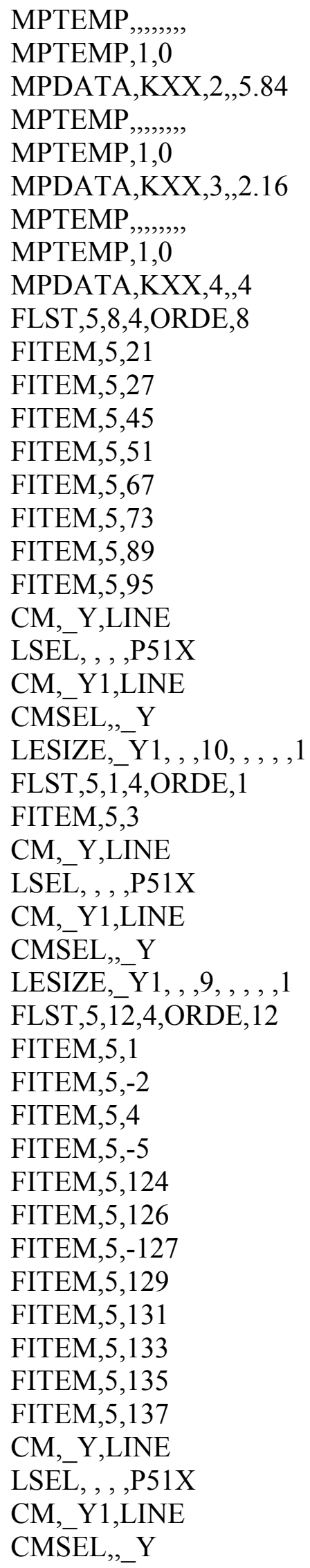




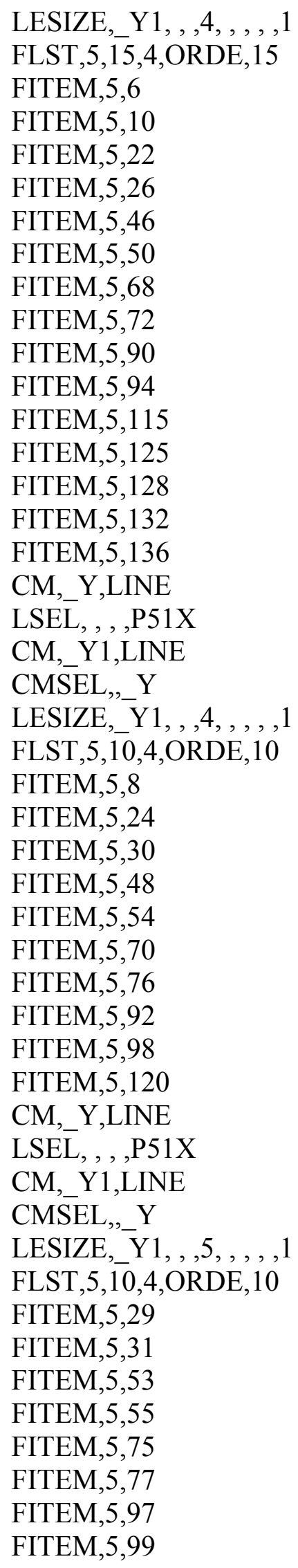


FITEM,5,119

FITEM,5,121

CM,_Y,LINE

LSEL, , , P51X

CM,_Y1,LINE

CMSEL,,YY

LESIZE,_Y1, , ,6, , , , ,1

FLST, 5,2,4,ORDE,2

FITEM,5,111

FITEM,5,117

CM,_Y,LINE

LSEL, , , P51X

CM,_Y1,LINE

CMSEL,,YY

LESIZE,_Y1, , , , , , , ,1

FLST, 5, 1,4,ORDE, 1

FITEM,5,113

CM, Y,LINE

LSEL, , , ,P51X

CM,_Y1,LINE

CMSEL,,YY

LESIZE, Y1, , ,10, , , , ,1

FLST,5,8,4,ORDE,8

FITEM,5,23

FITEM,5,25

FITEM,5,47

FITEM,5,49

FITEM,5,69

FITEM,5,71

FITEM,5,91

FITEM,5,93

CM,_Y,LINE

LSEL, , ,P51X

CM,_Y1,LINE

CMSEL,,Y

LESIZE,_Y1, , 3, , , , ,1

FLST,5,2,4,ORDE,2

FITEM,5,7

FITEM,5,9

CM,_Y,LINE

LSEL, , , ,P51X

CM,_Y1,LINE

CMSEL,, Y

LESIZE,_Y1, , 3, , , , ,1

FLST,5,10,4,ORDE, 10

FITEM,5,19

FITEM,5,-20 
FITEM,5,37

FITEM,5,40

FITEM,5,59

FITEM,5,62

FITEM,5,81

FITEM,5,84

FITEM,5,103

FITEM,5,106

CM,_Y,LINE

LSEL, , , ,P51X

CM,_Y1,LINE

CMSEL,,Y

LESIZE,_YY1, , ,10, , , , ,1

FLST,5,15,4,ORDE, 15

FITEM,5,20

FITEM,5,32

FITEM,5,52

FITEM,5,56

FITEM,5,74

FITEM,5,78

FITEM,5,96

FITEM,5,100

FITEM,5,118

FITEM,5, 122

FITEM,5,-123

FITEM,5,130

FITEM,5,134

FITEM,5,138

FITEM,5,-139

CM,_Y,LINE

LSEL, , , ,P51X

CM,_Y1,LINE

CMSEL, Y Y

LESIZE,_Y1, , ,6, , , , ,1

FLST,5,1,4,ORDE, 1

FITEM,5,28

CM,_Y,LINE

LSEL, , ,P51X

CM,_Y1,LINE

CMSEL,,Y

LESIZE,_Y1, , ,6, , , , ,1

FLST,5,1,4,ORDE,1

FITEM,5,33

CM,_Y,LINE

LSEL, , ,P51X

CM,_Y1,LINE

CMSEL,,YY 


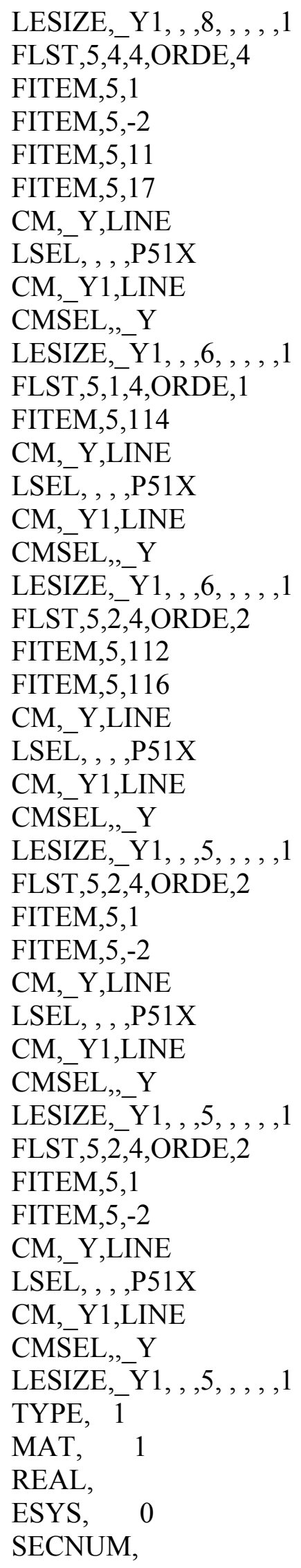




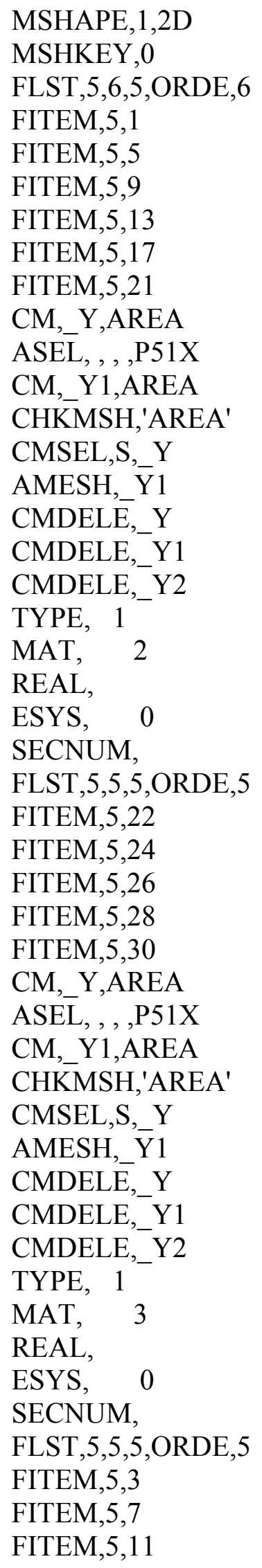


FITEM,5,15

FITEM,5,19

CM, Y,AREA

ASEL, , , P51X

CM,_Y1,AREA

CHKMSH,'AREA'

CMSEL,S,_Y

AMESH, Y 1

CMDELE, Y

CMDELE, Y1

CMDELE,_Y2

TYPE, 1

MAT, 4

REAL,

ESYS, 0

SECNUM,

FLST, 5,5,5,ORDE,5

FITEM,5,23

FITEM,5,25

FITEM,5,27

FITEM,5,29

FITEM,5,31

CM,_Y,AREA

ASEL, , , P51X

CM,_Y1,AREA

CHKMSH,'AREA'

CMSEL,S,_Y

AMESH, Y 1

CMDELE,_Y

CMDELE,_Y1

CMDELE,_Y2

FLST,2,2,1,ORDE,2

FITEM,2, 10

FITEM,2,16

/GO

D,P51X, ,1203, , , TEMP, , , , ,

FLST, 2, 1,1,ORDE,1

FITEM,2,2146

$/ \mathrm{GO}$

D,P51X, ,1205.01, , , ,TEMP , , , ,

FLST,2,2,1,ORDE,2

FITEM,2,611

FITEM,2,-612

$/ \mathrm{GO}$

D,P51X, ,1202, , , TEMP, , , , ,

FLST,2, 1,1,ORDE,1

FITEM,2,2282 


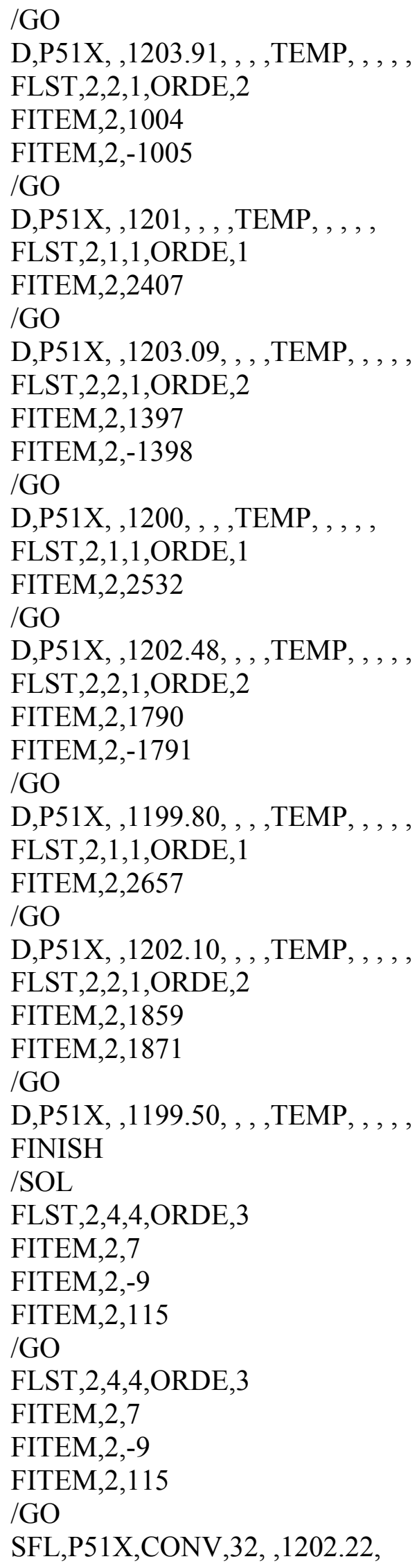


FLST, 2,4,4,ORDE,3

FITEM,2,29

FITEM,2,-31

FITEM,2,123

/GO

SFL,P51X,CONV,224, ,1179.68, FLST, 2,4,4,ORDE,3

FITEM,2,23

FITEM,2,-25

FITEM,2,125

/GO

SFL,P51X,CONV,32, ,1201.08, FLST, 2,4,4,ORDE,3

FITEM,2,53

FITEM,2,-55

FITEM,2,130

/GO

SFL,P51X,CONV,224, ,1179.45, FLST, 2,4,4,ORDE,3

FITEM,2,47

FITEM,2,-49

FITEM,2,128

/GO

SFL,P51X,CONV,244, , 1200.24, FLST, 2,4,4,ORDE,3

FITEM,2,75

FITEM,2,-77

FITEM,2,134

/GO

SFL,P51X,CONV,32, ,1199.61,

FLST, 2,4,4,ORDE,3

FITEM,2,97

FITEM,2,-99

FITEM,2,138

/GO

SFL,P51X,CONV,224, ,1179.15, FLST, 2,4,4,ORDE,3

FITEM,2,91

FITEM,2,-93

FITEM,2,136

/GO

SFL,P51X,CONV,32, ,1199.17, FLST, 2,4,4,ORDE,3

FITEM,2,119

FITEM,2,-121

FITEM,2,139

/GO 
SFL,P51X,CONV,224, ,1179.09,

FLST,2,4,4,ORDE,3

FITEM,2,75

FITEM,2,-77

FITEM,2,134

/GO

SFL,P51X,CONV,224, ,1179.28,

FLST,2,4,4,ORDE,3

FITEM,2,69

FITEM,2,-71

FITEM,2,132

$/ \mathrm{GO}$

SFL,P51X,CONV,32, ,1199.61,

FINISH

/SOL

SOLVE

FINISH

/PREP7

ETCHG,TTS

MPTEMP,,,,,,,

MPTEMP, 1,0

MPDATA,EX,1,,60e9

MPDATA,PRXY, $1, .22$

MPTEMP,,,,,,,

MPTEMP, 1,0

MPDATA,EX,2,,96e9

MPDATA,PRXY,2,.22

MPTEMP,

MPTEMP, 1,0

MPDATA,EX,3,200e9

MPDATA,PRXY,3,.22

MPTEMP,,,,,,,

MPTEMP, 1,0

MPDATA,EX,4,96.71e9

MPDATA,PRXY,4,..22

MPTEMP,,,,,,,,

MPTEMP, 1,0

UIMP,1,REFT, ,

MPDATA,ALPX,1,8.56e-6

MPTEMP,,,,,,,

MPTEMP $, 1,0$

UIMP, 2,REFT, ,

MPDATA,ALPX,2,,11e-6

MPTEMP,,,,,,,

MPTEMP, 1,0

UIMP,3,REFT, ,

MPDATA,ALPX,3,10.5e-6 


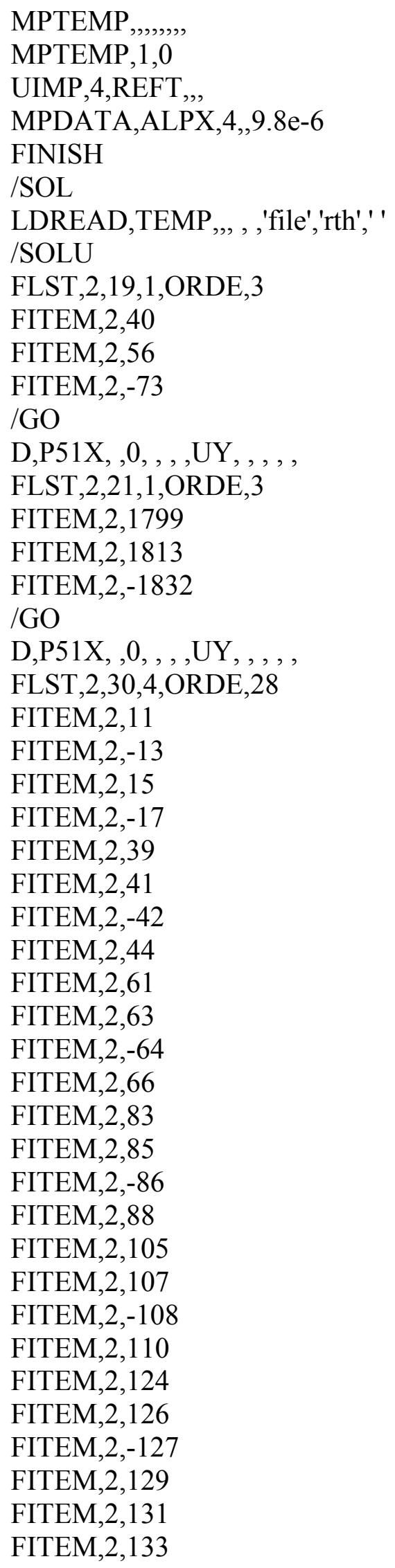


FITEM,2,135

FITEM,2,137

/GO

DL,P51X, ,UY,0

SOLVE

FINISH 


\section{Appendix B}

Temperature output from MATLAB used in ANSYS ${ }^{\text {TM }}$ for three-dimensional analysis

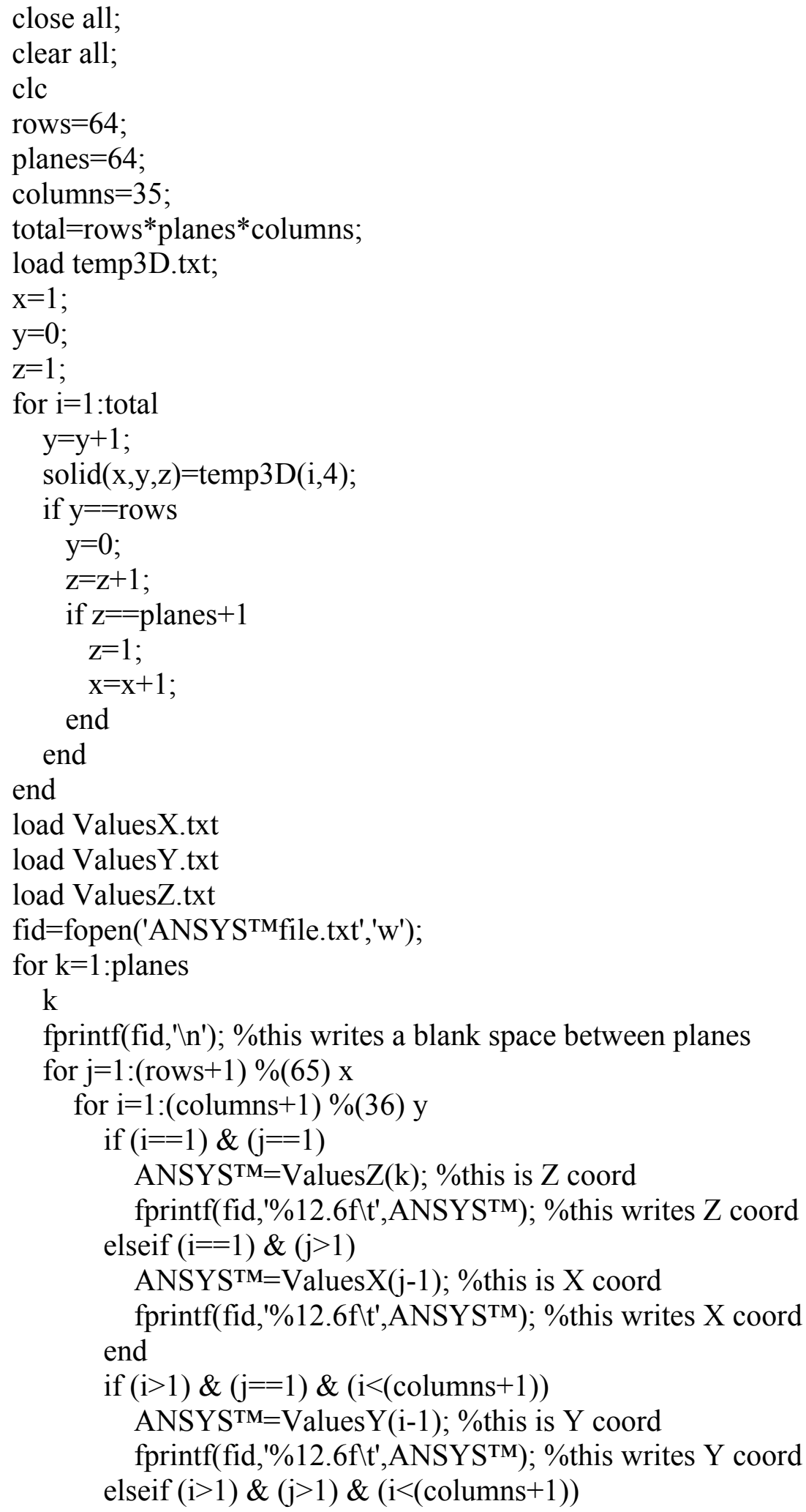




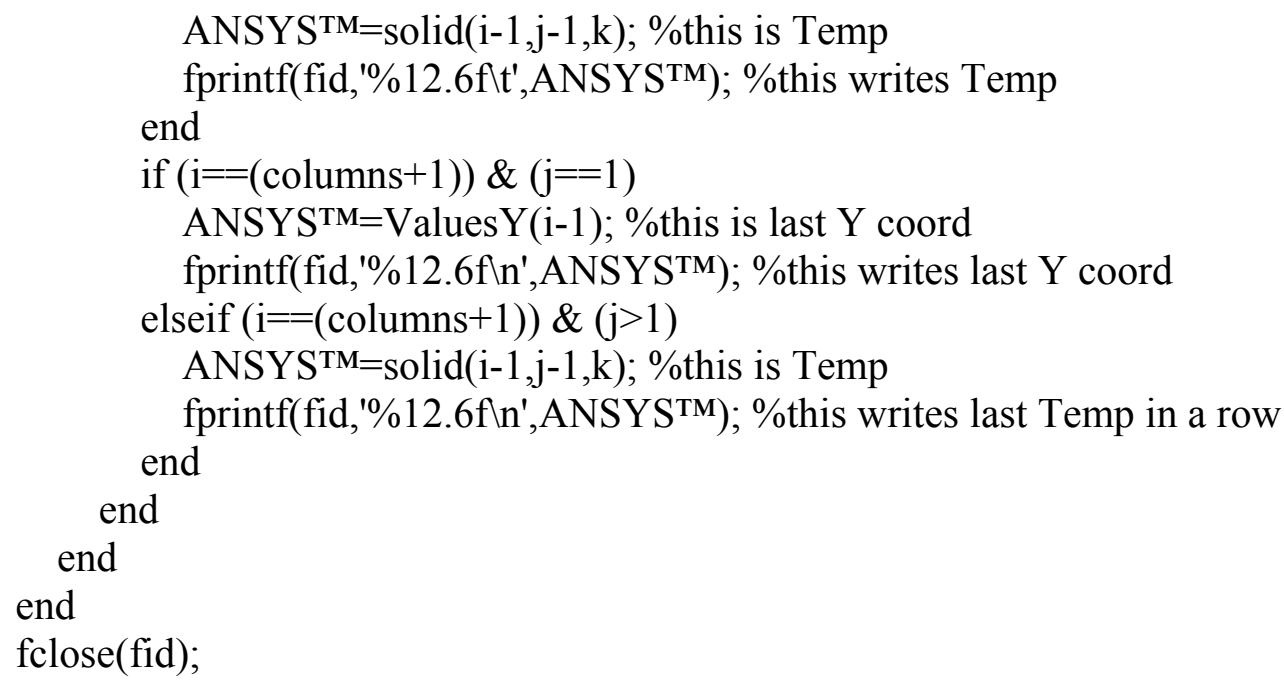




\section{Appendix $\mathrm{C}$}

Structural Analysis of three-dimensional SOFC using ANSYSTM

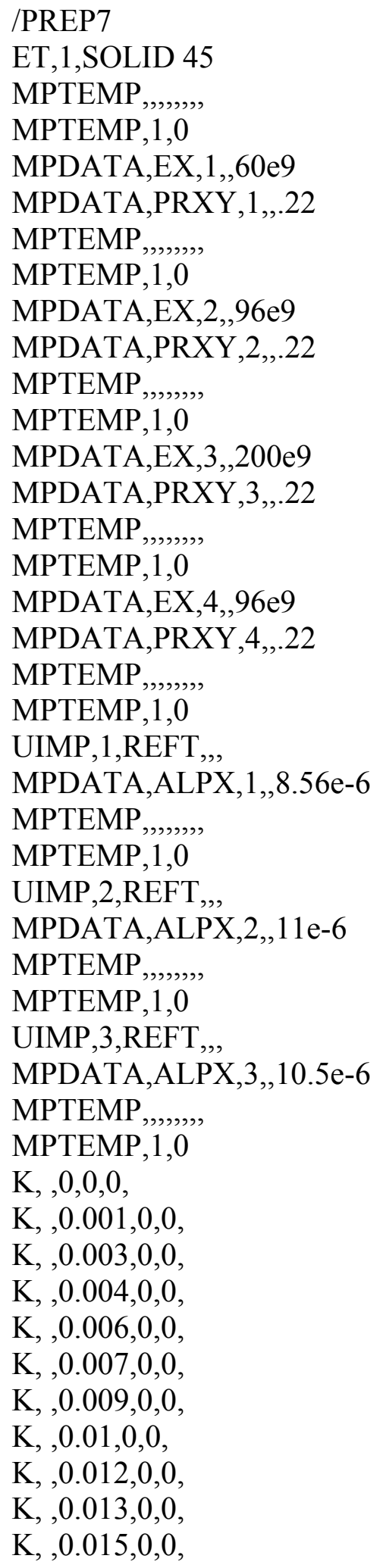


$\mathrm{K}, 0.016,0,0$,

$\mathrm{K}, 0.016,0.001,0$,

$\mathrm{K}, 0.015,0.001,0$,

$\mathrm{K}, 0.013,0.001,0$,

$\mathrm{K}, 0.012,0.001,0$,

$\mathrm{K}, 0.01,0.001,0$,

$\mathrm{K}, 0.009,0.001,0$,

$\mathrm{K}, 0.007,0.001,0$,

$\mathrm{K}, 0.006,0.001,0$,

$\mathrm{K}, 0.004,0.001,0$,

$\mathrm{K}, 0.003,0.001,0$,

$\mathrm{K}, 0.001,0.001,0$,

$\mathrm{K}, 0,0.001,0$,

$\mathrm{K}, 0,0.003,0$,

$\mathrm{K}, 0.001,0.003,0$,

$\mathrm{K}, 0.003,0.003,0$,

$\mathrm{K}, 0.004,0.003,0$,

$\mathrm{K}, 0.006,0.003,0$,

$\mathrm{K},, 0.007,0.003,0$,

$\mathrm{K}, 0.009,0.003,0$,

$\mathrm{K}, 0.01,0.003,0$,

$\mathrm{K}, 0.012,0.003,0$,

$\mathrm{K},, 0.013,0.003,0$,

$\mathrm{K}, 0.015,0.003,0$,

$\mathrm{K}, 0.016,0.003,0$,

$\mathrm{K},, 0.016,0.0035,0$,

$\mathrm{K}, 0.015,0.0035,0$,

$\mathrm{K}, 0.013,0.0035,0$,

$\mathrm{K},, 0.010,0.0035,0$,

$\mathrm{K},, 0.012,0.0035,0$,

$\mathrm{K}, 0.009,0.0035,0$,

$\mathrm{K},, 0.007,0.0035,0$,

$\mathrm{K}, 0.006,0.0035,0$,

$\mathrm{K},, 0.004,0.0035,0$,

$\mathrm{K},, 0.003,0.0035,0$,

$\mathrm{K}, 0.001,0.0035,0$,

$\mathrm{K}, 0.000,0.0035,0$,

FLST, 2,4,3

FITEM,2,24

FITEM,2,23

FITEM,2,2

FITEM,2,1

A,P51X

FLST, 2,4,3

FITEM,2,23

FITEM,2,22

FITEM,2,3 
FITEM,2,2

A,P51X

FLST,2,4,3

FITEM,2,22

FITEM,2,21

FITEM,2,4

FITEM,2,3

A,P51X

FLST,2,4,3

FITEM,2,21

FITEM,2,20

FITEM,2,5

FITEM,2,4

A,P51X

FLST, 2,4,3

FITEM,2,20

FITEM,2,19

FITEM,2,6

FITEM,2,5

A,P51X

FLST,2,4,3

FITEM,2,19

FITEM,2, 18

FITEM,2,7

FITEM,2,6

A,P51X

FLST,2,4,3

FITEM,2, 18

FITEM,2,17

FITEM,2,8

FITEM,2,7

A,P51X

FLST,2,4,3

FITEM,2, 17

FITEM,2, 16

FITEM,2,9

FITEM,2,8

A,P51X

FLST, 2,4,3

FITEM,2,16

FITEM,2,15

FITEM,2, 10

FITEM,2,9

A,P51X

FLST,2,4,3

FITEM,2, 15

FITEM,2,14 
FITEM,2,11

FITEM,2,10

A,P51X

FLST, 2,4,3

FITEM,2,14

FITEM,2,13

FITEM,2, 12

FITEM,2,11

A,P51X

FLST, 2,4,3

FITEM,2,35

FITEM,2, 14

FITEM,2, 13

FITEM,2,36

A,P51X

FLST,2,4,3

FITEM,2,38

FITEM,2,35

FITEM,2,36

FITEM,2,37

A,P51X

FLST,2,4,3

FITEM,2,41

FITEM,2,33

FITEM,2,34

FITEM,2,39

A,P51X

FLST,2,4,3

FITEM,2,39

FITEM,2,38

FITEM,2,35

FITEM,2,34

A,P51X

FLST, 2,4,3

FITEM,2,33

FITEM,2,16

FITEM,2,15

FITEM,2,34

A,P51X

FLST, 2,4,3

FITEM,2,40

FITEM,2,41

FITEM,2,33

FITEM,2,32

A,P51X

FLST, 2,4,3

FITEM,2,42 
FITEM,2,40

FITEM,2,32

FITEM,2,31

A,P51X

FLST,2,4,3

FITEM,2,31

FITEM,2,32

FITEM,2, 17

FITEM,2,18

A,P51X

FLST,2,4,3

FITEM,2,44

FITEM,2,43

FITEM,2,30

FITEM,2,29

A,P51X

FLST, 2,4,3

FITEM,2,43

FITEM,2,42

FITEM,2,31

FITEM,2,30

A,P51X

FLST,2,4,3

FITEM,2,29

FITEM,2,30

FITEM,2,19

FITEM,2,20

A,P51X

FLST,2,4,3

FITEM,2,45

FITEM,2,44

FITEM,2,29

FITEM,2,28

A,P51X

FLST,2,4,3

FITEM,2,46

FITEM,2,45

FITEM,2,28

FITEM,2,27

A,P51X

FLST,2,4,3

FITEM,2,27

FITEM,2,28

FITEM,2,21

FITEM,2,22

A,P51X

FLST,2,4,3 
FITEM,2,47

FITEM,2,46

FITEM,2,27

FITEM,2,26

A,P51X

FLST, 2,4,3

FITEM,2,26

FITEM,2,23

FITEM,2,24

FITEM,2,25

A,P51X

FLST, 2,4,3

FITEM,2,47

FITEM,2,26

FITEM,2,25

FITEM,2,48

A,P51X

FLST, 2, 28,5,ORDE,2

FITEM,2,1

FITEM,2,-28

VEXT,P51X, , ,0,0,0.016,,,

$\mathrm{K}, 0,0.004,0$,

$\mathrm{K}, 0,0.004,0.001$,

$\mathrm{K}, 0,0.004,0.003$,

$\mathrm{K}, 0,0.004,0.004$,

$\mathrm{K}, 0,0.004,0.006$,

$\mathrm{K}, 0,0.004,0.007$,

$\mathrm{K}, 0,0.004,0.009$,

$\mathrm{K},, 0,0.004,0.01$,

$\mathrm{K}, 0,0.004,0.012$,

$\mathrm{K}, 0,0.004,0.013$,

$\mathrm{K}, 0,0.004,0.015$,

$\mathrm{K}, 0,0.004,0.016$,

$\mathrm{K}, 0,0.0045,0.016$,

$\mathrm{K}, 0,0.0045,0.015$,

$\mathrm{K}, 0,0.0045,0.013$,

$\mathrm{K},, 0,0.0045,0.012$,

$\mathrm{K}, 0,0.0045,0.010$,

$\mathrm{K}$, , 0,0.0045,0.009,

$\mathrm{K}, 0,0.0045,0.007$,

$\mathrm{K}$, , 0,0.0045,0.006,

$\mathrm{K},, 0,0.0045,0.004$,

$\mathrm{K},, 0,0.0045,0.003$,

$\mathrm{K}, 0,0.0045,0.001$,

$\mathrm{K}, 0,0.0045,0.000$,

$\mathrm{K}, 0,0.0065,0$,

$\mathrm{K},, 0,0.0065,0.001$, 
$\mathrm{K}$, ,0,0.0065,0.003,

$\mathrm{K},, 0,0.0065,0.004$,

$\mathrm{K},, 0,0.0065,0.006$,

$\mathrm{K},, 0,0.0065,0.007$,

$\mathrm{K}$, ,0,0.0065,0.009,

$\mathrm{K}, 0,0.0065,0.01$,

$\mathrm{K},, 0,0.0065,0.012$,

$\mathrm{K}, 0,0.0065,0.013$,

$\mathrm{K},, 0,0.0065,0.015$,

$\mathrm{K},, 0,0.0065,0.016$,

$\mathrm{K},, 0,0.0075,0.016$,

$\mathrm{K}, 0,0.0075,0.015$,

$\mathrm{K},, 0,0.0075,0.013$,

$\mathrm{K},, 0,0.0075,0.012$,

$\mathrm{K},, 0,0.0075,0.010$,

$\mathrm{K},, 0,0.0075,0.009$,

$\mathrm{K}, 0,0.0075,0.007$,

$\mathrm{K},, 0,0.0075,0.006$,

$\mathrm{K},, 0,0.0075,0.004$,

$\mathrm{K},, 0,0.0075,0.003$,

$\mathrm{K},, 0,0.0075,0.001$,

$\mathrm{K}, 0,0.0075,0.000$, /PREP7

FLST, 2,4,3

FITEM,2,144

FITEM,2,143

FITEM,2,122

FITEM,2,121

A,P51X

FLST, 2,4,3

FITEM,2,143

FITEM,2,142

FITEM,2,123

FITEM,2,122

A,P51X

FLST,2,4,3

FITEM,2,142

FITEM,2,141

FITEM,2,124

FITEM,2,123

A,P51X

FLST,2,4,3

FITEM,2,141

FITEM,2, 140

FITEM,2, 125

FITEM,2,124

A,P51X 
FLST, 2,4,3

FITEM,2,140

FITEM,2,139

FITEM,2,126

FITEM,2,125

A,P51X

FLST,2,4,3

FITEM,2,139

FITEM,2,138

FITEM,2,127

FITEM,2,126

A,P51X

FLST, 2,4,3

FITEM,2,138

FITEM,2,137

FITEM,2,128

FITEM,2,127

A,P51X

FLST,2,4,3

FITEM,2,137

FITEM,2,136

FITEM,2,129

FITEM,2,128

A,P51X

FLST,2,4,3

FITEM,2, 136

FITEM,2,135

FITEM,2,130

FITEM,2,129

A,P51X

FLST,2,4,3

FITEM,2,135

FITEM,2,134

FITEM,2,131

FITEM,2,130

A,P51X

FLST,2,4,3

FITEM,2,133

FITEM,2,132

FITEM,2,131

FITEM,2,134

A,P51X

FLST, 2,4,3

FITEM,2, 121

FITEM,2,120

FITEM,2,119

FITEM,2,122 

A,P51X
FLST,2,4,3
FITEM,2,123
FITEM,2,118
FITEM,2,117
FITEM,2,124
A,P51X
FLST,2,4,3
FITEM,2,125
FITEM,2,116
FITEM,2,115
FITEM,2,126
A,P51X
FLST,2,4,3
FITEM,2,127
FITEM,2,114
FITEM,2,113
FITEM,2,128
A,P51X
FLST, 2,4,3
FITEM,2,129
FITEM,2,112
FITEM,2,111
FITEM,2,130
A,P51X
FLST, 2,4,3
FITEM,2,131
FITEM,2,110
FITEM,2,109
FITEM,2,132
A,P51X
FLST,2,4,3
FITEM,2, 120
FITEM,2,97
FITEM,2,98
FITEM,2,119
A,P51X
FLST, 2,4,3
FITEM,2,119
FITEM,2,118
FITEM,2,99
FITEM,2,98
A,P51X
FLST, 2,4,3
FITEM,2,118
FITEM,2,117
FITEM,2,100 
FITEM,2,99

A,P51X

FLST,2,4,3

FITEM,2,117

FITEM,2,116

FITEM,2,101

FITEM,2,100

A,P51X

FLST,2,4,3

FITEM,2,116

FITEM,2,115

FITEM,2,102

FITEM,2,101

A,P51X

FLST, 2,4,3

FITEM,2,115

FITEM,2,114

FITEM,2,103

FITEM,2,102

A,P51X

FLST,2,4,3

FITEM,2,114

FITEM,2,113

FITEM,2,104

FITEM,2,103

A,P51X

FLST,2,4,3

FITEM,2,113

FITEM,2,112

FITEM,2,105

FITEM,2,104

A,P51X

FLST,2,4,3

FITEM,2,112

FITEM,2,111

FITEM,2,106

FITEM,2,105

A,P51X

FLST,2,4,3

FITEM,2,111

FITEM,2,110

FITEM,2,107

FITEM,2,106

A,P51X

FLST,2,4,3

FITEM,2,110

FITEM,2,109 
FITEM,2,108

FITEM,2,107

A,P51X

FLST,2,28,5,ORDE,2

FITEM,2,137

FITEM,2,-164

VEXT,P51X, , ,0.016,0,0,,,

FLST, 2,4,3

FITEM,2,97

FITEM,2,48

FITEM,2,96

FITEM,2,108

A,P51X

FLST,2,1,5,ORDE,1

FITEM,2,273

VEXT,P51X, , ,0.016,0,0,,,

FLST,2,278,5,ORDE,2

FITEM,2,1

FITEM,2,-278

AGLUE,P51X

FLST,2, 17,5,ORDE, 17

FITEM,2,210

FITEM,2,214

FITEM,2,218

FITEM,2,222

FITEM,2,226

FITEM,2,230

FITEM,2,234

FITEM,2,238

FITEM,2,242

FITEM,2,245

FITEM,2,249

FITEM,2,252

FITEM,2,256

FITEM,2,259

FITEM,2,263

FITEM,2,266

FITEM,2,270

AGLUE,P51X

FLST,2, 17,5,ORDE, 17

FITEM,2,29

FITEM,2,34

FITEM,2,38

FITEM,2,42

FITEM,2,46

FITEM,2,50

FITEM,2,54 
FITEM,2,58

FITEM,2,62

FITEM,2,66

FITEM,2,70

FITEM,2,74

FITEM,2,90

FITEM,2,101

FITEM,2,112

FITEM,2,123

FITEM,2,130

AGLUE,P51X

FLST,2,2,5,ORDE,2

FITEM,2,33

FITEM,2,132

AGLUE,P51X

FLST,2,2,5,ORDE,2

FITEM,2,68

FITEM,2,75

AGLUE,P51X

FLST,2,24,6,ORDE, 17

FITEM,2,12

FITEM,2,-14

FITEM,2, 16

FITEM,2, 18

FITEM,2,-20

FITEM,2,22

FITEM,2,24

FITEM,2,-25

FITEM,2,27

FITEM,2,-28

FITEM,2,40

FITEM,2,-46

FITEM,2,48

FITEM,2,50

FITEM,2,52

FITEM,2,54

FITEM,2,56

VGLUE,P51X

FLST,5,10,4,ORDE, 10

FITEM,5,45

FITEM,5,49

FITEM,5,61

FITEM,5,65

FITEM,5,73

FITEM,5,157

FITEM,5,161

FITEM,5,181 
FITEM,5,185

FITEM,5,197

CM,_Y,LINE

LSEL, , , ,P51X

CM,_Y1,LINE

CMSEL,_Y

LESIZE,_Y1, , , 8, , , , , 1

FLST, 5, 12,4,ORDE, 12

FITEM,5,40

FITEM,5,44

FITEM,5,52

FITEM,5,57

FITEM,5,68

FITEM,5,80

FITEM,5,146

FITEM,5, 152

FITEM,5,166

FITEM,5,173

FITEM,5,190

FITEM,5,207

CM,_Y,LINE

LSEL, , , ,P51X

CM,_Y1,LINE

CMSEL, $Y$

LESIZE,_Y1, , ,4, , , , ,1

FLST, 5,4,4,ORDE,4

FITEM,5,417

FITEM,5,-418

FITEM,5,420

FITEM,5,422

CM,_Y,LINE

LSEL, , , ,P51X

CM,_Y1,LINE

CMSEL,,Y

LESIZE,_Y1, , ,4, , , , ,1

FLST, 5,2,4,ORDE,2

FITEM,5,380

FITEM,5,416

CM,_Y,LINE

LSEL, , , P51X

CM,_Y1,LINE

CMSEL,,YY

LESIZE,_Y1, , ,64, , , , ,1

TYPE, 1

MAT, 3

REAL,

ESYS, 0 


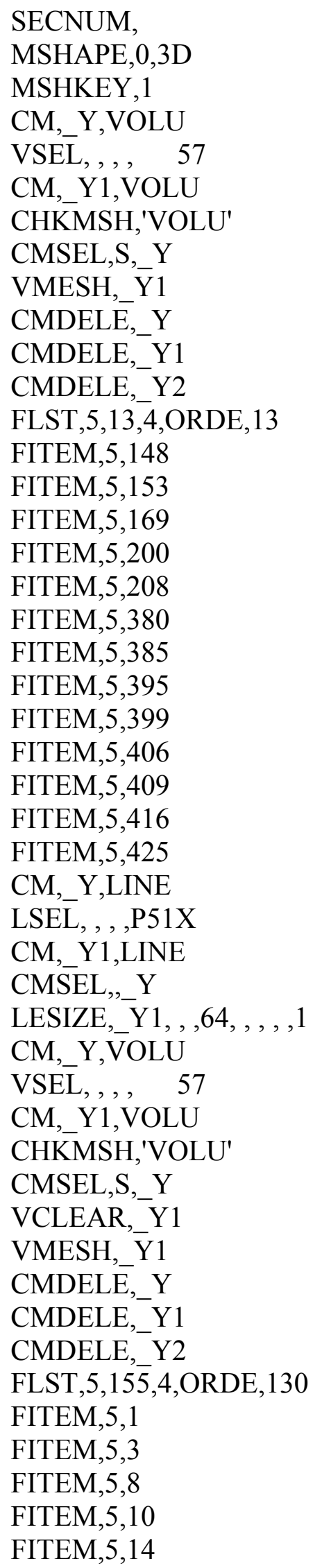


FITEM,5,16

FITEM,5,20

FITEM,5,22

FITEM,5,26

FITEM,5,28

FITEM,5,32

FITEM,5,34

FITEM,5,37

FITEM,5,-44

FITEM,5,51

FITEM,5,-54

FITEM,5,57

FITEM,5,-60

FITEM,5,67

FITEM,5,-70

FITEM,5,75

FITEM,5,78

FITEM,5,-81

FITEM,5,83

FITEM,5,94

FITEM,5,96

FITEM,5,104

FITEM,5,106

FITEM,5,114

FITEM,5,116

FITEM,5,124

FITEM,5,126

FITEM,5,134

FITEM,5,136

FITEM,5,141

FITEM,5,144

FITEM,5,-145

FITEM,5,149

FITEM,5,-151

FITEM,5,163

FITEM,5,167

FITEM,5,-168

FITEM,5,174

FITEM,5,-176

FITEM,5,187

FITEM,5,191

FITEM,5,-192

FITEM,5,199

FITEM,5,204

FITEM,5,206

FITEM,5,209

FITEM,5,-212 
FITEM,5,214

FITEM,5,216

FITEM,5,-218

FITEM,5,220

FITEM,5,222

FITEM,5,-224

FITEM,5,226

FITEM,5,228

FITEM,5,-230

FITEM,5,232

FITEM,5,234

FITEM,5,-236

FITEM,5,238

FITEM,5,240

FITEM,5,-242

FITEM,5,244

FITEM,5,247

FITEM,5,250

FITEM,5,253

FITEM,5,256

FITEM,5,259

FITEM,5,262

FITEM,5,-263

FITEM,5,265

FITEM,5,267

FITEM,5,-268

FITEM,5,270

FITEM,5,272

FITEM,5,-273

FITEM,5,275

FITEM,5,277

FITEM,5,-278

FITEM,5,280

FITEM,5,282

FITEM,5,-283

FITEM,5,285

FITEM,5,287

FITEM,5,-288

FITEM,5,290

FITEM,5,-292

FITEM,5,298

FITEM,5,303

FITEM,5,-304

FITEM,5,308

FITEM,5,313

FITEM,5,-314

FITEM,5,318 
FITEM,5,323

FITEM,5,-324

FITEM,5,328

FITEM,5,333

FITEM,5,-334

FITEM,5,338

FITEM,5,342

FITEM,5,-343

FITEM,5,348

FITEM,5,353

FITEM,5,358

FITEM,5,363

FITEM,5,368

FITEM,5,373

FITEM,5,377

FITEM,5,-379

FITEM,5,383

FITEM,5,386

FITEM,5,-387

FITEM,5,390

FITEM,5,393

FITEM,5,-394

FITEM,5,397

FITEM,5,400

FITEM,5,-401

FITEM,5,404

FITEM,5,407

FITEM,5,-408

FITEM,5,411

FITEM,5,414

FITEM,5,-415

CM,_Y,LINE

LSEL, , , ,P51X

CM,_Y1,LINE

CMSEL,,YY

LESIZE,_Y1, , ,4, , , , ,1

FLST,5,71,4,ORDE,71

FITEM,5,2

FITEM,5,4

FITEM,5,6

FITEM,5,9

FITEM,5,12

FITEM,5,15

FITEM,5,21

FITEM,5,24

FITEM,5,27

FITEM,5,30 

FITEM,5,33
FITEM,5,35
FITEM,5,-36
FITEM,5,47
FITEM,5,-48
FITEM,5,55
FITEM,5,-56
FITEM,5,63
FITEM,5,-64
FITEM,5,71
FITEM,5,-72
FITEM,5,76
FITEM,5,-77
FITEM,5,82
FITEM,5,84
FITEM,5,90
FITEM,5,95
FITEM,5,100
FITEM,5,105
FITEM,5,110
FITEM,5,115
FITEM,5,120
FITEM,5,125
FITEM,5,130
FITEM,5,135
FITEM,5,139
FITEM,5,-140
FITEM,5,159
FITEM,5,-160
FITEM,5,171
FITEM,5,-172
FITEM,5,183
FITEM,5,-184
FITEM,5,195
FITEM,5,-196
FITEM,5,202
FITEM,5,-203
FITEM,5,243
FITEM,5,245
FITEM,5,-246
FITEM,5,248
FITEM,5,-249
FITEM,5,251
FITEM,5,-252
FITEM,5,254
FITEM,5,-255
FITEM,5,257 
FITEM,5,-258

FITEM,5,260

FITEM,5,347

FITEM,5,349

FITEM,5,352

FITEM,5,354

FITEM,5,357

FITEM,5,359

FITEM,5,362

FITEM,5,364

FITEM,5,367

FITEM,5,369

FITEM,5,372

FITEM,5,374

CM,_Y,LINE

LSEL, , , P51X

CM,_Y1,LINE

CMSEL,,Y

LESIZE,_Y1, , ,5, , , , 1

FLST, 5,60,4,ORDE,60

FITEM,5,5

FITEM,5,7

FITEM,5,11

FITEM,5,13

FITEM,5,17

FITEM,5,19

FITEM,5,23

FITEM,5,25

FITEM,5,29

FITEM,5,31

FITEM,5,46

FITEM,5,50

FITEM,5,62

FITEM,5,66

FITEM,5,74

FITEM,5,89

FITEM,5,91

FITEM,5,99

FITEM,5,101

FITEM,5,109

FITEM,5,111

FITEM,5,119

FITEM,5,121

FITEM,5,129

FITEM,5,131

FITEM,5,158

FITEM,5,162 
FITEM,5,182

FITEM,5,186

FITEM,5,198

FITEM,5,213

FITEM,5,215

FITEM,5,219

FITEM,5,221

FITEM,5,225

FITEM,5,227

FITEM,5,231

FITEM,5,233

FITEM,5,237

FITEM,5,239

FITEM,5,264

FITEM,5,269

FITEM,5,274

FITEM,5,279

FITEM,5,284

FITEM,5,297

FITEM,5,299

FITEM,5,307

FITEM,5,309

FITEM,5,317

FITEM,5,319

FITEM,5,327

FITEM,5,329

FITEM,5,337

FITEM,5,339

FITEM,5,382

FITEM,5,389

FITEM,5,396

FITEM,5,403

FITEM,5,410

CM,_Y,LINE

LSEL, , , ,P51X

CM,_Y1,LINE

CMSEL,,Y

LESIZE,_Y1, , ,8, , , , ,1

FLST, 5,31,4,ORDE, 31

FITEM,5,85

FITEM,5,87

FITEM,5,-88

FITEM,5,93

FITEM,5,98

FITEM,5,103

FITEM,5,108

FITEM,5,113 


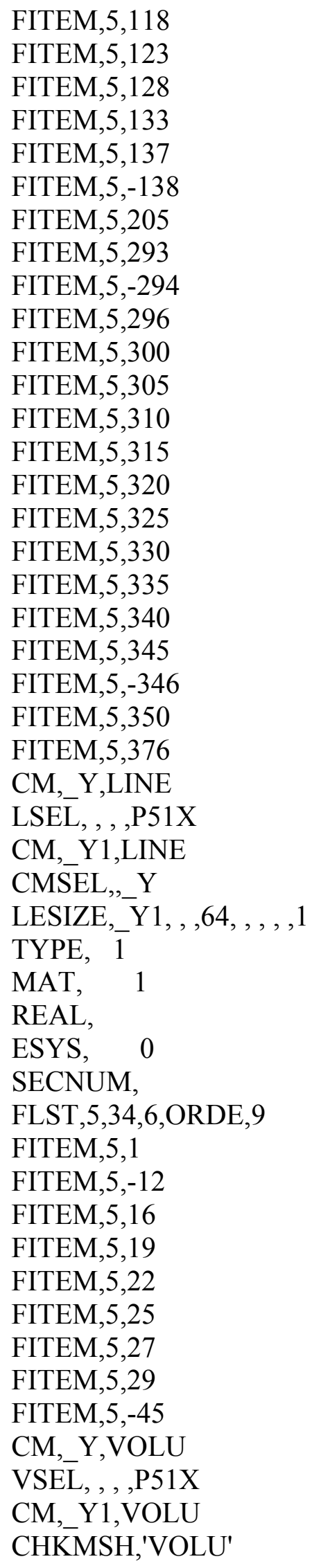




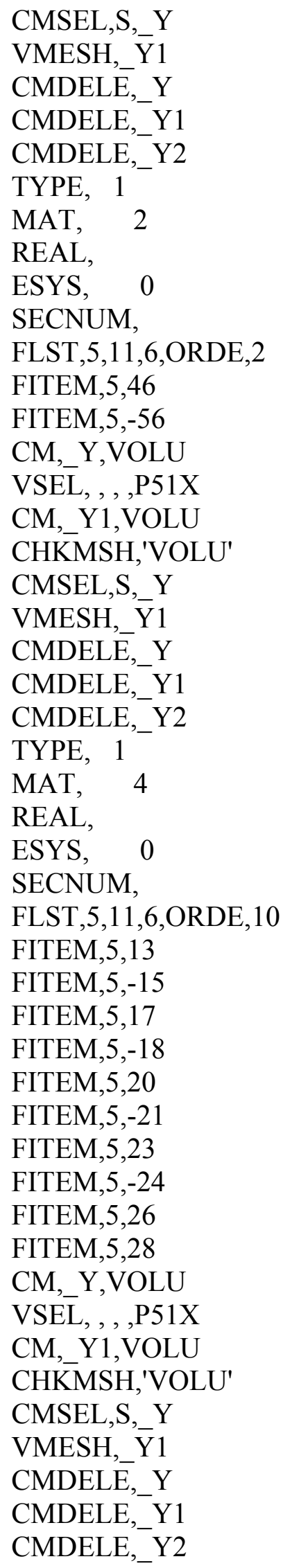




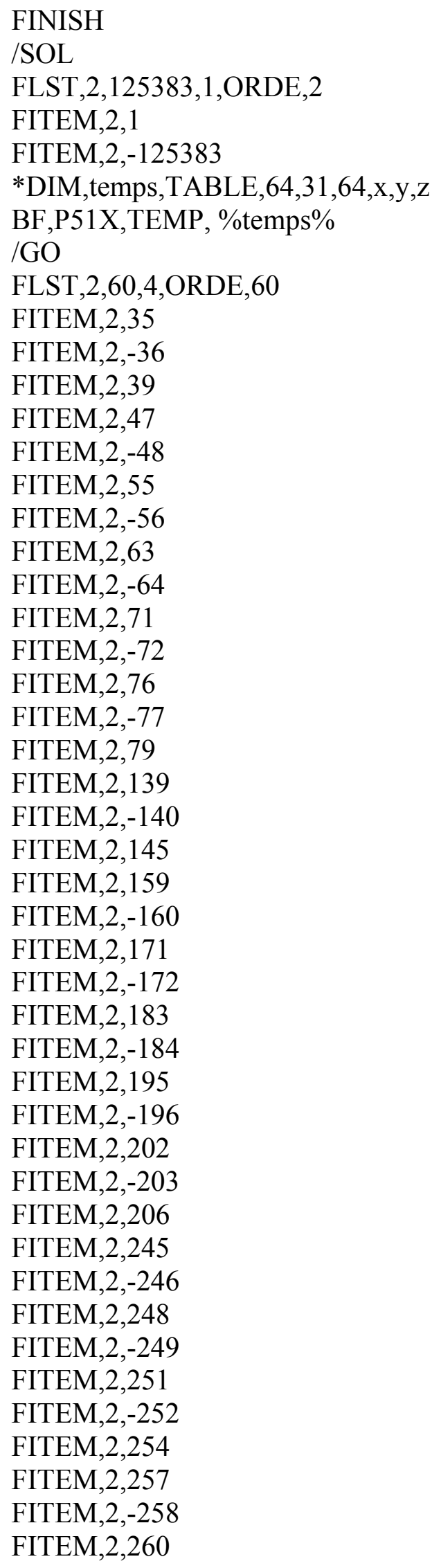


FITEM,2,-261

FITEM,2,287

FITEM,2,347

FITEM,2,349

FITEM,2,352

FITEM,2,354

FITEM,2,357

FITEM,2,362

FITEM,2,364

FITEM,2,367

FITEM,2,372

FITEM,2,374

FITEM,2,377

FITEM,2,414

FITEM,2,417

FITEM,2,-418

FITEM,2,420

FITEM,2,422

/GO

DL,P51X, ,UY,0

FLST,2,2,1,ORDE,2

FITEM,2,56369

FITEM,2,76186

$/ \mathrm{GO}$

D,P51X, ,0, , ,UX, , , , ,

FLST,2,2,1,ORDE,2

FITEM,2,65655

FITEM,2,65695

/GO

D,P51X, ,0, , ,UZ, , , ,

SOLVE

FINISH 